\title{
Epac-mediated modulation of neurotransmitter release from cultured hippocampal neurons
}

\author{
Dissertation \\ zur Erlangung des mathematisch-naturwissenschaftlichen Doktorgrades \\ "Doctor rerum naturalium" \\ der Georg-August-Universität Göttingen
}

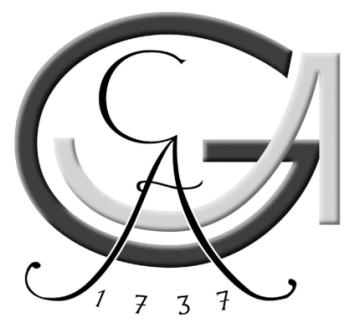

vorgelegt von

Isabella Gekel

aus Hermannstadt (Rumänien) 
D7

Referent:

Prof. Dr. Erwin Neher

Korreferent:

Prof. Dr. Reinhard Jahn

Tag der Disputation: $\quad$ 07.04.2008 
Hiermit erkläre ich, dass ich die vorliegende Dissertation mit dem Titel

"Epac-mediated modulation of neurotransmitter release from cultured hippocampal neurons"

selbständig und ohne unerlaubte Hilfe angefertigt habe. Alle Stellen, die wörtlich oder sinngemäß veröffentlichtem oder unveröffentlichtem Schrifttum entnommen sind, habe ich als solche kenntlich gemacht.

Göttingen, den 17.03.2008 

Publication Note

Large parts of the Results and Discussion section of this Ph.D. thesis work were accepted for publication by the Journal of Neuroscience. 



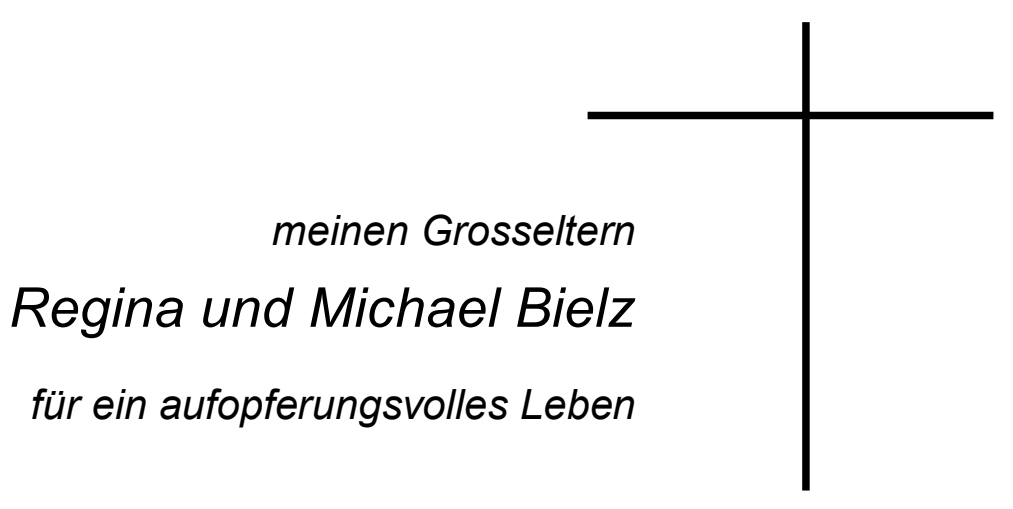



“... Geheimnisvoll am lichten Tag Lässt sich Natur des Schleiers nicht berauben, Und was sie deinem Geist nicht offenbaren mag, Das zwingst du ihr nicht ab mit Hebeln und mit Schrauben. ..."

(Johann Wolfgang von Goethe, Faust, Erster Teil, Nacht) 



\section{ABSTRACT}

CAMP regulates secretory processes through both protein kinase $A$ (PKA)-independent and PKA-dependent signaling pathways. However, their relative contributions to fast neurotransmission are unclear at present, although the cAMP-mediated increase in neurotransmitter release could be attributed to an increase of vesicular release probability and to the enhancement of the number of releasable vesicles in various neuronal preparations. The present study analysed the contribution of the novel CAMP receptor Epac to the cAMP-related modulation of neurotransmission. Neurotransmitter release from cultured murine or rat hippocampal excitatory autaptic neurons was monitored during low and high frequency stimulation in the presence or absence of Epac-Selective $\underline{\text { Cyclic }} \underline{\mathrm{AMP}} \underline{\text { Analogs }}$ (ESCAs) using the patch-clamp technique. ESCA-induced Epac activation increased both the action potential-evoked excitatory postsynaptic current (EPSC) amplitudes during $0.2 \mathrm{~Hz}$ frequency stimulation and the number of spontaneous fusion events (mEPSCs) from autaptic excitatory Dentate Gyrus-neurons. The magnitude of potentiation depended on the average EPSC amplitude recorded during the first two minutes, on the cell culture age, and on the presynaptic calcium ion concentration.

ESCA $_{1}$ (8-pCPT-2'-O-Me-cAMP)-mediated Epac activation accounted on average for $38 \%$ of the forskolin-induced increase in evoked EPSC amplitudes and for $100 \%$ of the forskolin-induced increase in mEPSC frequency. Forskolin is generally believed to enhance intracellular CAMP levels by stimulation of adenylyl cyclase activity. The mEPSC amplitude and the number of readily releasable vesicles remained unchanged upon brief ESCA $_{1}$ treatment (1.2 minutes). In conclusion, $\mathrm{ESCA}_{1}$ application increased vesicular release probability. Finally, the data show that $\mathrm{ESCA}_{1}$ - and phorbol esters-stimulated signaling pathways interact. The observed coupling of both signaling pathways was dependent on protein kinase $\mathrm{C}$ activity. 
- XV - 


\section{ZUSAMMENFASSUNG}

cAMP beeinflusst sekretorische Prozesse sowohl durch Protein Kinase A (PKA)-abhängige als auch durch PKA-unabhängige Signaltransduktionsprozesse. Dennoch ist der jeweilige Anteil an einer cAMP-vermittelten Regulation der Neurotransmission nur unzureichend bekannt. In verschiedenen Preparationen von Nervenzellen konnte gezeigt werden, dass eine cAMP-bedingte Steigerung der Neurotransmitterfreisetzung sowohl auf eine Erhöhung der vesikulären Freisetzungswahrscheinlichkeit als auch auf eine Zunahme der Zahl freisetzbarer Vesikel zurückgeführt werden kann. In der vorliegenden Dissertation wurde die Beteilung des neuen cAMP Rezeptors Epac an der cAMP-vermittelten Regulation der Neurotransmission untersucht. Mit Hilfe des Patch-Clamp Verfahrens wurde die Neurotransmitterfreisetzung bei hoch- oder niedrigfrequenter Stimulation kultivierter exzitatorischer autaptischer Nervenzellen bestimmt; und zwar in An- oder Abwesenheit Epac-selektiver cylischer AMP Analoga (ESCAs). Bei niedrigfrequenter Stimulation $(0.2 \mathrm{~Hz})$ von autaptischen Neuronen des Dentatus Gyrus führte eine ESCA-induzierte Epac Aktivierung sowohl zur Erhöhung Aktionspotential-evozierter exzitatorischer postsynaptischer Stromamplituden als auch zur Zunahme der Anzahl spontaner Vesikelfusionen mit der presynaptischen Plasmamembran. Das Ausmaß der beobachteten Potenzierungen war abhängig von der in den ersten zwei Minuten gemessenene mittleren Stromamplitude der Nervenzelle, aber auch vom Alter der Zellkultur und der presynaptischen Kalziumionenkonzentration.

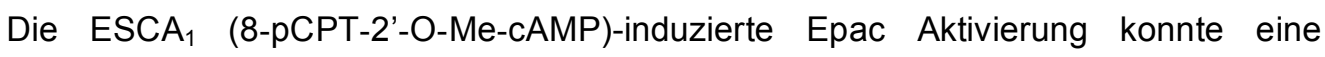
Forskolin-vermittelte Erhöhung von Aktionspotential-evozierten exzitatorischen postsynaptischen Stromamplituden im Durchschnitt zu $38 \%$ und die Forskolin-vermittelten Zunahme der Anzahl spontaner Vesikelfusionen zu $100 \%$ erklären. Allgemein wird angenommen, dass Forskolin die Aktivität von Adenylatcyclasen erhöht und damit die intrazelluläre cAMP Konzentration. Die Stromamplitude spontaner Vesikelfusionen wurde durch eine kurzzeitige Applikation von ESCA 1 (1.2 Minuten) nicht verändert. Gleiches traf auf

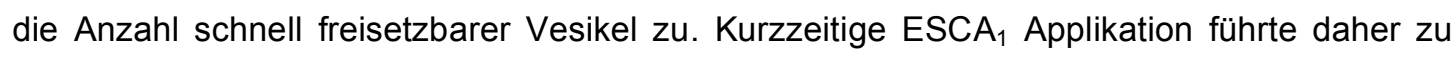
einer Erhöhung der vesikulären Freisetzungswahrscheinlichkeit. Darüber hinaus konnte gezeigt werden, dass die an der Neurotransmission beteiligten ESCA $_{1-}$ und Phorbolester-induzierten Signaltransduktionswege miteinander gekoppelt sind. Diese Kopplung war von der Protein Kinase C Aktivität abhängig. 
- xvii - 


\section{Table of Contents}

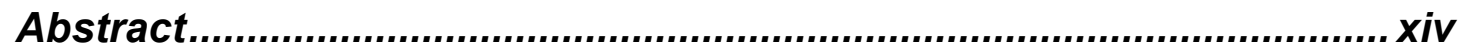

Zusammenfassung............................................................................ $x$.

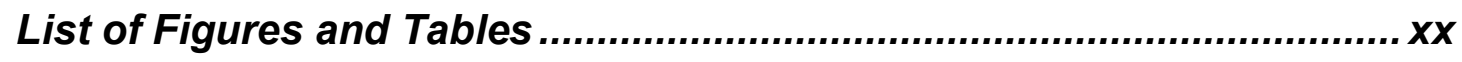

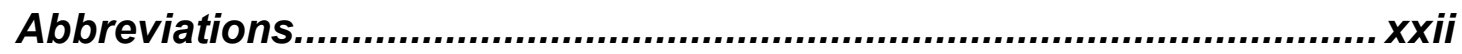

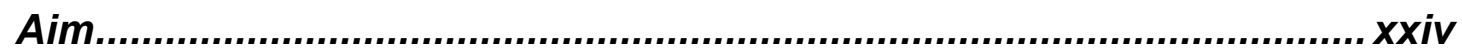

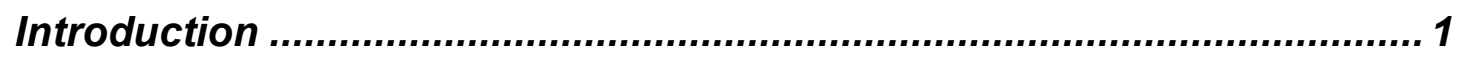

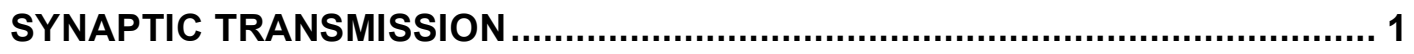

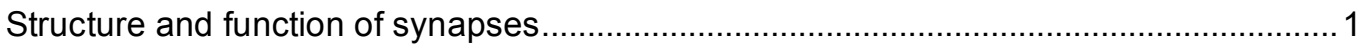

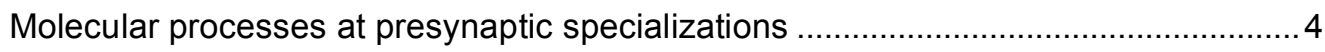

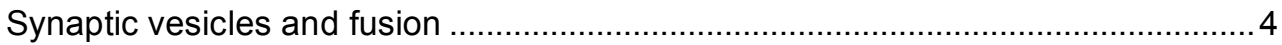

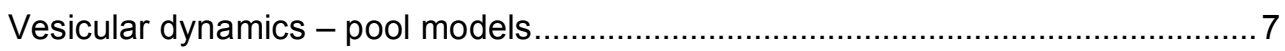

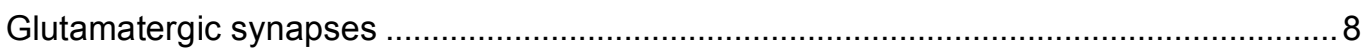

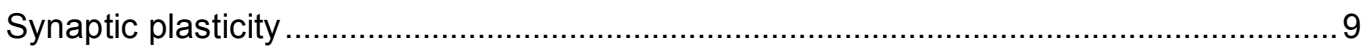

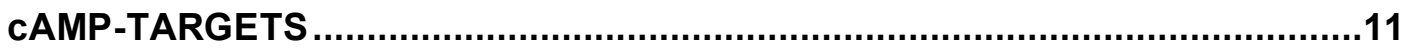

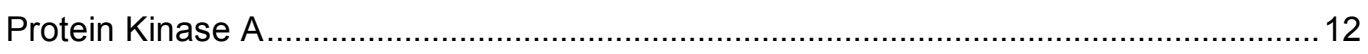

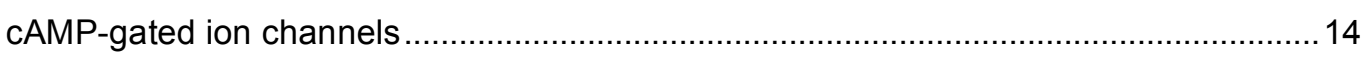

Epac - exchange protein directly activated by cAMP ............................................15

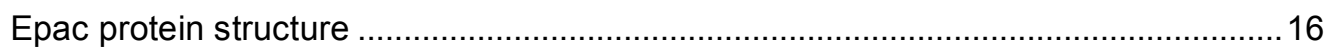

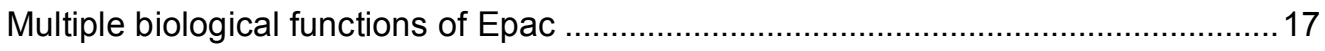

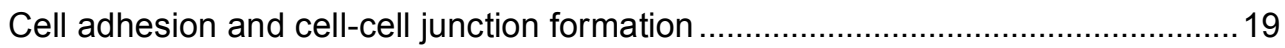

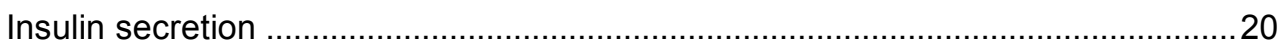

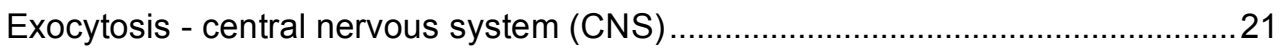

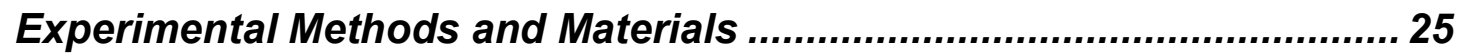

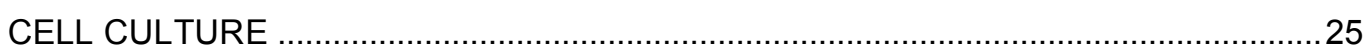

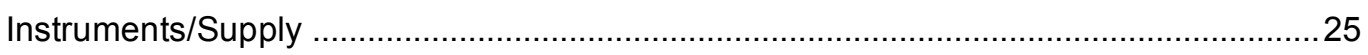

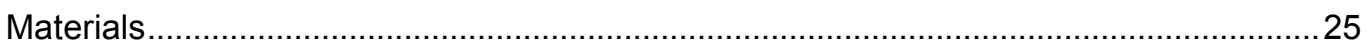

Media

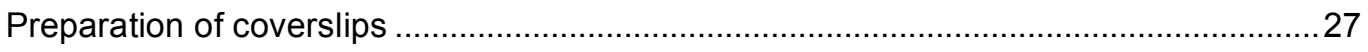

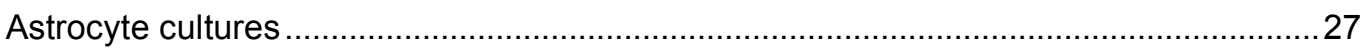

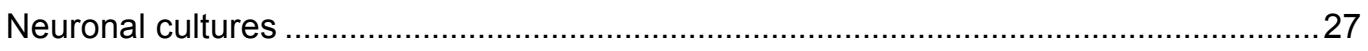

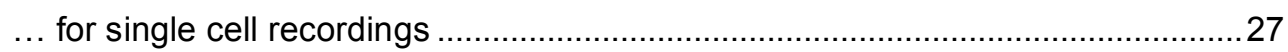

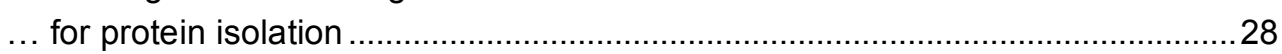

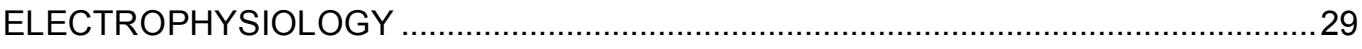

Materials

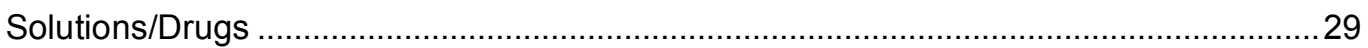

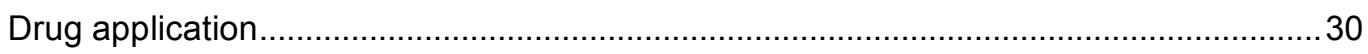

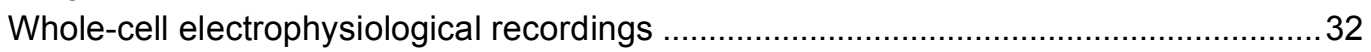




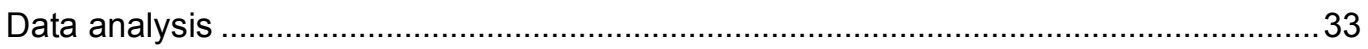

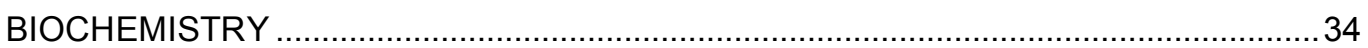

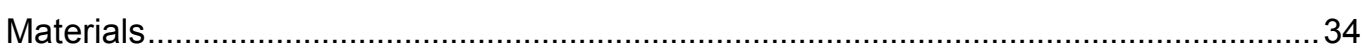

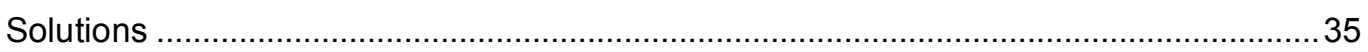

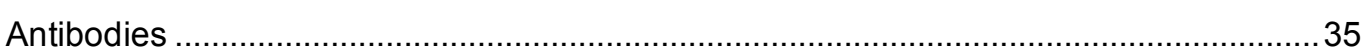

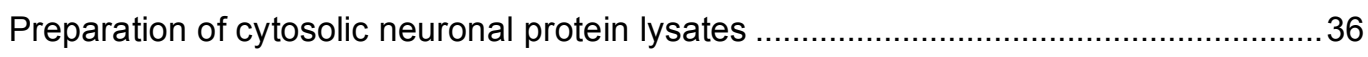

Determination of protein concentration - Bradford assay ........................................ 36

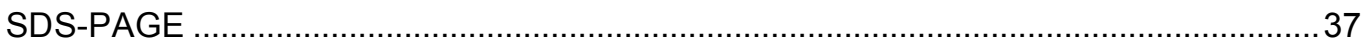

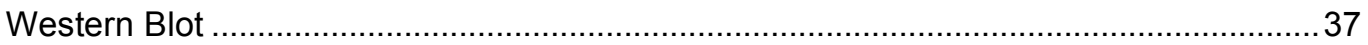

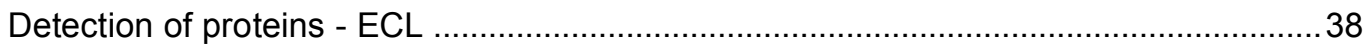

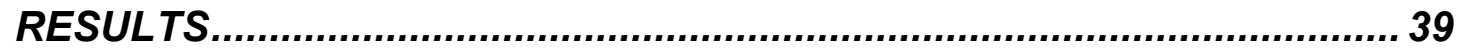

Cultured autaptic neurons express both Epac $(1,2)$ isoforms ................................ 39

$\mathrm{ESCA}_{1}$ is a specific activator of Epac in autaptic neurons................................... 39

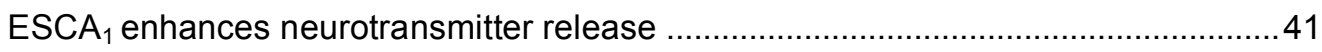

Structurally related ESCAs mimick the ESCA $_{1}$ effect .........................................44

Potentiation of synaptic strength by various pharmacological agents depends on the initial EPSC amplitude, the type of neuronal preparation, and the animal species .46

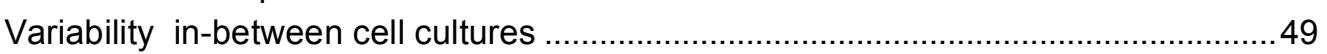

Epac activation is presynaptic in origin and increases

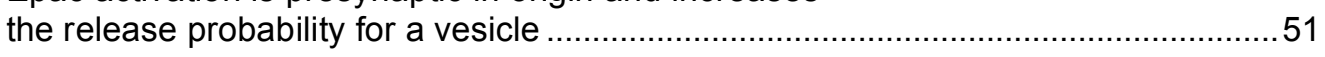

$\mathrm{ESCA}_{1}$ enhanced mEPSC frequency during $0.2 \mathrm{~Hz}$ stimulation ................................54

cAMP-to-PKC signaling occurs upon Epac activation ............................................55

Persistence of the ESCA $_{1}$ effect post prolonged PDBu treatment ..........................63

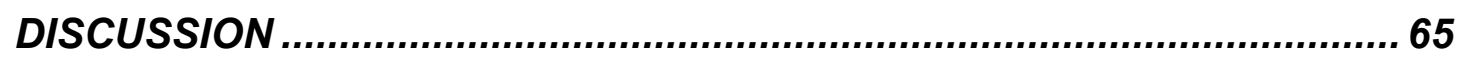

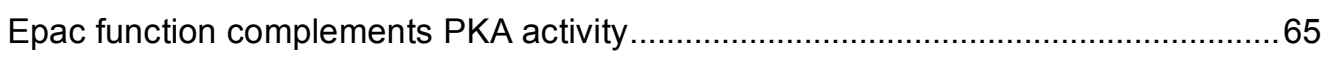

Epac function involves Epac-to-PKC signaling ...................................................... 67

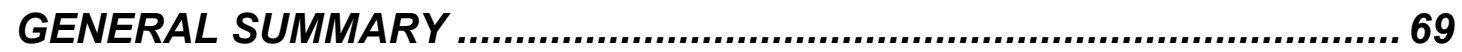

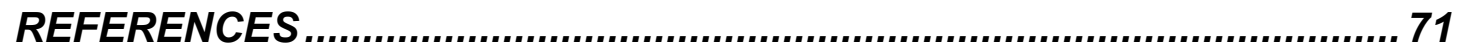

APPENDIX

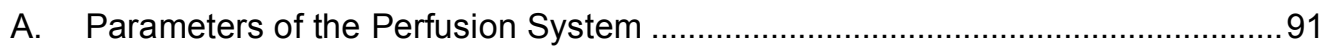

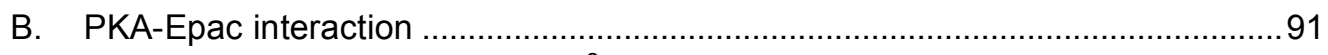

C. Epac activity and presynaptic $\mathrm{Ca}^{2+}$ influx interact synergistically.....................94

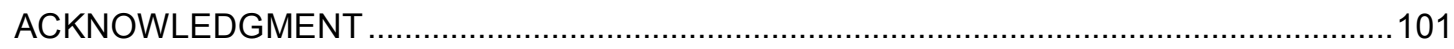

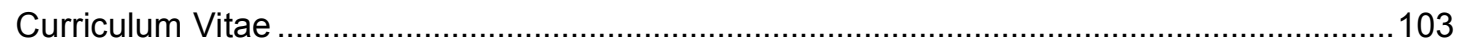




\section{List of Figures and Tables}

Figure 1: General structure of synapses. 2

Figure 2: Timing of synaptic transmission.

$\begin{array}{lll}\text { Figure } & \text { 3: } \text { Characteristics of vesicle pools. } & 7\end{array}$

$\begin{array}{ll}\text { Figure 4: The multi domain structure of Epac. } & 17\end{array}$

$\begin{array}{ll}\text { Figure 5: Epac effectors and biological function. } & 18\end{array}$

$\begin{array}{ll}\text { Figure 6: Cultured autaptic neurons. } & \mathbf{2 8}\end{array}$

Figure 7: Neurons isolated from the murine Dentate Gyrus (DIV10). 28

$\begin{array}{ll}\text { Figure 8: Drug Application System. } & \mathbf{3 1}\end{array}$

Figure 9: Epac expression in neuronal cell cultures and its specific activation by the CAMP analog $E S C A_{1}$.

Figure 10: $E S C A_{1}$ enhances neurotransmitter release at excitatory autaptic neurons from Dentate Gyrus.

Figure 11: Effects of $E S C A_{2}$ and $E S C A_{3}$ on neurotransmitter release at excitatory autaptic neurons from Dentate Gyrus.

Figure 12: The initial EPSC amplitude (EPSC 0 ) determines the amount of EPSC amplitude potentiation.

Figure 13: Variability in-between cell cultures.

Figure 14: Activation of Epac increases mEPSC frequency in murine DG-neurons.

Figure 15: The number of sucrose-releasable vesicles is a characteristic function of the initial EPSC amplitude and does not change upon application of $E S C A_{1}$.

Figure 16: Washout of $E S C A_{1}$ and its effect on mEPSC frequency during $0.2 \mathrm{~Hz}$ stimulation.

Figure 17: Activation of Epac enhances a subsequently induced PDBu effect.

Figure 18: Inhibition of $P K C$ activity by bisindolylmaleimide I reduces the PDBu-effect.

Figure 19: Downregulation of PKC activity by prolonged preincubation of neuronal cultures with PDBu abolishes the PDBu-effect. 
Figure 20: $E S C A_{1}$ effect on neurotransmitter release after

downregulation of PKC activity.

Figure 21: 6-Bnz-CAMP enhances neurotransmitter release at excitatory

autaptic neurons from Dentate Gyrus

Figure 22: Impact of different PKA-inhibitors

on the forskolin- and the $E S C A_{1}$-effect.

93

Figure 23: General inhibition of adenylyl cyclase activity

by MDL 12,330A affects neurotransmitter release

negatively during high frequency stimulation.

96

Figure 24: $M D L$ 12,330A-mediated inhibition of neurotransmission

is partially rescued by ESCA $_{1}$.

98

Table 1: Genetic manipulations demonstrating a role for $C A M P / P K A$ signaling in hippocampal synaptic plasticity.

Table 2: Flow rates of the perfusion system.

91 


\section{Abbreviations}

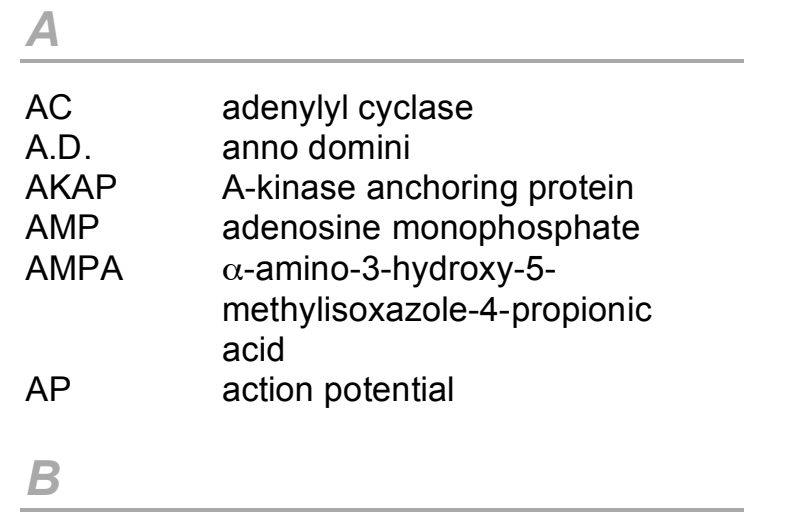

$\begin{array}{ll}\text { BIS-I } & \text { bisindolylmaleimide I } \\ \text { BSA } & \text { bovine serum albumin }\end{array}$

C

\begin{tabular}{ll}
\hline CaMK & $\begin{array}{l}\text { calmodulin-dependent } \\
\text { cyclic AMP }\end{array}$ \\
CAPS & $\begin{array}{l}\text { calcium-dependent } \\
\text { activator protein for } \\
\text { secretion }\end{array}$ \\
cDCll division cycle 25 \\
cDClic-nucleotide-binding \\
cNBD & $\begin{array}{l}\text { cyclic domain } \\
\text { cyclic nucleotide-gated }\end{array}$ \\
CNG & coating \\
CT &
\end{tabular}

D

$\begin{array}{ll}\text { DAG } & \text { diacylglycerol } \\ \text { DEP } & \begin{array}{l}\text { Dishevelled, Egl-10, } \\ \text { Pleckstrin domain }\end{array} \\ \text { DG } & \begin{array}{l}\text { Dentate Gyrus } \\ \text { day in vitro }\end{array} \\ \text { DIV } & \begin{array}{l}\text { Dulbecco's modified Eagle } \\ \text { DMEM }\end{array} \\ \text { Dedium } \\ \text { DMSO } & \text { dimethylsulfoxide }\end{array}$

\begin{tabular}{ll}
$E$ & \\
\hline ECL & $\begin{array}{l}\text { enhanced } \\
\text { chemoluminescence } \\
\text { ethylenediaminetetraacetic } \\
\text { acid } \\
\text { ethylene gylcol-bis( } \beta \text { - } \\
\text { aminoethyl ether)- }\end{array}$ \\
EGTA & $\begin{array}{l}\text { N,N,N',N'-tetraacetic acid } \\
\text { early long-term potentiation } \\
\text { exchange protein } \\
\text { directly activated by } \\
\text { cAMP } \\
\text { excitatory postsynaptic } \\
\text { current }\end{array}$ \\
Epac &
\end{tabular}

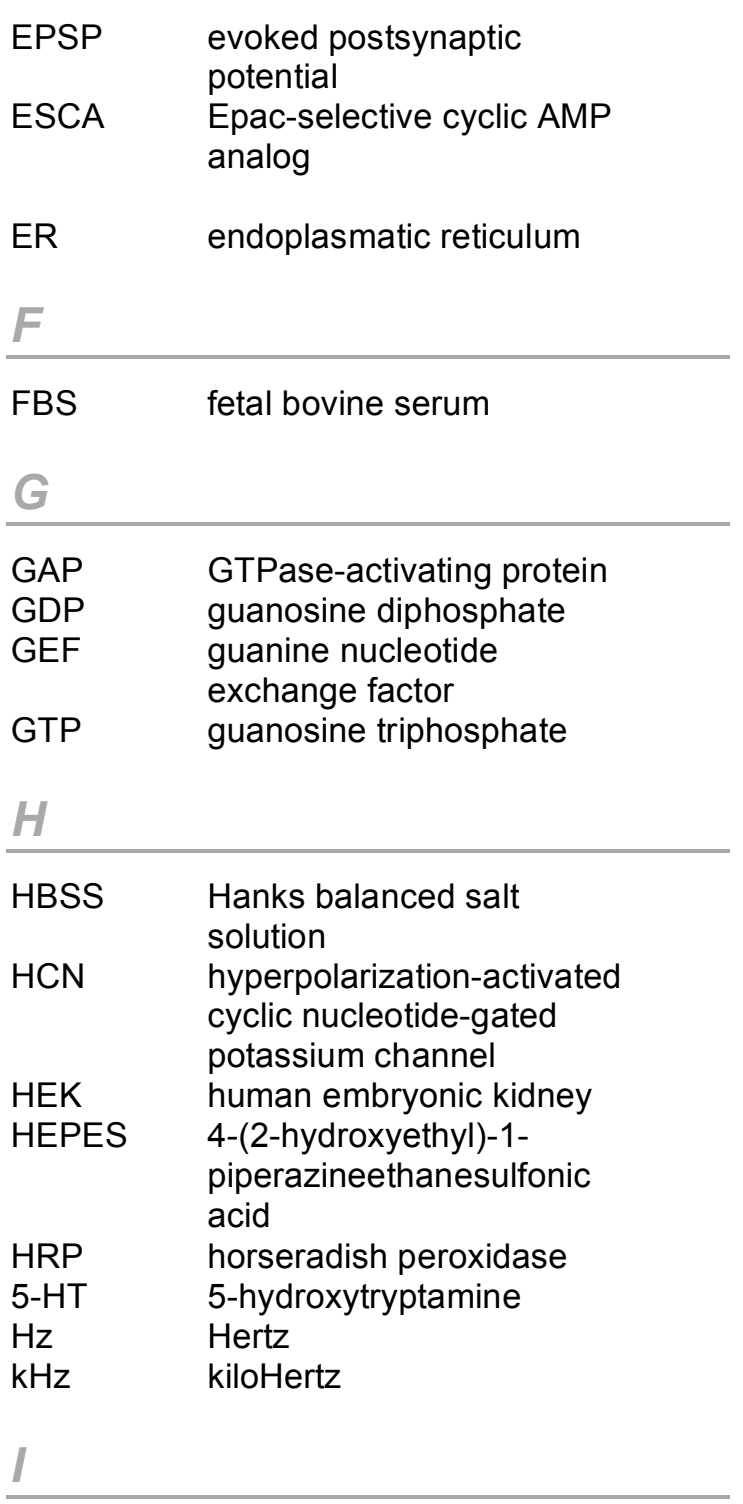

$\begin{array}{ll}\text { IAI } & \text { inter-application interval } \\ \text { I.D. } & \text { inner diameter }\end{array}$

I.D. inner diameter

\begin{tabular}{ll}
$K$ & \\
\hline KS & Kolmogorov-Smirnov \\
$L$ & \\
\hline LTD & $\begin{array}{l}\text { long-term depression } \\
\text { L-LTP } \\
\text { LTP }\end{array}$ \\
$\begin{array}{ll}\text { late long-term potentiation } \\
\text { long-term potentiation }\end{array}$ \\
\hline MAPK & $\begin{array}{l}\text { mitogen-activated protein } \\
\text { kinase }\end{array}$
\end{tabular}


$\begin{array}{ll}\text { mEPSC } & \text { miniature EPSC } \\ \text { mRNA } & \text { messenger ribonucleic acid }\end{array}$

\section{N}

NBA Neurobasal-A medium

NMDA N-methyl-D-aspartate

NMRI Naval Medical Research

Institute

O.D. outer diameter

$P$

p probability

$p \quad$ release probability

PAGE polyacrylamide gel

Electrophoresis

PDBu phorbol-12,13-dibutyrate

PDE phosphodiesterase

PKB protein kinase $B$

PKC protein kinase $\mathrm{C}$

Kinase

PLC phospholipase C

PSD postsynaptic density

PTFE poly(tetrafluoroethylene)

$R$

RA Ras-association domain

REM Ras-exchange motif

RNA ribonucleic acid

$\mathrm{RP} \quad$ reserve pool of vesicles

RRP readily releasable pool of vesicles

Rs series resistance

S

sAPP soluble amyloid precursor protein

S.D. $\quad$ standard deviation

SDS sodium dodecyl sulfate

SEM standard error of the mean

SFCA surfactant free cellulose

acetate

siRNA small interfering RNA

SM Sec1/Munc18-like

SNAP-25 synaptosomal-associated protein of $25 \mathrm{kDa}$

SNARE soluble

$\mathrm{N}$-ethylmaleimide-sensitive factor attachment protein receptor

SUR sulfonylurea receptor

SV synaptic vesicle
TTX tetrodotoxin

V

VDCC voltage-dependent calcium channel 


\section{Aim}

Since the second century A. D. and the identification of the brain as the organ of the mind by Galen of Pergamum, scientists are interested in the biological basis of sensation, learning, memory, thinking, and consciousness.

Since 1958 simple invertebrate systems, including Aplysia, Drosophila, and C. elegans, were introduced as model organisms to analyze elementary aspects of behavior and learning at the cellular and molecular level. Experiments performed on motorneurons from Aplysia californica revealed that synaptic changes are related to learning and memory storage, and that cyclic AMP (cAMP) plays a crucial role in their regulation [Cedar et al., 1972]. The discovery of cAMP and its target molecule, protein kinase A (PKA), by Earl Sutherland became a milestone in the development of the signal theory of second messengers [Rall and Sutherland, 1958; Sutherland et al., 1965]. When Eric Kandel, James Schwartz and Paul Greengard elucidated the relationship between CAMP changes and neuronal short-term plasticity they concluded that CAMP and PKA are both necessary and sufficient to strengthen the connectivity between sensory neurons and motorneurons in Aplysia. They suggested that cAMP and PKA are the first elements in a chain of biochemical processes leading to neuronal plasticity. Similar observations were made later for mammalian glutamatergic central synapses: cAMP enhanced neurotransmitter release from presynaptic terminals, and this could be attributed to the direct activation of PKA.

However, by 1997 it became obvious that PKA may not represent the sole cAMP-target involved in the modulation of neurotransmitter release [Brandon et al., 1997]. The development of the gene knockout technology by Mario Capechi and Oliver Smythies helped to generate PKA-deficient mice lacking different PKA subunits. Still, those mice were performing well in mnemonic tasks. Their basal neurotransmission and short-term plasticity was unaltered.

In 1998, a novel cAMP receptor was identified: the exchange protein

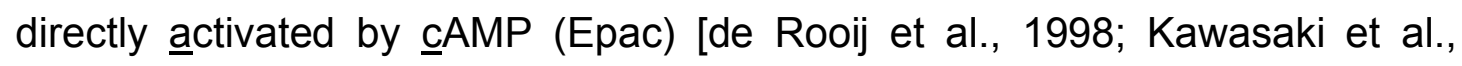
1998]. At present, PKA-independent, Epac-mediated modulation of secretory 
processes was reported for a variety of neuronal and non-neuronal secretory cells.

cAMP regulates secretory processes through both PKA-dependent and PKA-independent signaling pathways. In various neuronal preparations, forskolin-mediated activation of intracellular cAMP production by stimulating adenylyl cyclase activity increased vesicular release probability $(p)$ and the number of releasable vesicles. However, the relative contributions of PKA-dependent and PKA-independent pathways to the modulation of fast neurotransmitter release are unclear. At present, research on cAMP-mediated signaling is focused on several elementary questions:

- What are the molecular mechanisms for PKA-independent signaling?

- Are developmental aspects involved in their regulation?

- How do PKA-dependent and PKA-independent signaling pathways interact mechanistically or temporally/spatially?

- How are the second messenger actions of cAMP and calcium or diacylgycerol integrated during secretory processes?

In this study the relative contribution of cAMP-mediated Epacdependent signaling pathways to fast neurotransmitter release from glutamatergic central nervous synapses was analysed:

A. Does the novel cAMP-binding protein Epac contribute to neurotransmitter release from central synapses?

B. What step of exocyctosis is regulated by Epac activity?

C. What is Epac's mechanism of action?

Neurotransmitter release is monitored during low and high frequency stimulation of nerve cells in the presence or absence of Epac-activating cAMP-analogues using the patch-clamp technique. The model system of choice are cultured excitatory autaptic neurons derived from different regions of the murine and rat hippocampal formation (with a special emphasis on neurons isolated from murine Dentate Gyrus). 


\section{Introduction}

\section{SYNAPTIC TRANSMISSION}

Two attributes of the nerve cells, their active channel gating and their passive cable properties, play a vital role for the enormous computing power of the brain. In our brain 30 to 100 billion neurons communicate with each other with different speed through one quadrillion $\left(10^{15}\right)$ contacts. These specialized cellular junctions termed synapses (Charles Sherrington, 1897) are complex structures equipped with a machinery for fast information transfer. Most mammalian synapses use chemical neurotransmitters to transmit information from the presynaptic to the postsynaptic cell. These transmitters may either excite or inhibit the target cell, depending on the transmitter type and the nature of the receptor/ion channel activated by the transmitter in the membrane of the target neuron.

\section{Structure and function of synapses}

Synaptic connections between neurons are specific and not formed at random. A recognition process establishes the first contact, and a reinforcement process maintains it [Waites et al., 2005]. Chemical synapses are designed to convey information in a polarized manner between two neurons. A typical synapse usually consists of precisely aligned presynaptic and postsynaptic elements (Fig. 1). Typically the presynaptic component is an axon terminal and the postsynaptic component represents a neuronal dendrite, cell body or muscle cell. Both compartments, presynaptic and postsynaptic, possess specializations that facilitate the information flow [Palay, 1956]. The presynaptic axonal terminal contains

1. clusters of neurotransmitter-filled synaptic vesicles (SV),

2. presynaptic membrane densities (active zones) that represent sites for the fusion of synaptic vesicles and the subsequent exocytosis of their constituent neurotransmitters [Gray, 1963]

3. smooth endoplasmatic reticulum required for vesicular biogenesis and recirculation 
4. accumulations of mitochondria to generate the energy required for the synthesis and release of neurotransmitter.

On the other hand, typical postsynaptic specializations include the clustering of neurotransmitter receptors and their downstream signaling elements in close apposition to the active zones [Sheng and Hoogenraad, 2007]. The accumulation of membranous and perimembranous proteins at synaptic junctions gives rise to postsynaptic densities (PSD), that is, regions of the postsynaptic contacts that exhibit increased electron density and staining in the electron microscope. Active zones and their opposed postsynaptic densities are separated by a narrow synaptic cleft (150-200Å).

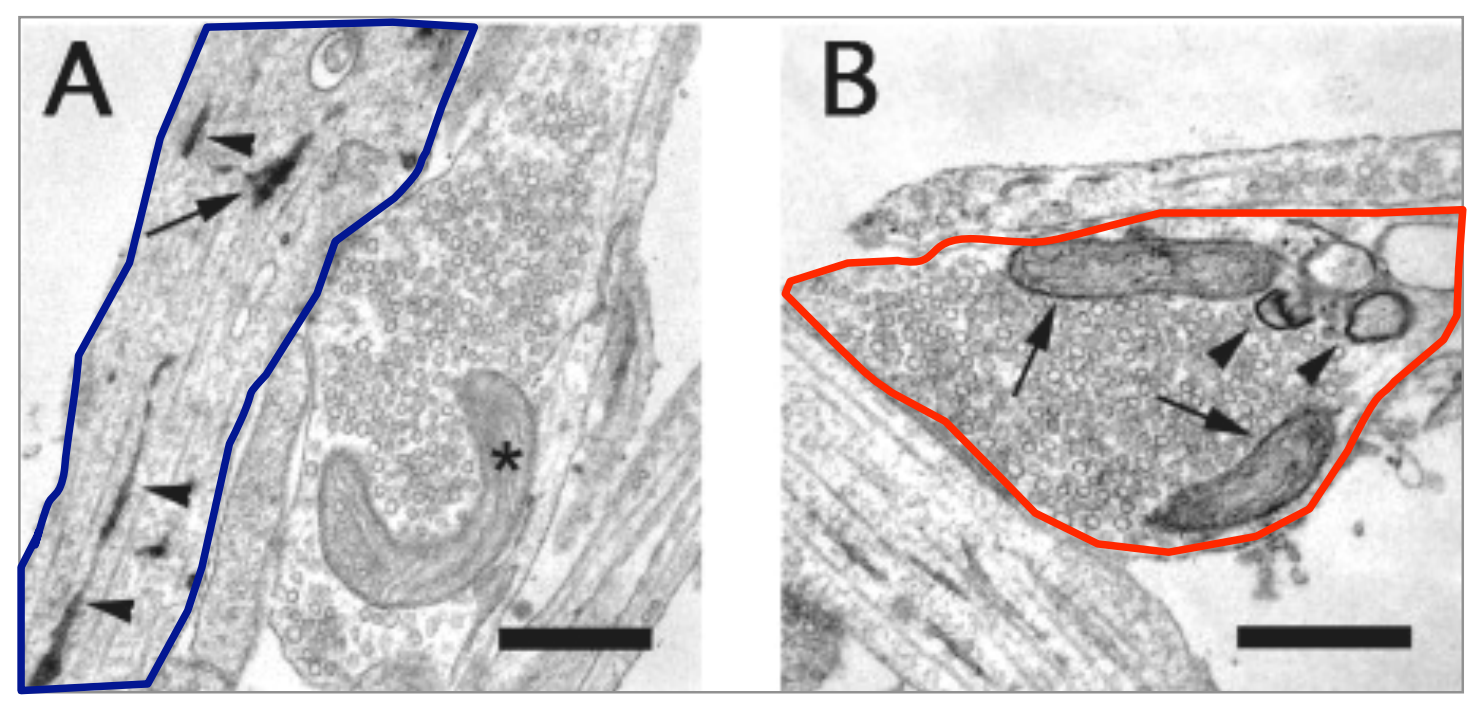

Fig. 1 General structure of synapses. A, B: Electron micrographs of cultured hippocampal neurons. In the distal dendrite (A, blue; postsynaptic element) arrowheads indicate horseradish peroxidase (HRP)-labeling of the endoplasmatic reticulum (ER). The asterisk indicates a presynaptic mitochondrion. In the presynaptic bouton $(B$, red) arrows indicate labeled mitochondria in addition to the arrowhead-marked ER. The presynaptic terminal is filled with synaptic vesicles which are devoid of HRP labeling. Scale bar: $500 \mathrm{~nm}$. [from Schikorski et al., 2007]

Upon the arrival of an electrical signal in form of an action potential (AP) neurotransmitter is secreted from the presynaptic nerve terminal (Fig. 2). The release of neurotransmitter from vesicles is triggered by $\mathrm{Ca}^{2+}$ ion influx through voltage-dependent $\mathrm{Ca}^{2+}$ channels (VDCCs), which are opened when the membrane is depolarized by the arrival of the AP [Katz, 1969]. $\mathrm{Ca}^{2+}$ ions 
enter into the cell because of a large concentration gradient between the extracellular space and the intracellular environment. $\mathrm{Ca}^{2+}$ influx regulates the activity of a multitude of proteins that is involved in the exocytosis, subsequent endocytosis and recycling of synaptic vesicles [Murthy and De Camilli, 2003; Südhof, 2004]. Upon $\mathrm{Ca}^{2+}$ influx, vesicles fuse with the presynaptic plasmamembrane at the active zones and release each at least 1000 to 4000 transmitter molecules in less than a millisecond into the extracellular space [Edwards, 1995]. The neurotransmitter molecules diffuse across the synaptic cleft and bind to the appropriate postsynaptic receptors to mediate influx of ions across the postsynaptic membrane. The local depolarization is experimentally detectable as a postsynaptic potential or current. Scaffolding and signaling proteins at the PSD which anchor the neurotransmitter receptors opposite to the release sites mediate the signal transduction in the postsynaptic cell [Boeckers, 2006; Sheng and Hoogenraad, 2007].

Different synapses formed by a neuron have distinct release probabilities regulated by the target [Rosenmund et al., 1993; Dobrunz and Stevens, 1997; Dobrunz, 2002].

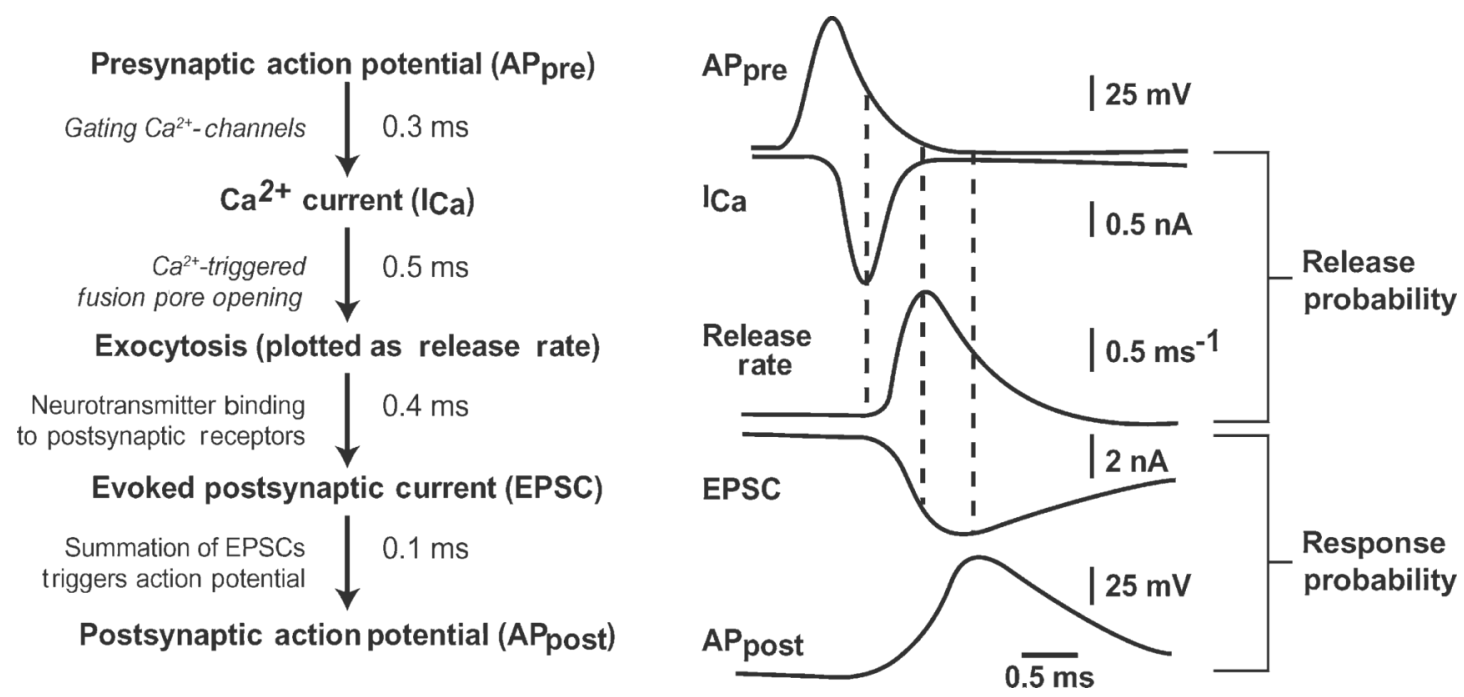

Fig. 2 Timing of synaptic transmission. left: Event sequence occuring at a synapse. right: corresponding events from a calyx of Held synapse (excitatory synapse of the brainstem). The scale bars apply to all traces [from Südhof, 2004] 


\section{Molecular processes at presynaptic specializations}

At the active zone of a presynaptic terminal synaptic vesicles undergo a local cycle of trafficking before becoming fusion-competent [Cecarelli et al., 1972; Heuser and Reese, 1973]. The exocytotic process involves targeted translocation of vesicles to the sites of release. The key steps of exocytosis include the recruitment of vesicles to the plasma membrane, their docking (initial contact with the plasma membrane) and priming (preparation of vesicles for fusion), and finally their $\mathrm{Ca}^{2+}$-triggered fusion with the plasma membrane [Südhof, 1995, 2004]. Cell membrane added during exocytosis is subsequently retrieved by a process called endocytosis [Slepnev and De Camilli, 2000; Littleton, 2006]. Thereby surface proteins and lipids are recycled. It is currently believed that both processes, exo- and endocytosis, are tightly coupled [Gundelfinger et al., 2003; Ryan, 2006]. The question of how synapses maintain an active recycling pool of synaptic vesicles to support synaptic transmission during high-frequency stimulation is still a startling and often controversially discussed problem.

\section{Synaptic vesicles and fusion}

The identification of the correlative between the observed quantal nature of neurotransmitter release [Del Castillo and Katz, 1954] and the presence of small vesicular organelles in the presynaptic terminal [Palay and Palade, 1955] evolved into one of today's core questions. What are the molecular mechanisms that allow for the sensation of the incoming $\mathrm{Ca}^{2+}$ signal? How exactly is the $\mathrm{Ca}^{2+}$ signal subsequently translated into the fusion of the vesicular membrane with the plasma membrane? Counteracting electrostatic forces between both membranes impede their fusion [Jahn and Grubmüller, 2002; Jahn et al., 2003].

Synaptic vesicles are highly complex structures similar to other nanostructures such as ribosomes or viruses. They have a diameter of approximately $40 \mathrm{~nm}$. A quantitative description of synaptic vesicles showed that the SV membrane contains a high protein density: a quarter of the entire membrane volume can be attributed to transmembrane domains [Takamori et al., 2006]. At present, vesicle translocation, target recognition, docking, and 
fusion are known to involve each the ordered and sequential recruitment of protein complexes from the cytosol. The membrane constituents of the SV play a major role in orchestrating these processes.

Synaptic vesicles are imbedded in a network of cytoskeletal elements, including intermediate filaments, microtubules, and microfilaments. In resting nerve terminals most synaptic vesicles are immobile [Greengard et al., 1993; Hilfiker et al., 1999; Chi et al., 2001; Mozhayeva et al., 2002]. By affecting the protein-protein interactions between SVs and the cytoskeletal matrix stimulation-induced $\mathrm{Ca}^{2+}$ entry triggers the rearrangement of filamentous actin, enhances vesicular mobility, and translocates secretory vesicles to exocytic sites [Bernstein and Bamburg, 1989; Morales et al., 2000; Jovanovic et al. 2001]. The formation of stable coiled coils by soluble $\underline{N}$-ethylmaleimidesensitive factor attachment protein receptor (SNARE) proteins present on both membranes contributes the energy needed for both membranes to overcome the counteracting force barrier [Blasi et al., 1993ab; Hanson et al., 1997; Weber et al., 1998]. Three different SNARE proteins participate as a single copy in the formation of a thermostable, sodium dodecyl sulfate and protease resistant core complex (or SNARE complex): synaptobrevin on the vesicular membrane (v-SNARE), syntaxin and SNAP-25 (šynaptosomalassociated protein of $\underline{25} \mathrm{kDa}$ ) on the plasma membrane (t-SNAREs) [Fasshauer et al., 2002]. According to the current view, initiation of the SNARE complex assembly in the presence of $\mathrm{Ca}^{2+}$, ATP and additional cytoplasmic factors is the key molecular event underlying the priming process [Lonart, 2002; Martin, 2003]. However, the mechanism and relative timing of the SNARE complex formation with respect to the $\mathrm{Ca}^{2+}$-trigger is unclear.

Since fusion mediated by SNAREs only, is slow and uncoordinated [Nicholson et al., 1998; Fasshauer and Margittai, 2004], many accessory factors that modulate SNARE-driven exocytosis are necessary. Two conserved SNARE-interacting protein families are known to regulate the SNARE complex assembly: small cytosolic GTPases and Sec1/Munc18-like (SM) proteins.

Small cytosolic GTPases have emerged as strong SV traffick controllers in both exo- and endocytic pathways in all eukaryotic cells. They are molecular switches cycling between a GDP-bound inactive and a 
GTP-bound active state [reviewed by Wennerberg et al., 2005]. Their activity is regulated by a variety of guanine nucleotide exchange factors (GEFs) and GTPase-activating proteins (GAPs) [Bos et al., 2007]. Biochemical and genetic experiments have demonstrated a role for GTP hydrolysis in regulating the intracellular transport of vesicles between different membrane compartments both spatially and temporally [Melançon et al., 1987; Walworth et al., 1989; Matteoli et al., 1991].

SM-proteins represent a small family of conserved soluble proteins of 60-70 kDa that regulate SNARE assembly by direct binding to SNARE proteins [Toonen, 2003]. Munc18-1, is the essential SM-protein involved in neuronal exocytosis. Its gene ablation prevents mammalian exocytosis [Verhage et al., 2000], whereas its overexpression results in an increase of vesicle secretion [Voets et al., 2001]. Syntaxin1A traffics in an inactive form to the plasma membrane, requiring the interaction with Munc18-1 [Medine et al., 2007; Arunachalam et al., 2007]. Thereby Munc18-1 prevents the formation of ectopic SNARE complexes.

In addition to small GTPases and SM-proteins which are present in all eukaryotic cells, a number of neuron-/secretion-specific SNARE complex accelerator proteins exist, e.g. Munc13, complexins, synaptotagmins, and $\mathrm{Ca}^{2+}$-dependent activator proteins for secretion (CAPS) [Hanson et al., 1997]. At present, Munc13 is one of the best characterized. Munc13 describes a family of conserved proteins of $200 \mathrm{kDa}$ [Brose et al., 2000]. It contains a diacylglycerol (DAG) binding C1-domain, two or three C2-domains, and a syntaxin1 binding domain [Brose et al., 1995; Betz et al., 1997, 1998]. Gene ablation studies in worms, flies and mice demonstrated that unc13/Munc13 proteins are essential for both spontaneous and evoked release. They regulate the size of the pool of readily releasable vesicles at a post-docking stage [Richmond et al., 1999; Aravamudan et al., 1999; Augustin et al., 1999; Rosenmund et al., 2002]. unc13/Munc13 proteins are crucial for synaptic vesicle priming and were proposed to induce a conformational change in syntaxin1 upon binding, thereby promoting the SNARE complex assembly [Richmond et al., 2001]. The MUN domain of Munc13-1, which is the key for this priming function, appears to compete with Munc18-1 for the binding to membrane-anchored SNARE complexes [Guan et al., 2008]. 


\section{Vesicular dynamics - pool models}

Physiological studies suggest that synaptic vesicles are not equally releasable upon neuronal stimulation [Birks and Maclntosh, 1961; Elmquist and Quastel, 1965; Quastel, 1997]. The vesicles appear to be sorted into pools. However, it is still unclear how physiologically defined pools relate to morphological ones. There is no convincing evidence available to show that pool-specific morphological differences of vesicles exist or to demonstrate that their distribution in the presynaptic terminal differs.

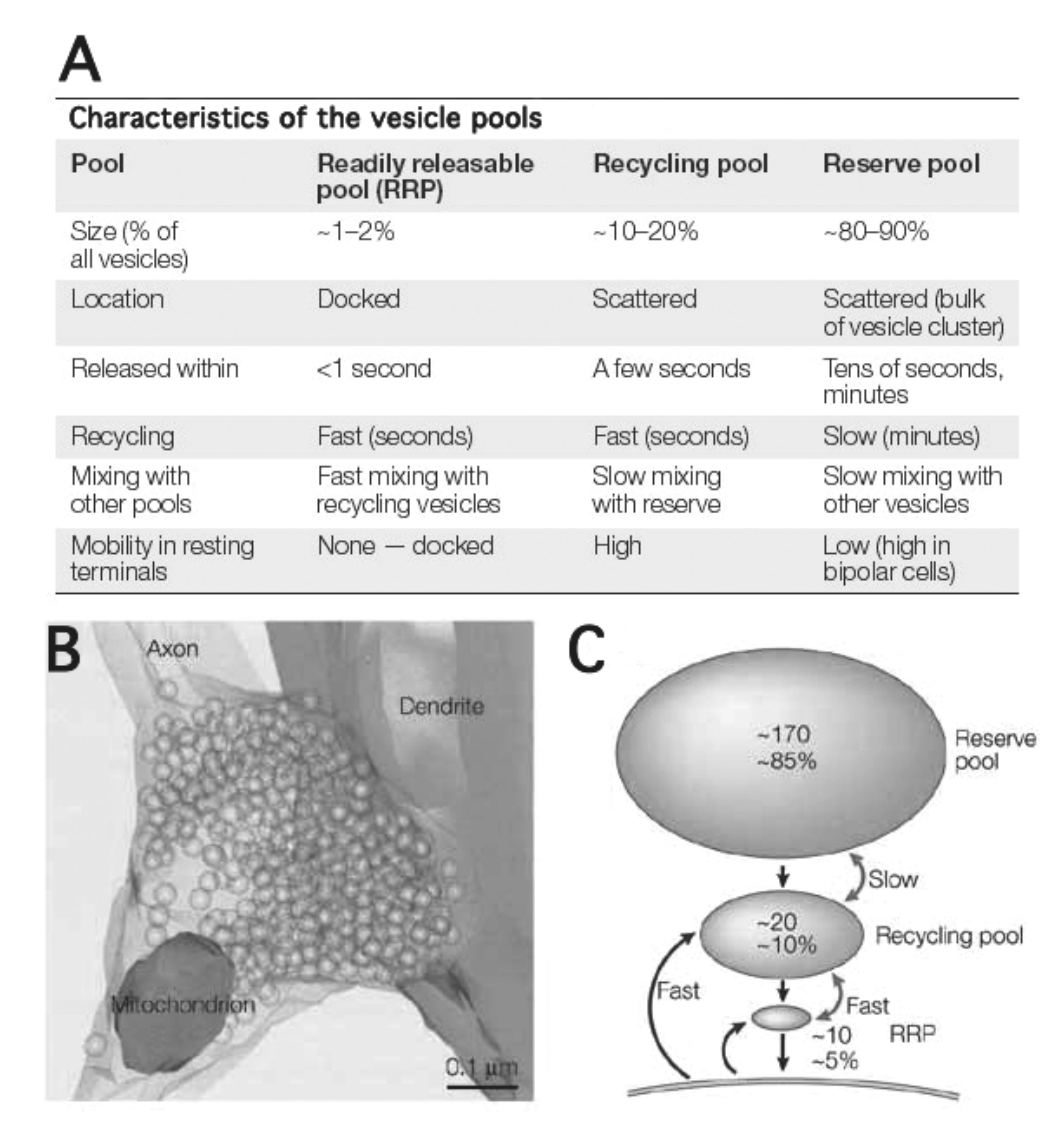

Fig. 3 Characteristics of vesicle pools. A. General information on presynaptic vesicle pools. B. 3Dreconstruction of a synaptic bouton from a hippocampal neuron grown in culture. $\mathbf{C}$. Pool sizes (given as numbers or in $\%$ of the total number of presynaptic vesicles) and mixing rates (double arrows) of hippocampal neurons. [modified from Rizzoli and Betz, 2005]

At present, three functionally different vesicle pools are thought to exist at the presynaptic nerve terminal [reviewed by Rizzoli and Betz, 2005; Fig. 3]. First, a readily releasable pool of vesicles (RRP) was described. This pool of vesicles can be depleted within a few milliseconds or tens of milliseconds with strong stimuli such as calcium uncaging [Heidelberger et al., 1994] or depolarizations [Sakaba and Neher, 2001a,b]. The number of readily releasable vesicles is believed to correspond morphologically to the number 
of docked vesicles [Murthy et al., 2001; Schikorski and Stevens, 1997, 2001]. During moderate physiological stimulation a recycling pool of vesicles maintains neurotransmitter release. The reserve pool (RP), finally, consists of SVs which are only released during intense stimulation.

\section{Glutamatergic synapses}

Throughout my thesis work I will focus on excitatory synapses. Most excitatory synapses of the vertebrate central nervous system are glutamatergic: they use the amino acid glutamate as their neurotransmitter. The release of glutamate activates different types of ligand-gated ion channels. The primary subtypes of glutamate receptors are the $\alpha$-amino-3hydroxy-5-methylisoxazole-4-propionic acid (AMPA) and the N-methyl-Daspartate (NMDA) receptors [Kaczmarek et al., 1997; Genoux and Montgomery, 2007]. The AMPA-type glutamate receptors determine the excitability of the post-synaptic cell. They conduct most of the current flow at resting membrane potentials [Hollmann et al., 1991]. AMPA receptors activate quickly in less than a millisecond [Dingledine et al., 1999]. In contrast, the activation of NMDA-type receptors occurs on a much slower time-scale of several milliseconds. At resting potentials they are nonconducting due to a voltage-dependent magnesium block [Nowak et al, 1984]. NMDA-type receptors conduct currents only after membrane depolarization. These ion channels have unusual permeability properties: in addition to slow deactivation kinetics they show high calcium ion permeability. Only few (5 30) NMDA receptors are present at the PSD, whereas the number of AMPA receptors has been estimated to 30-100 channels [Silver et al., 1992; Spruston et al., 1995]. NMDA receptors hardly contribute to fast excitatory transmission and phenomena of short-term plasticity, but they are supposed to be important for development and long-term changes in synaptic efficacy [Malinow and Malenka, 2002; Kopp et al., 2007].

After release, glutamate molecules are rapidly removed from the synaptic cleft. Diffusion or binding to glutamate transporters for glial and neuronal uptake ensure a rapid clearance of abundant transmitter molecules. [Diamond and Jahr, 1997; Herman and Jahr, 2007]. 


\section{Synaptic plasticity}

Plasticity of the circuitry that wires the brain is a fundamental property of neurons. It is thought to underlie behavior, cognition, learning and memory [Hebb, 1949; Eccles, 1964]. Synaptic plasticity is defined as an activity dependent change in the strength of synapses [Bliss and Lømo, 1973]. The development of new synapses, the activity dependent changes in the strength of existing synapses, and the elimination of synapses have been proposed to form the basis of this plasticity [reviewed by Waites et al., 2005; BruelJungerman et al., 2007].

In general, the signal across a synapse can be altered by presynaptic and/or postsynaptic mechanisms. Changes in the intracellular concentration of seconds messengers, such as $\mathrm{Ca}^{2+}$ ions, DAG and CAMP, increase or decrease neurotransmitter release either on a short-term (in the range of milliseconds to minutes) or a long-term (in the range of hours to weeks) timescale [Zucker and Regehr, 2002; Malenka, 2003]. The mechanisms of both forms of synaptic plasticity differ. Long-term changes more likely involve the restructuring of synapses and changes in gene expression. Membrane trafficking of postsynaptic ionotropic receptors is considered as being crucial for the initiation of long-term synaptic plasticity [Collingridge et al., 2004]. However, rapid modulation of presynaptic function was also observed during long-term potentiation [Zalutsky and Nicoll, 1990; Yeckel et al., 1999; Zakharenko et al., 2001]. Short-term plasticity on the other hand is believed to be primarily presynaptic in origin [Fisher et al., 1997]. At the presynaptic nerve terminal, the modulation of synaptic vesicle exocytosis is the major mechanism for regulating synaptic strength. Modulation of $\mathrm{Ca}^{2+}$ influx during an action potential, direct effects on the fusion machinery consequently modifying neurotransmitter release probability, or manipulations of the number of releasable vesicles can regulate the amount of neurotransmitter release. Short-term synaptic enhancement, such as facilitation, is believed to result mainly from an activity-dependent increase of the concentration of residual presynaptic $\mathrm{Ca}^{2+}$ [Katz and Miledi, 1968; Regehr et al., 1994]. In contrast, short-term synaptic depression may originate from many processes, such as the depletion of readily releasable vesicles, the autocrine or paracrine 
regulation of presynaptic function via metabotropic or ionotropic receptors, or desensitization of postsynaptic receptors [reviewed by Zucker and Regehr, 2002].

Second messengers play a vital role in modulating the activity of proteins that regulate neuronal information exchange [Leenders and Sheng, 2005]. Intrinsic/peripheral vesicle proteins, synaptic plasma membrane proteins or lipids, and cytosolic/cytoskeletal proteins are structurally or enzymatically modified due to kinase-/phosphatase-mediated phosphorylation or dephosphorylation processes, $\mathrm{Ca}^{2+}$-regulation and GTP/ATP hydrolysis.

In vivo experiments revealed a prominent role for protein kinases in initiating synaptic plasticity. Several signaling cascades involving CaMKII, PKA, PKC, CaMKIV, mitogen-activated protein kinases (MAPKs), tyrosine kinases, protein phosphatases $1 / 2 \mathrm{~A}$ and calcineurin have been extensively analyzed [Weisskopf et al., 1993; Soderling, 2000; Nguyen and Woo, 2003; Leenders and Sheng, 2005; Mayford, 2007]. Many of these cascades interact and give rise to complex networks of signaling molecules. PKC activity, for example, is crucial for all key steps involved in exocytosis at the presynaptic nerve terminal. PKC was shown to affect MAPK signaling, Munc18 activity, SNAP-25 and VDCC function [Hamilton et al., 2001; Hu et al., 2003a,b; Wierda et al., 2007; Pozzi et al., 2008].

During my Ph.D. thesis work, I am interested in the cAMP-mediated presynaptic modulation of neurotransmitter release involving novel PKA-independent signaling pathways. 


\section{CAMP-TARGETS}

In 1957 Earl Sutherland discovered cAMP [Rall and Sutherland, 1958]. Its discovery led to the second messenger concept of cellular signaling [Sutherland et al. 1965; Sutherland and Robinson, 1966]. cAMP is produced from ATP by adenylyl cyclase (AC) activity [Rall and Sutherland, 1962] in response to a variety of extracellular signals such as hormones, growth factors and neurotransmitters and is rapidly hydrolyzed by cyclic AMP phosphodiesterases (PDEs) into adenosine 5'-monophosphate [Sutherland and Rall, 1958; Sutherland et al., 1962; Butcher and Sutherland, 1962; Beavo et al., 1970; Houslay, 1998].

Elevation of intracellular cAMP levels leads to the activation of different cAMP targets and controls a wide variety of cellular events including metabolism, gene regulation, cell shape, cytoskeletal modelling, cell migration, proliferation, differentiation, apoptosis and secretion [reviewed by Skålhegg and Tasken, 2000]. In order to explain how cAMP can specifically modulate so many different cellular events, it has been suggested that parallel and spatially segregated cAMP signalling pathways coexist within a cell [Zaccolo et al., 2002; DiPilato et al., 2004]. Although cAMP-dependent protein kinase A (PKA), the first cAMP target known [Walsh et al., 1968], had become a model of protein kinase structure and regulation, it turned out that not all of the cAMP-related effects are mediated by a general activation of PKA. The cyclic nucleotide binding domain (CNBD) originated in bacteria where binding of cAMP activates transcription factors, namely the catabolite gene activation proteins [Passner et al., 2000]. Later in phylogeny the cNBD is found not only in the CAMP- and cGMP-dependent protein kinases, but also in several types of ion channels directly modulated by cyclic nucleotides [Ludwig et al., 1998], and in the Epac family of guanine exchange factors [de Rooij et al., 1998; Kawasaki et al., 1998].

However, at present the existence of other CAMP-binding proteins is unclear. Proteins with sequence similarities to the cNBDs [de Rooij et al., 1999; Pak et al., 2002] or proteins that can bind cAMP without having the cNBD motif, like the extracellular cAMP receptors of Dictyostelium discoideum 
[Klein et al., 1988; Bankir et al., 2002], may insert new twists into the cAMP second messenger signaling system.

\section{Protein Kinase A}

cAMP-dependent protein kinases are widely distributed in the animal kingdom and in different tissues [Kuo and Greengard, 1969]. High levels of cAMP-dependent protein kinase were found in the nervous system [Miyamoto et al., 1969a,b]. From the seventies until the late nineties, it was believed that most if not all of the cAMP effects were mediated by the activation of cAMPdependent serine-threonine protein kinases. By the early eighties Krebs (1983) had tabulated some 50 enzymes that were known to undergo phosphorylation-dephosphorylation of which almost half were dependent on PKA.

PKAs are present as two types of isoenzymes, PKAI and PKAll, in most cells. They are tetramers composed of two catalytic (C) and two regulatory (Rl $\alpha \beta$ or RII $\alpha \beta$ ) subunits [Beavo et al., 1975]. Each $R$ subunit has two cAMP-binding domains (site $A$ and site $B$ ). Upon binding of two cAMP molecules on each of the $\mathrm{R}$ subunits, the inactive tetramer is dissociated into one dimer of $\mathrm{R}$ subunits and two active $\mathrm{C}$ subunits.

An important role of cAMP in the nervous system has been envisioned since 1962 when it was found that the enzymes responsible for its synthesis and degradation are more abundant in the brain than in other mamalian tissue [Sutherland et al., 1962]. However, it was not until 1969 that there was any electrophysiological evidence that second messengers, such as cyclic AMP, might be mediators of a membrane response [Siggins et al., 1969; Goldberg and Singer, 1969]. Electrical activity or the application of various agents known to cause membrane depolarization increased cAMP formation and modulated biochemical responses in nervous tissue [Kakiuchi et al., 1969; Greengard et al., 1970; Shimizu et al., 1970]. Experiments from the laboratory of Eric Kandel showed that cAMP plays a crucial role in the regulation of synaptic changes which are related to learning and memory storage. When Eric Kandel and James Schwartz published their first paper in 1972 about the role of cAMP in the nervous system of Aplysia californica, they stated vaguely: 
'... (cAMP) may mediate some of the biochemical changes which follow synaptic transmission' [Cedar et al., 1972]. Later, Eric Kandel, James Schwartz and Paul Greengard concluded that cAMP and PKA are both necessary and sufficient to strengthen the connectivity between sensory neurons and motorneurons in Aplysia, and suggested that CAMP and PKA are the first elements in a chain of biochemical processes leading to neuronal plasticity [Castellucci et al., 1980 \& 1982]. Similar observations were made later for mammalian glutamatergic central synapses: cAMP enhanced neurotransmitter release from presynaptic terminals, and this could be attributed to the direct activation of PKA [Weisskopf et al., 1994; Leßmann and Heumann, 1997].

For over a decade, the enhancement of regulated exocytosis by PKA has remained unexplained at the molecular level. PKA not only inhibits potassium channel function [Siegelbaum et al., 1982], but also regulates vesicular dynamics by phosphorylation of synapsins, SNAP25, and voltagedependent calcium channels [Menegon et al., 2006; Nagy et al., 2004; Hell et al., 1995].

Because genetic manipulations confer specificity, precision, and reproducibility of the directed mutations, many studies have examined the role of PKA in hippocampal plasticity by deleting or overexpressing particular isoforms of regulatory and catalytic subunits in the hippocampus [McKnight et al. 1988a,b; Brandon et al., 1995; Abel et al., 1997]. PKA has been implicated in the expression of specific forms of long-term potentiation (LTP) and longterm depression (LTD) [Nguyen and Woo, 2003; Table 1]. However, basal neurotransmission and short-term plasticity were unaffected in neurons deficient for different PKA subunits [Brandon et al., 1997]. Similarly, total PKA activity was unaffected in the hippocampus and amygdala, while basal PKA activity was reduced by $26 \%$ in the brains of $C \beta-/-$ mice despite a compensatory increase in $\mathrm{C} \alpha$ protein when knocking out all PKA C $\beta$ subunit isoforms in mice [Howe et al., 2002]. 
Table 1 Genetic manipulations demonstrating a role for cAMP/PKA signaling in hippocampal synaptic plasticity [adapted from Nguyen and Woo, 2003].

\begin{tabular}{|c|c|c|c|c|c|}
\hline \multirow{2}{*}{ Gene } & \multicolumn{3}{|c|}{ Synaptic plasticity phenotypes } & \multirow{2}{*}{$\begin{array}{c}\text { other } \\
\text { phenotypes of } \\
\text { interest }\end{array}$} & \multirow{2}{*}{ References } \\
\hline & E-LTP & L-LTP & LTD & & \\
\hline$C \beta-I-$ & $\begin{array}{l}\mathbf{-}(\mathrm{CA} 1) \\
\boldsymbol{\Downarrow}(\mathrm{CA} 3)\end{array}$ & $\downarrow \downarrow(C A 1)$ & $\downarrow \downarrow(C A 1)$ & - PKA activity & $\begin{array}{c}\text { Huang et al. } \\
\text { (1995); Qi et al. } \\
\text { (1996) }\end{array}$ \\
\hline & - (CA1) & & & & $\begin{array}{l}\text { Brandon et al. } \\
\text { (1995); Huang }\end{array}$ \\
\hline $\mathbf{R I} \beta-I-$ & $\Downarrow \Downarrow(\mathrm{CA} 3)$ & - (CA1) & $\downarrow \downarrow$ & - PKA activity & et al. (1995) \\
\hline$R(A B)$ & - (CA1) & $\downarrow \Downarrow(\mathrm{CA} 1)$ & $\mathrm{nt}$ & $\begin{array}{l}\sim 40 \% \downarrow \text { PKA } \\
\text { activity; } \downarrow \downarrow \text { long- } \\
\text { term memory }\end{array}$ & $\begin{array}{c}\text { Abel et al. } \\
\text { (1997); } \\
\text { Rotenberg et al. } \\
(2000)\end{array}$ \\
\hline & & & & & Wu et al. (1995); \\
\hline & - (CA1) & & & & Villacres et al. \\
\hline AC1 -I- & $\downarrow \downarrow(C A 3)$ & - (CA1) & $\mathrm{nt}$ & & (1998) \\
\hline $\begin{array}{l}\mathrm{AC} 1-1- \\
\& \mathrm{AC} 8-1-\end{array}$ & - (CA1) & $\downarrow \downarrow(C A 1)$ & nt & $\begin{array}{l}\boldsymbol{\Downarrow} \text { long-term } \\
\text { memory }\end{array}$ & $\begin{array}{l}\text { Wong et al. } \\
\text { (1999) }\end{array}$ \\
\hline
\end{tabular}

\section{cAMP-gated ion channels}

In the sensory system cyclic nucleotide-gated (CNG) channels are essential components for the generation of the primary electrical response. Signal transduction in olfactory receptor neurons proceeds via G-protein-mediated elevation of intracellular cAMP in response to odorant binding by 7-helix receptors [Nakamura and Gold, 1987]. CNG channels are widely expressed in the central nervous system [Kingston et al., 1996; Bradley et al. 1997; Wei et al., 1998]. They represent nonselective cation channels that mediated $\mathrm{Ca}^{2+}$ and $\mathrm{Na}^{+}$ion influx in response to the direct binding of intracellular cyclic nucleotides [Yau et al., 1994]. The CNG-channel family includes pacemarker 
voltage-gated potassium channels [Bräuer et al., 2001; Mansuy, 2004]. The rise of intracellular $\mathrm{Ca}^{2+}$ by $\mathrm{CNG}$ channel activity was proposed to play a role in the synaptic plasticity underlying learning and memory [Zufall et al. 1997; Parent et al., 1998; Matulef and Zagotta, 2003; Wang et al., 2007].

\section{Epac - exchange protein directly activated by cAMP}

In 1998, two novel cAMP receptors, Epac1 and Epac2, were identified [de Rooij et al., 1998; Kawasaki et al., 1998]. These findings were based on sequence database searches for proteins that could explain the insensitivity of cAMP-induced activation of the small GTPase Rap1 to inhibitors of PKA [de Rooij et al., 1998, 2000]. Epac1 was moreover identified as cAMP-GEFI in a differential screen for messenger RNAs enriched in the striatum of the brain [Kawasaki et al., 1998]. The Epac proteins are guanine nucleotide exchange factors (GEFs) which specifically activate the small Ras-like GTPases Rap1 and Rap2 upon cAMP binding. Rap proteins are molecular switches cycling between a GDP-bound inactive and a GTP-bound active state. GEF-mediated activation of Rap increases nucleotide dissociation by several orders of magnitude.

Epac1 and Epac2 exhibit a distinct expression pattern in mature and developing tissues. Epac1 mRNA is ubiquitously expressed, with high expression levels in the thyroid, kidney, ovary, skeletal muscle and in specific regions of the murine and rat brain [Kawasaki et al., 1998]. Epac2 mRNA expression is prominent in the brain and endocrine tissues [Ozaki et al., 2000]. In differentiating male mouse germ cells Epac1 shows a predominant sub-plasmamembrane localization, whereas Epac2 is mainly present in the cytosol with a diffuse spotted distribution [Aivatiadou et al., 2005]. Upon Rap1 activation endogeneous Epac2 is redistributed and results in a predominant Golgi/vesicular localization [Aivatiadou et al., 2005].

The interaction of cAMP with Epac is highly dynamic, implying a rapid dissociation rate [Kraemer et al., 2001]. In vitro results show that the binding affinity of cAMP for PKA and Epac are similar [Dao et al., 2006]. However, in vivo observations that PKA and Epac respond similarly to elevated levels of cAMP are currently lacking. 


\section{Epac protein structure}

Epac1 and Epac2 are multi-domain proteins that consist of an $\mathrm{N}$ terminal regulatory region and a C-terminal catalytic region [Bos, 2006]. The activity of Epac depends on the binding of cAMP to the regulatory domain [de Rooij et al., 1998, 2000]. Epac1 and Epac2 have one and two cAMP binding sites, respectively. Both cAMP binding sites are located at the $\mathrm{N}$-terminal part of the proteins. The $\mathrm{N}$-terminal regulatory region of Epac is an auto-inhibitory domain that blocks GEF activity for Rap proteins [de Rooij et al., 1998, 2000]. The second cyclic-nucleotide-binding domain (cNBD-B) of Epac2, which is common to Epac1 and Epac2, keeps Epac in an inactive state. Auto-inhibition by the regulatory domain is repressed by binding of CAMP to CNBD-B inducing a conformational change in the phosphate binding cassette [Rehmann et al., 2003a,b, 2006]. The function of the first cNBD of Epac2 (cNBD-A) is currently unclear. It binds cAMP with low affinity. In vivo experiments using Epac-based FRET sensors showed that fluctuations of intracellular cAMP levels occur in the micromolar range and are indeed coupled to the activation of Epac [DiPilato et al., 2004; Landa et al., 2005]. The $\mathrm{K}_{d}$ for binding of cAMP to Epac1 is $2.8 \mu \mathrm{M}$, whereas for Epac2 cNBD-A and cNBD-B exhibit a $\mathrm{K}_{d}$ of 87 and $1.2 \mu \mathrm{M}$, respectively [de Rooij et al., 2000; Christensen et al., 2003].

The regulatory domain of both Epac isoforms also contains a Dishevelled, Egl-10, Pleckstrin (DEP) domain. Deletion of this domain abolishes membrane association of Epac [de Rooij et al, 2000] and reduces its nucleotide exchange activity toward Rap [Ponsioen et al., 2004]. DEP domains target DEP-containing proteins to the sites of their intracellular action, most likely through the interaction with either a lipid or a membrane protein. Recently, DEP domain interactions with members of the extended SNARE protein family have been reported [Martemyanov et al., 2003].

The C-terminal catalytic region comprises a Ras-exchange motif (REM) domain, a Ras-association domain (RA) and a CDC25-homology domain (CDC25-HD). The REM domain is conserved in almost all mammalian GEFs with a CDC25-HD and is required for the stabilization of the catalytic helix [Boriack-Sjodin et al., 1998] and for the binding to other regulatory proteins 
[Margarit et al., 2003]. Interaction of the RA domain with Ras-GTP was shown to recruit Epac2 to the plasma membrane [Li et al., 2006].

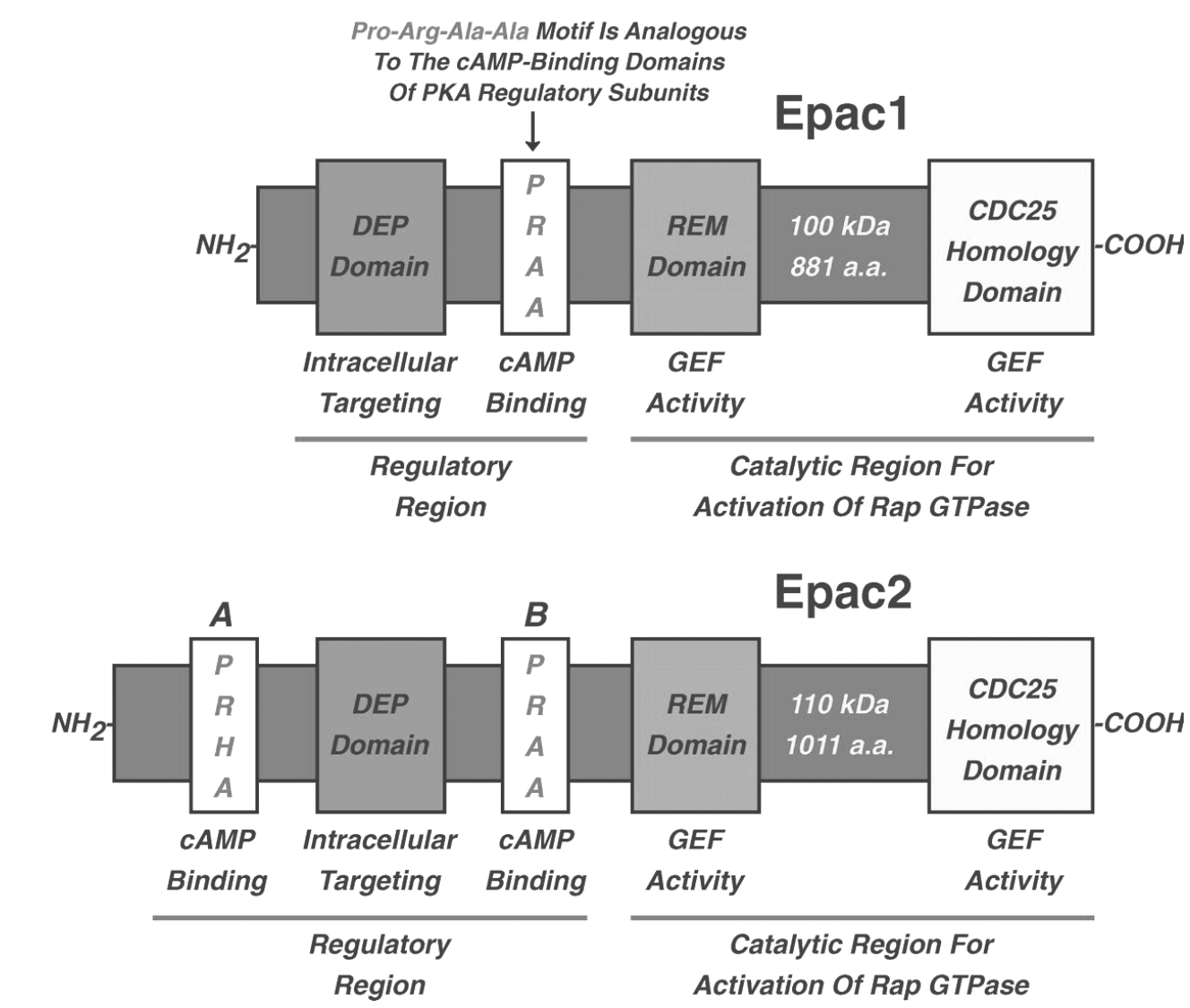

Fig. 4 The multi domain structure of Epac. The domain structure of Epac1 and Epac2 are shown, indicating the regulatory region with the cyclic nucleotide binding domain(s) and the catalytic region with the CDC25-homology domain responsible for the guanine-nucleotide exchange atcivity. The two Epac isoforms are encoded by two distinct genes. [from Holz et al., 2006]

\section{Multiple biological functions of Epac}

The discovery and characterization of a novel cAMP signal transduction mechanism involving the Epac family of cAMP receptors led to the reevaluation of cAMP actions. Epac proteins have been reported to control several effector proteins and regulate cell proliferation, cell survival, gene transcription, vesicle trafficking, secretion/exocytosis and ion transport [reviewed by Roscioni et al., 2007; Fig. 5]. They exert their biological function alone or in concert with PKA. A-kinase anchoring proteins (AKAPs) known to 
interact with PKA and PDEs may coordinate Epac-driven signaling [Dodge-Kafka et al., 2005; Dodge-Kafka and Kapiloff, 2006].

By serving as a cAMP-binding protein with intrinsic GEF activity, Epac couples cAMP production to the activation of Rap, a small GTPase of the Ras family. Cellular processes stimulated as a consequence of the Epac-mediated activation of Rap include integrin-mediated cell adhesion, vascular endothelial cell barrier formation, cardiac gap junction formation, mitogen-activated protein kinase (MAPK) signaling, hormone gene expression, and phospholipase C-epsilon (PLC- $\varepsilon$ ) activation [reviewed by Holz et al., 2006].

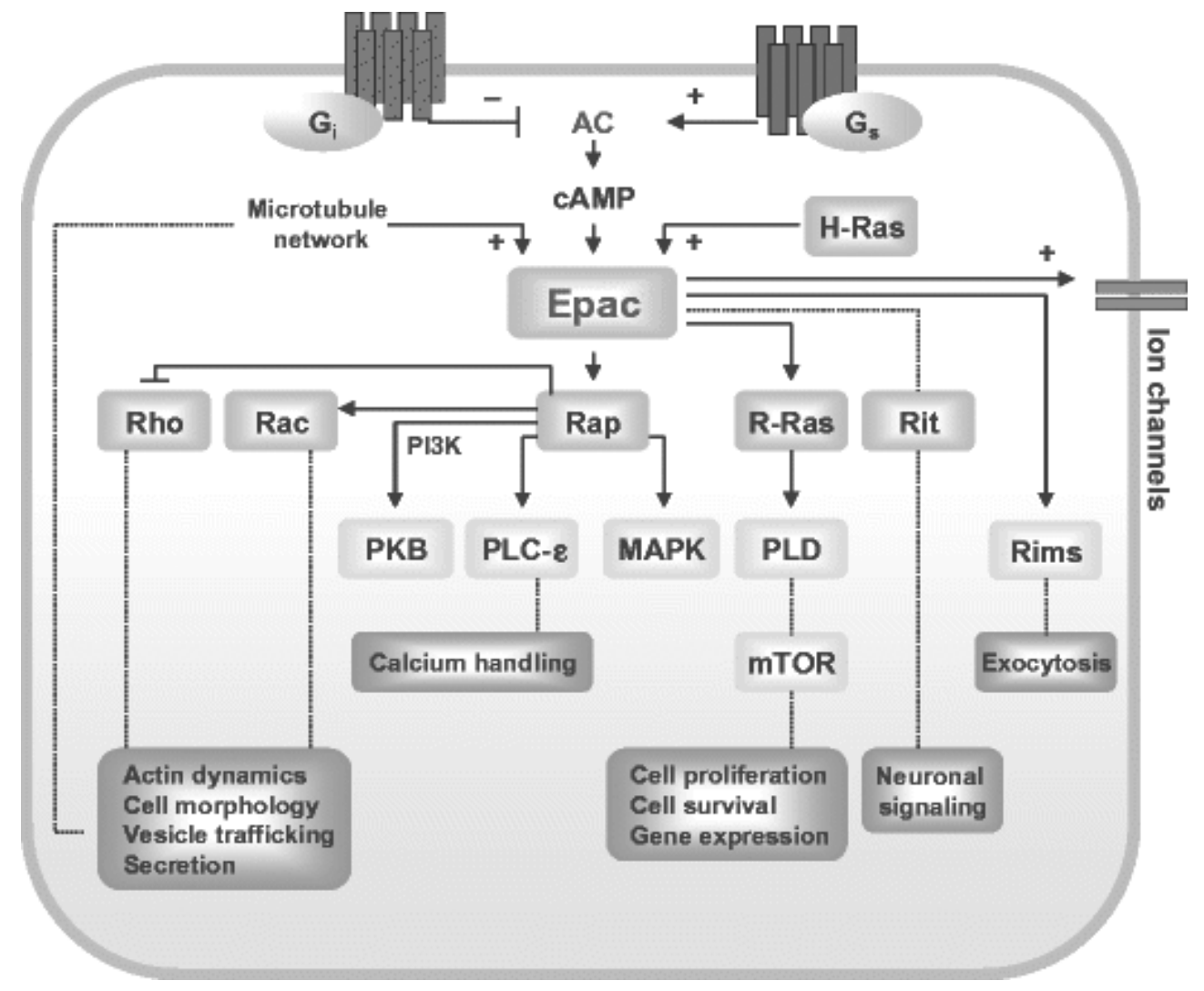

Fig. 5 Epac effectors and biological function. Schematic representation of the Epac signaling pathway. H-Ras, R-Ras, Rap, Rac, Rho are small GTPases of the Ras superfamily. AC: adenylyl cyclase; $G_{i}$ : inhibitory small G-protein; $G_{s}$ : stimulatory small $G$ protein; PLD: phospholipase D; PLC: phospholipase C; mTOR: mamalian target of rapamycin; PKB: protein kinase $B$; Epac2 is recruited to the plasma membrane by H-Ras. The GEF activity of Epac1 is regulated by LC2 MAP1A, a microtubue-associated protein. [adapted from Roscioni et al., 2007] 
Both Rap1 and Rap2 are targets for Epac1 and Epac2. In contrast to Rap1, the current knowledge about Rap2 effectors and Rap2-driven cellular responses is rather limited. Rap2 is localized to the plasma membrane and intracellular compartments [de Rooij et al., 1998, Quilliam et al., 2002]. Activation of PLC- $\varepsilon$ by Epac and Rap2 results in the generation of inositol1,4,5-trisphosphate and increases cellular calcium [Schmidt et al., 2001; Evellin et al. 2002]. Gi-coupled and intracellular cAMP-level reducing receptors inhibit Epac-Rap2-PLC- $\varepsilon$ driven cellular responses [vom Dorp et al., 2004]. PLC- $\varepsilon$ seems to represent a molecular link between the second messengers calcium and CAMP and members of the Ras superfamily of small GTPases [Roscioni et al., 2007].

Moreover, Epac is also reported to interact with Ras GTPases [Li et al., 2006; De Jesus et al., 2006], microtubule associated proteins [Yarwood, 2005], secretory granule-associated proteins such as Rim2 and Piccolo [Ozaki et al., 2000; Fujimoto et al., 2002], and the sulfonylurea receptor-1 (SUR1), a subunit of ATP-sensitive $\mathrm{K}^{+}$channels [Kang et al., 2006].

In the light of an accumulating body of evidence indicating a role for Epac in cell physiology I will emphasize in the following paragraphs its function in cell adhesion and cell-cell junction formation, insulin secretion, and neurotransmitter release.

\section{Cell adhesion and cell-cell junction formation}

Several studies support the idea that Rap1 has an important role in the regulation of integrins [reviewed by Bos, 2003, 2005]. Integrins are a family of cell surface molecules that regulate cell adhesion to specific extracellular matrix components such as fibronectin, or to specific receptors on neighbouring cells [reviewed by Morgan et al., 2007]. Extracellular stimuli that induce increased intracellular cAMP levels might regulate cell adhesion through an Epac/Rap-mediated signaling pathway [Rangarajan et al., 2003]. Adhesion to fibronectin occurs more rapidly after stimulation of Epac/Rap1 activity. 
The effect of Epac on cell-cell junction (gap junction) formation has been observed most clearly in endothelial cells [Kooistra et al., 2005]. Gap junctions are channels formed by two connexons and are involved in the coordinated contraction of heart muscle cells. Various stimuli, including prostaglandins that elevate the level of CAMP, inhibit cell permeability [Cullere et al., 2005; Fukuhara et al., 2005]. This effect is mediated by both PKA and Epac, and involves junction maturation. PKA regulates channel gating, whereas Epac predominantly stimulates the accumulation of connexons and the tightening of the gap junctions.

\section{Insulin secretion}

Elevation of intracellular cAMP levels upon stimulation by insulin secretagogue hormones, such as the glucagon-like hormone (GLP-1), enhances $\mathrm{Ca}^{2+}$-dependent insulin exocytosis from pancreatic $\beta$-cells. The insulin secretory response is biphasic [Curry et al., 1968]. The first and the second phase result from the exocytosis of insulin secretory granules in the readily releasable pool and in the reserve pool, respectively [Barg et al., 2002; Bratanova-Tochkova et al., 2002]. cAMP potentiates both phases [Prentki and Matschinsky, 1987] and requires the interaction between cAMP and $\mathrm{Ca}^{2+}$ signaling [Charles et al., 1973, 1975; Howell et al., 1994]. In addition to the PKA-dependent modulation of ion channel and transporter activities [Béguin et al., 1999; Britsch et al., 1995; Kanno et al., 1998], direct effects of cAMP on exocytotic processes have been shown in cAMP-regulated insulin secretion. Epac-signaling complements PKA activity [Kashima et al., 2001]. Activation of Epac2 facilitates fast $\mathrm{Ca}^{2+}$-dependent exocytosis by increasing the size of the RRP of secretory granules [Eliasson et al., 2003]. Facilitation of fast exocytosis is reduced by downregulation of Epac2 expression or by transfection with dominant negative Epac2. It is assumed that the Epac2/Piccolo/Rim2 macromolecular complex confers this stimulatory effects of cAMP and $\mathrm{Ca}^{2+}$ on insulin secretion. Epac2 directly interacts with the insulin granule-associated protein Rim2 and the cytoskeletal matrix protein Piccolo [Fujimoto et al., 2002]. Insulin granule priming is a necessary step for 
glucose-dependent first- and second-phase secretion [Daniel et al., 1999]. The potential role of Epac as a regulator of insulin secretion is emphasized by studies demonstrating an interaction of Rim2 with the small GTPase Rab3A [Ozaki et al., 2000]. Rab3A is located on the cytoplasmic surface of insulin secretory granules [lezzi et al., 1999]. It regulates the recruitment and docking of granules at the plasma membrane [Yaekura et al., 2003]. Epac2 does not stimulate the exchange of guanyl nucleotides at Rab3A, in contrast to its regulation of Rap1 activity.

Alternatively, the stimulatory effect of Epac2 activity on secretion may result by virtue of its ability to promote insulin granule acidification, another step necessary for granule priming. Epac2 stimulates exocytosis by interacting with insulin granule-associated sulfonylurea receptors (SUR1) [Eliasson et al., 2003]. Thereby Epac2 promotes the opening of CIC-3 chloride channels located in the secretory granule membrane. Influx of $\mathrm{Cl}^{-}$ions into the secretory granule lumen generates an electromotive force facilitating the ATP-dependent uptake of protons $\left(\mathrm{H}^{+}\right)$by a V-type $\mathrm{H}^{+}$-ATPase.

Finally, the Epac2/Rim2 complex [Shibasaki et al., 2004] not only serves as a scaffold for Piccolo, the L-type $\mathrm{Ca}^{2+}$ channel $\alpha$-subunit, and SUR1 but also binds and orchestrates Munc13-1 activity [Seino and Shibasaki, 2006]. cAMP fully rescues the priming defects caused by Munc13-1 deficiency via Epac and PKA signaling pathways and requires downstream Munc131/Rim2 interaction [Kwan et al., 2007]. Epac activation alone is incapable of fully rescuing the exocytotic defects in pancreatic $\beta$-cells deficient for Munc131. The RRP and the refilling of a releasable pool of vesicles are only partially restored after Epac activation, whereas PKA completely restores the RRP and partially rescues the refilling.

\section{Exocytosis - central nervous system (CNS)}

Similarly to its regulatory function in insulin secretion, cAMP is known to enhance glutamate release from presynaptic terminals at excitatory mammalian cerebral synapses [Weisskopf et al., 1994; Leßmann and Heumann, 1997]. Traditionally, this cAMP-mediated enhancement of 
neurotransmitter release was attributed to the direct activation of protein kinase A [Castellucci et al., 1980; Chavez-Noriega and Stevens, 1994]. cAMP-PKA signaling participates in the enhancement of vesicle fusion at multiple levels including the recruitment of synaptic vesicles from the reserve pool, the enhancement of $\mathrm{Ca}^{2+}$ influx, and the direct modulation of vesicle fusion. PKA was shown to phosphorylate a large number of proteins associated with synaptic vesicle exocytosis [reviewed by Seino and Shibasaki, 2006]. In cultured hippocampal neurons, activation of PKA causes synaptic facilitation by directly elevating the release probability of individual vesicles during $\mathrm{Ca}^{2+}$-induced exocytosis [Trudeau et al., 1996]. While specific inhibitors of PKA effectively block potentiation of exocytosis in hippocampal neurons and pancreatic $\beta$-cells [Trudeau et al., 1996; Renstrom et al., 1997], they are ineffective at the calyx of Held synapse in the auditory system [Sakaba and Neher, 2001c]. However, the adenylyl cyclase agonist forskolin increases both the number of releasable vesicles and their release probability at the calyx of Held synapse without affecting $\mathrm{Ca}^{2+}$ influx induced by presynaptic action potentials [Kaneko and Takahashi, 2004]. Forskolin attenuated only slow components of presynaptic potassium currents. The observed effect could be attributed to Epac signaling. Selective presynaptic Epac activation was proposed to modulate the rate of vesicle recruitment [Sakaba and Neher, 2003]. Epac activation accelerates the recovery of synaptic currents from post-tetanic depression, which had been slowed down in the presence of baclofen or GDP $\beta S$.

PKA-independent, Epac-mediated modulation of neurotransmitter release was also reported for the crayfish neuromuscular junction [Zhong and Zucker, 2005], and cortical neurons [Huang and Hsu, 2006]. At the crayfish neuromuscular junction cAMP-dependent enhancement of transmission apparently involves direct activation of HCN channels.

Further indirect evidence for a prominent role of Epac activity in the brain arises from experiments on nociceptor sensory neurons and Cos cells expressing the 5-hydroxytryptamine (5-HT) receptor. In nociceptor sensory neurons, which convert mechanical stimuli into pain sensation, stimulation of the $\beta$-adrenergic receptor sensitizes the response by a process that includes 
Epac-mediated activation and translocation of protein kinase $\mathrm{C} \varepsilon$ [Hucho et al., 2005]. In Cos cells expressing the 5-HT receptor, the concerted action of Epac, Rap1 and the small GTPase Rac releases the soluble ectodomain of the amyloid precursor protein sAPP $\alpha$ upon stimulation with 5-HT [Maillet et al., 2003; Robert et al., 2005].

However, at present information about the Epac-mediated mechanisms facilitating neurotransmitter release is sparse. Knock-out animals with a defect in Epac function or specific antagonists are still missing. Specificity of cAMPinduced Epac actions are presently tested mainly by Epac-Selective $\underline{\text { Cyclic }}$ AMP Analogs (ESCAs) [reviewed by Holz et al., 2008]. ESCAs incorporate a 2'-O-methyl substitution on the ribose ring of cAMP. This modification impairs their ability to activate PKA, while leaving their ability to activate Epac unaffected, when used at submillimolar concentrations [Enserink et al., 2002; Christensen et al., 2003]. At present, different structurally related ESCAs are available. They combine properties such as membrane permeability, Epac/PKA selectivity, and high-affinity binding to Epac. Extracellular application of cell-permeant ESCAs produces major alterations in intracellular processes. The molecular properties of various structurally related ESCAs allow for an Epac-related validation of the observed effects in context of cell-permeability or hydrolysis-resistance towards PDEs. In general, the cellpermeability of an ESCA is expected to correlate with its lipophilicity. Likewise, the use of Epac siRNA [Kooistra et al., 2005], Epac antisense deoxyoligonucleotides [Kashima et al., 2001], or the transfection of cells with dominant-negative Epac proteins that fail to bind cAMP [Kang et al., 2006] may further exclude a confounding role of PKA. 



\section{Experimental Methods and Materials}

\section{CELL CULTURE}

\section{Instruments/Supply}

Cytoperm Heraeus, Incubator, Thermo Fisher Scientific, Germany

Cell Culture Flask $75 \mathrm{~cm}^{2}$, sterile, BD Biosciences/Falcon ${ }^{\mathrm{TM}}$, Germany

Disposable Filter Unit, FP 30/0.2 CA-S, Red rim, $0.2 \mu \mathrm{m}$ cellulose acetate, sterile, Whatman/Schleicher\&Schuell, Germany

Falcon Tubes (50 mL, $15 \mathrm{~mL}$ ), BD Biosciences/Falcon ${ }^{\mathrm{TM}}$, Germany

Fine Bore Polyethene Tubing, Portex Limited, England

HERAsafe, safety cabinets, Heraeus Instruments, Thermo Fisher Scientific, Germany

KL 1500 electronic, Cold Light Source, Schott, Germany

Labofuge $^{G L}$, centrifuge, Kendo/Sorvall Heraeus

Microscope Zeiss Axiovert25, Zeiss, Germany

Microscope Zeiss ID03, Zeiss, Germany

Microscope Cover Glasses, 30 mm ø No1, Glaswarenfabrik Karl Hecht KG, Germany

Petri Dish, 35 mm ø, TC dish 35x10, Nunc, Germany

Plastic Stamp, $30 \mathrm{~mm} \varnothing, 500 \times 500 \mu \mathrm{m}$ squares, selfmade - MPI BPC, Göttingen, Germany

Precision Wipes, Kimtech, Kimberly-Clark Professional

SFCA (Surfactant free cellulose acetate) disposable filter units, Nalgene, Thermo Fisher Scientific, Germany

Surgical Instruments, World precision instruments, United States

Waterbath, GFL 1083, Gesellschaft für Labortechnik, Germany

6-well Cell Culture Plates, sterile, BD Biosciences/Falcon ${ }^{\mathrm{TM}}$, Germany

\section{Materials}

Agarose Typ II-A Medium EEO, Sigma

B-27 Serum free Supplement, Invitrogen

BSA, bovine serum albumin, Sigma

Cystein, Sigma

DMEM, Dulbecco's modified Eagle medium, Invitrogen/Gibco

5-Fluoro-2'-deoxyuridin, Sigma 
FBS, Fetal Bovine Serum, Invitrogen/Gibco, heat-inactivated for 30 min at $56^{\circ} \mathrm{C}$

Glutamax-I Supplement, Invitrogen/Gibco

HBSS, Hanks Balanced Salt Solution, Invitrogen/Gibco BRL

Rat Tail Collagen Type 1, BD Biosciences

$\mathrm{MITO}^{+}$Serum Extender, BD Biosciences

NBA, Neurobasal-A Medium, Invitrogen/Gibco

Papain, WorthingtonBiomedical Corporation

Penicillin/Streptomycin, Penicillin 50.000U/mL, Streptomycin $50 \mathrm{mg} / \mathrm{mL}$, Roche Diagnostics

Poly-D-Lysin, Sigma, 5mg/10mL H2O bidest

Trypsin/EDTA (0.05\%/0.02\%), Biochrom

Trypsin Inhibitor (Type II-O: Chicken Egg White), Sigma

Uridine, 1- $\beta$-D-Ribofuranosyluracil, Sigma

\section{Media}

\section{Coverslip coating solution}

Acetic acid $(17 \mathrm{mM})$

Poly-D-Lysine $(0.5 \mathrm{mg} / \mathrm{mL})$

Collagen $(1 \mathrm{mg} / \mathrm{mL})$

mixing ratio $3: 1: 1$

\section{Enzyme solution}

$2 \mathrm{mg}$ Cystein

$10 \mathrm{~mL}$ DMEM

$0.1 \mathrm{~mL} \mathrm{CaCl} 2(100 \mathrm{mM})$

$0.1 \mathrm{~mL}$ EDTA ( $50 \mathrm{mM}$ )

20-25 units Papain / mL Enzyme

solution; bubble with carbogen gas for

10-20 minutes

\section{Astrocyte Growth Medium}

$450 \mathrm{~mL}$ DMEM

$50 \mathrm{~mL}$ FBS

$1 \mathrm{~mL} \mathrm{MITO}^{+}$Serum Extender

$1 \mathrm{~mL}$ Penicillin/Streptomycin

(10000 IU Penicillin \& $10 \mathrm{mg}$

Streptomycin)

\section{FUDR solution}

25 mg 5-fluoro-2'-deoxyuridine (8.1 mM)

$62.5 \mathrm{mg}$ uridine (20.4 mM)

$12.5 \mathrm{~mL}$ DMEM

\section{Inactivating solution}

25mg Albumin

25mg Trypsin-Inhibitor

$10 \mathrm{~mL}$ FBS-Medium (10\%)

\section{Neuronal Growth Medium}

$500 \mathrm{~mL}$ Neurobasal-A Medium

$10 \mathrm{~mL}$ B27-Supplement

$5 \mathrm{~mL}$ Glutamax I

$1 \mathrm{~mL}$ Penicillin/Streptomycin

(10000 IU Penicillin \& 10 mg

Streptomycin) 


\section{Preparation of coverslips}

Glass coverslips were cleaned for several hours with $1 \mathrm{~N} \mathrm{HCl}$ and stored in ethanol. Prior to the seeding of astrocytes, coverslips were coated with 0.15 $\%$ agarose and sterilized by UV-light for $20 \mathrm{~min}$. Islands of substrate (a 3:1:1 mixture of acetic acid $(0.1 \%)$, rat tail collagen, and poly-D-lysine) were placed on top of the agarose using a stamp containing regularly spaced squares (500 $x 500 \mu \mathrm{m})$. The pretreated coverslips were sterilized a second time by UVlight for $20 \mathrm{~min}$.

\section{Astrocyte cultures}

Newborn NMRI mice were decapitated according to the rules of the state and animal welfare committee. Brains were removed in physiological salt solution (HBSS with $1.26 \mathrm{mM} \mathrm{CaCl}_{2}$ and $0.49 \mathrm{mM} \mathrm{MgCl}_{2}$ ) and cleaned of meninges and vascular tissue. Astrocytes were isolated from murine brain by enzymatic treatment with Trypsin/EDTA $(0.05 \% / 0.02 \%)$ and by mechanical dissociation. Astrocytes were grown in $75 \mathrm{~cm}^{2}$ cell culture flasks at $5 \% \mathrm{CO}_{2}$ and $95 \%$ humidity in DMEM containing $10 \% \mathrm{FBS}, 0.1 \% \mathrm{MITO}^{+}$serum extender, and $0.2 \%$ penicillin /streptomycin until cultures reached $70 \%$ confluency. Afterwards, astrocytes were seeded onto previously cleaned glass coverslips, and were grown until astrocyte microisland formed. Once astrocytes reached confluency, 5-fluoro-2'deoxyuridine $(10 \mu \mathrm{M})$ was added to inhibit further proliferation.

\section{Neuronal cultures}

\section{... for single cell recordings}

For electrophysiological experiments individual hippocampal neurons forming recurrent excitatory synapses (autapses) were grown in microisland cultures according to a modified protocol by Bekkers \& Stevens (1991) and Furshpan et al. (1976). Murine hippocampi were removed in physiological salt solution (HBSS with $1.26 \mathrm{mM} \mathrm{CaCl}_{2}$ and $0.49 \mathrm{mM} \mathrm{MgCl}_{2}$ ). (If not stated otherwise, the NMRI mouse strain was used.) Neurons were isolated from the Dentate Gyrus 
and the CA1 region of the hippocampal formation of $\mathrm{P} 0$ animals by enzymatic digestion (20-25 units Papain (Worthington) in DMEM supplemented with 20 $\%$ Cystein, $1 \mathrm{mM} \mathrm{CaCl} 2$, and $0.5 \mathrm{mM}$ EDTA) at $37{ }^{\circ} \mathrm{C}$ for 45 minutes and mechanical treatment. Neurons were seeded at low density on top of the astrocyte microislands and allowed to mature in Neurobasal A medium supplemented with $2 \%$ B27, $1 \%$ glutamax-I, $0.2 \%$ penicillin/streptomycin for at least 8 days prior to electrophysiological recordings. Only islands containing single neurons were examined.

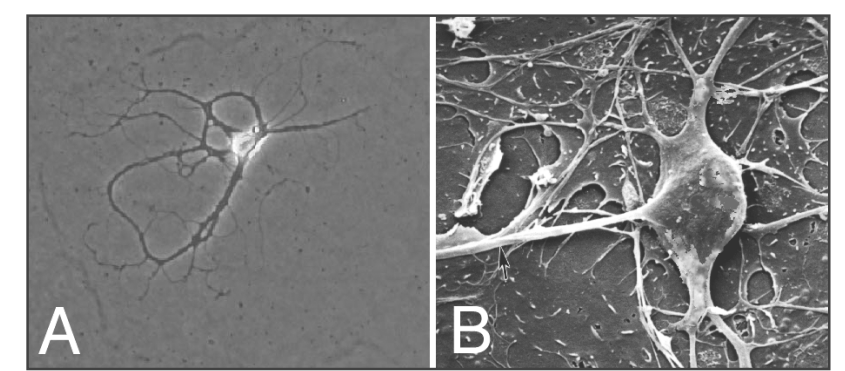

Fig. 6 Cultured Autaptic neurons.

A. Neuron on top of a faint astrocyte feeder layer as viewed by light microscopy (magnified 20x, Olympus IX70 microscope). B. Pyramidal neuron growing in culture on top of a feeding glial cell layer viewed by scanning electron microscopy (Fulton, James T., Processes in Animal Vision \{online\}\{Corona del Mar, CA. USA\} Vision Concepts, \{published 2000-08-01\}, \{revised 2000-08-01\}, \{cited 2000-08-01\}. <http://www.4colorvision.com>).

\section{... for protein isolation}

For immmunoblot analysis neuronal cultures were prepared from the Dentate Gyrus and the CA1 region of the hippocampal formation of newborn (P0/P1) animals and grown in collagen/poly-D-lysin-coated petri dishes $(10 \mathrm{~cm} \varnothing)$ in the absence of an astrocyte feeder layer.

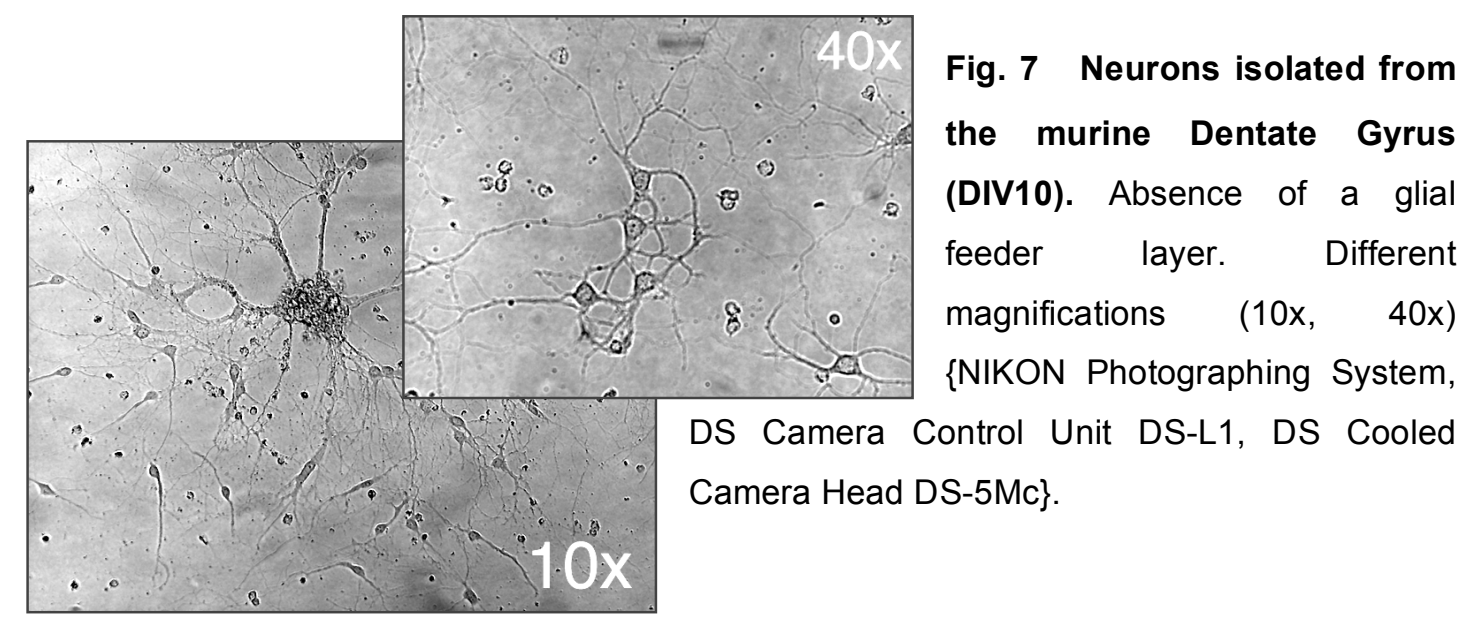




\section{ELECTROPHYSIOLOGY}

\section{Materials}

$\mathrm{Ag} / \mathrm{AgCl}$ patch electrode - selfmade (silver wire, Advent, U.K.)

Bath Electrode/Reference Electrode, E-205, 1.0mm dia. x 2.5mm pellet, Science Products $\mathrm{GmbH}$, Germany

Dial-A-Flo extension set, flow regulation of the perfusion with external solution, Hospira, Ireland

EPC-9 patch clamp amplifier, HEKA, Germany

Flaming/Brown Micropipette Puller, Model P-87, Sutter Instrument Company

Glas Pipettes, GB150F-8P, 0.86 × $1.50 \times 80$ mm, Science Products GmbH, Germany

Gravity-fed Reservoirs, $30 \mathrm{~mL}$ syringes, Terumo Europe N.V., Belgium

Heating Filaments for Sutter Puller, FB255B, 2,5mm square box filament, 2,5mm wide Science Products $\mathrm{GmbH}$, Germany

Multi-Pressure Control Unit (MPCU) Bath Handler, selfmade - MPI BPC Göttingen, Germany

Olympus IX70 microscope, Germany

Pulse 8.66 data acquisition sofware, HEKA Germany

Quartz Flow Pipes, Polymicro Technologies, Phoenix, AZ; 406-401 $\mu$ m i.d.

SF-77B Perfusion-Fast Step, Warner Instr. Corp., England

3-way diaphragm solenoid miniature PTFE-valves, 24V, Parker Hannifin Corporate / Pneutronics, United States

\section{Solutions/Drugs}

Bisindolylmaleimide I (BIS-I), Calbiochem/Merck, Germany

8-Bromoadenosine-3',5'-cyclic monophosphorothioate, Rp-isomer, Rp-8-Br-cAMPS, Biolog, Germany

Dimethylsulfoxide (DMSO), Sigma, Germany

Forskolin, Sigma, Germany

KT5720, Calbiochem/Merck, Germany

MDL 12,330A, Calbiochem/Merck, Germany

$\mathrm{N}^{6}$-Benzoyladenosine-3',5'-cyclic-monophosphate, 6-Bnz-cAMP, Biolog, Germany

8-pCPT-2'-O-Me-cAMP, ESCA ${ }_{1}$, Biolog, Germany

Phorbol-12,13-dibutyrate (PDBu), Calbiochem, Germany

8'-pMeOPT-2'-O-Me-cAMP, ESCA 3 , Biolog, Germany 
Sp-8'-pCPT-2'-O-Me-cAMPS, ESCA 2 , Biolog, Germany

Sucrose, Sigma, Germany

Tetrodotoxin (TTX), Sigma, Germany

\section{$\underline{\text { Standard internal } \mathrm{KCl} \text { solution }}$}

$136 \mathrm{mM} \mathrm{KCl}$

17.8 $\mathrm{mM}$ HEPES

12 mM Phosphocreatine $\mathrm{Na}_{2}$

4 mM ATP-Mg

$1 \mathrm{mM} \mathrm{K}-\mathrm{EGTA}$

$0.3 \mathrm{mM}$ GTP-Na $\mathrm{Na}_{2}$

$0.6 \mathrm{mM} \mathrm{MgCl} 2$

$\mathrm{pH} 7.4$

\section{Extracellular solution}

$10 \mathrm{mM}$ HEPES

$10 \mathrm{mM}$ Glucose

$120 \mathrm{mM} \mathrm{NaCl}$

$2.4 \mathrm{mM} \mathrm{KCl}$

$2 \mathrm{mM} \mathrm{CaCl}_{2}$

$1 \mathrm{mM} \mathrm{MgCl}_{2}$

pH 7.5-7.6, 298-305 mOsm

all chemicals from Sigma, Germany

\section{Drug application}

Drug application was performed by a fast perfusion system with a solution exchange time ranging from 190-300 ms depending on the viscosity of the solution applied as previously described (Rosenmund et al., 1995; application of aqueous glutamate solution to HEK293 cells expressing wilde-type glutamate receptors resulted in an exchange time of $190 \mathrm{~ms}$ ). For whole-cell experiments, control solution and pharmacological agents were applied using an array of six quartz flow pipes (Polymicro Technologies, Phoenix, AZ; 406$401 \mu \mathrm{m}$ i.d.) positioned in front of the neuron at the bottom edge of the microscopical field of view 100-200 $\mu \mathrm{M}$ apart (20x magnification, Olympus IX70 microscope), and connected to gravity-fed reservoirs. Each flow pipe was controlled by a solenoid valve and was moved with a SF-77B PerfusionFast Step (Warner Instr. Corp.) device. The opening of the solenoid valves and the movement of the flow pipes were triggered by the EPC- 9 patch clamp amplifier according to the protocol designed with the Pulse 8.66 data acquisition sofware. Neurons were constantly perfused the applied solution. The flow rate from the flow pipes was $0.52 \pm 0.03 \mathrm{~mL} / \mathrm{min}$ (mean \pm S.D.), corresponding to a rate of $0.07 \mathrm{~m} / \mathrm{s}$. In addition to the local perfusion with flow pipes, the whole bath (volume, $2 \mathrm{~mL}$ ) was perfused at $0.8 \mathrm{~mL} / \mathrm{min}$ to prevent accumulation of drugs. Adequate positioning and solution exchange was 
examined at the beginning and end of each experiment. After every neuronal recording the bath chamber was cleaned with $70 \%$ ethanol and demineralized water to avoid drug-related cross-contamination. The drugs used and their concentrations were: baclofen $(100 \mu \mathrm{M}), 6$-Bnz-cAMP $(150 \mu \mathrm{M})$, 8-pCPT-2'O-Me-cAMP (50 $\mu \mathrm{M}$; ESCA 1 ), forskolin $(50 \mu \mathrm{M})$, phorbol-12,13-dibutyrate (1 $\mu \mathrm{M})$, tetrodotoxin (300 $\mathrm{nM})$. Most compounds were diluted into the external solution from concentrated dimethylsulfoxide (DMSO)-stock solutions. The final concentrations of DMSO were $<0.1 \%$.

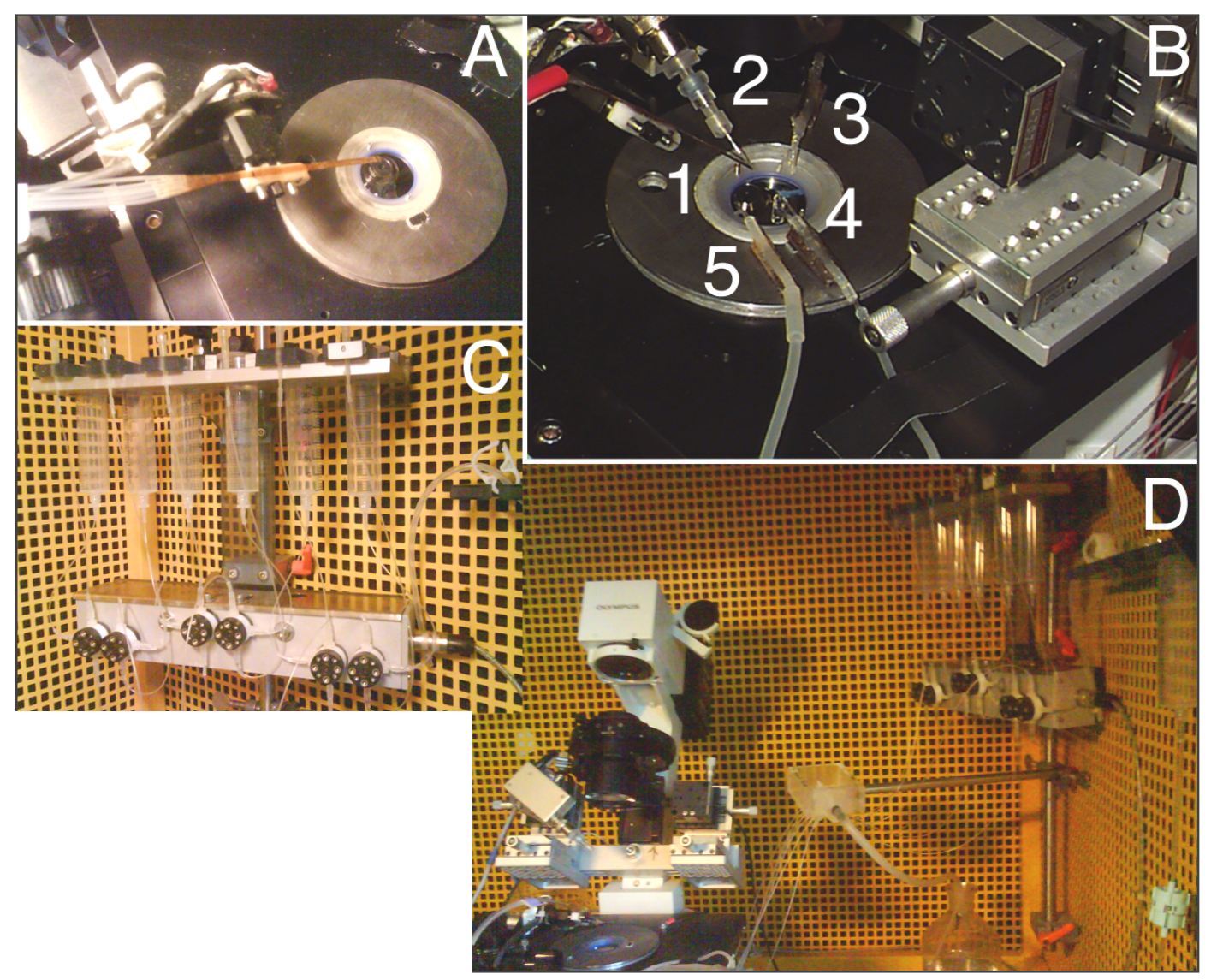

Fig. 8 Drug Application System. A. Flow-pipe consisting of six quartz tubes (Polymicro Technologies Phoenix, AZ, United States, TSP400530, standard polyimide

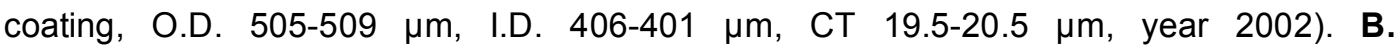
Configuration of the patch-clamp components in the bath-chamber. (1) flow-pipe, (2) patch-clamp electrode, (3) reference(bath-)-electrode \& suction system for removal of excess bath-fluid, (4) pressure sensor to control for the bath-fluid level, (5) perfusion of the bath-chamber with additional control solution. C. Gravity-fed reservoirs, one for every tube of the flow-pipe (incl. 3-way diaphragm solenoid miniature PTFE-valves, 24V, Parker Hannifin Corporate / Pneutronics, United States). D. Complete perfusion system. 


\section{Whole-cell electrophysiological recordings}

Evoked excitatory postsynaptic currents (EPSCs) were recorded from isolated cultured autaptic neurons between DIV8 to DIV15 at a holding potential of -70 $m \mathrm{~V}$ with an EPC-9 patch clamp amplifier (HEKA, Germany).

An $\mathrm{Ag} / \mathrm{AgCl}$ electrode connected the preamplifier (headstage containing the preamplifier mounted on a micromanipulator) with the intracellular solution in the patch pipette, and via a bath electrode with the extracellular solution. The pipette holder was airtight connected to an air pressure sensor, and a mouthpiece for oral pressure adjustment. Patchpipettes were pulled in five steps from borosilicate capillaries (GB150F-8P, $0.86 \times 1.50 \times 80 \mathrm{~mm}$, Science Products $\mathrm{GmbH}$ ) on a horizontal pipette puller (Flaming/Brown micropipette puller, Model P-87, Sutter Instrument Company). The heat-polished pipette tips had a pipette resistance ranging from 2.5 to 3.5 $\mathrm{M} \Omega$. In general, recordings were performed only as long as the leak current was smaller than $300 \mathrm{pA}$, typically ranging between $10 \mathrm{pA}$ and 180 pA. The internal software controlled compensation circuits of the EPC-9 amplifier were used to compensate for charging transients of the pipette wall, and of the cell membrane. Compensation for the pipette capacitance was performed in the cell-attached configuration. In the whole-cell mode cell membrane capacitance and membrane resistance were corrected. Membrane voltage errors due to high access resistances to the cell, were compensated by using the automatic EPC-9 Rs-compensation (time constant of $100 \mu \mathrm{s}$ ). The fraction of series-resistance compensation was set to $70 \%$.

Neurons were depolarized from $-70 \mathrm{mV}$ to $0 \mathrm{mV}$ for $2 \mathrm{~ms}$ every $5 \mathrm{~s}(0.2$ $\mathrm{Hz}$ ). The recorded EPSC trace length was $1 \mathrm{~s}$. Current traces were digitized at $20 \mathrm{kHz}$ and low-pass filtered at $3 \mathrm{kHz}$. The extracellular solution $(10 \mathrm{mM}$ HEPES, $10 \mathrm{mM}$ Glucose, $120 \mathrm{mM} \mathrm{NaCl}, 2.4 \mathrm{mM} \mathrm{KCl}$; pH 7.5-7.6, 298-305 mOsm) contained $2 \mathrm{mM} \mathrm{CaCl} 2$ and $1 \mathrm{mM} \mathrm{MgCl}_{2}$. The fire-polished patch electrodes (GB150F-8P, Science Products $\mathrm{GmbH}$, Germany) were filled with $\mathrm{KCl}$-based internal solution (136 mM KCl, $17.8 \mathrm{mM}$ HEPES, $12 \mathrm{mM}$ Phosphocreatine $\mathrm{Na}_{2}$, $4 \mathrm{mM}$ ATP-Mg, $1 \mathrm{mM} \mathrm{K-EGTA}$, $0.3 \mathrm{mM}$ GTP-Na 2 , 0.6 $\mathrm{mM} \mathrm{MgCl} ; \mathrm{pH}$ 7.4). The uncompensated series resistance did not exceed 4 $\mathrm{M} \Omega$ during whole-cell recording of autaptic neurons. 


\section{Data analysis}

Offline analysis was performed with AxoGraph 4.5 (Axon Instruments, U.S.A.), Excel (Microsoft, U.S.A.), KaleidaGraph 3.0 (Synergy Sofware, U.S.A.) and IgorPro (Wavemetrics, U.S.A.) software. Prior to analysis with AxoGraph EPSCs were offset corrected. The initial EPSC (EPSC ${ }_{0}$ ) was used as a reference when comparing the effects under control- and drug-condition. The $\mathrm{EPSC}_{0}$ describes the steady state EPSC amplitudes measured prior to drug application (usually the mean EPSC amplitude recorded from a given neuron over the first 2 minutes). The drug-effect was described by the potentiation factor. The potentiation factor was calculated according to the following equation:

$$
E P S C \text { Potentiation }=\frac{E P S C(d r u g)_{\text {steady state }}}{E P S C_{0 \text { steady state }}}
$$

mEPSCs (miniature EPSCs) were detected using a sliding template algorithm (Clements and Bekkers, 1997). The mEPSC template (linear summation of two exponentials) length of $15 \mathrm{~ms}$ allowed detection of non-overlapping mEPSCs. The template was automatically offset to account for fluctuations in the baseline, and the amplitude was scaled to fit the analysis window. Events were only accepted as mEPSCs when the calculated detection criterion exceeded the standard deviation of the background noise at least 3.5 -fold. To avoid false positive events, we considered only those mEPSCs which fitted to all of the following imposed criteria: amplitude interval $[-100 ;-8] \mathrm{pA}$, rise time $[0.24 ; 0.71] \mathrm{ms}$, and width $[0.67 ; 4] \mathrm{ms}$. Events, which fulfilled these criteria were then averaged to calculate mean mEPSC amplitude and charge for each neuron individually. The total number of releasable vesicles (RRP) was determined by a $4.5 \mathrm{~s}$ application of external saline solution made hypertonic by the addition of $500 \mathrm{mM}$ sucrose. For every cell analysed the total number of releasable vesicles was defined as the charge during the transient burst of exocytotic activity that followed application of the hypertonic solution divided by the mean charge of the corresponding mEPSC [Rosenmund and Stevens, 1996]. A pedestal defined by the late-sucrose response was subtracted from the total charge. 
Generally, the measured data are reported as mean \pm SEM, if they were averaged over the maximal initial EPSC amplitude $\left(E{ }^{2} C_{0}\right)$ range from $0<\mathrm{EPSC}_{0}<16 \mathrm{nA}$. If defined $\mathrm{EPSC}_{0}$ classes were considered, the variability in the measured effects was of interest, and the data are presented as mean \pm S.D.. For normally distributed data statistical analysis was performed using either the paired or unpaired two-tailed Student's t-test with ${ }^{*} p<0.05,{ }^{* *} p<$ 0.01 , and ${ }^{* * *} p<0.001$. For unpaired comparisons unequal variances were assumed. Samples showing no normal distribution were statistically analysed by the non-parametric Kolmogorov-Smirnov (KS) test.

The total number of cells and the number of cultures are given by $\mathrm{N}$ or $\mathrm{n}$, respectively. We adopted the acronym ESCA (Epac-selective cyclic AMP analog) from Holz et al. (2008) for the 2'-O-methyl substituted adenosine-3',5'cyclic monophosphate analogs that activate the Epac protein family. $E_{S C A}$ specifically denotes 8-pCPT-2'-O-Me-cAMP.

\section{BIOCHEMISTRY}

\section{Materials}

40\% Acrylamide/Bis Solution 29:1 (3.3\%C), Bio-Rad Laboratories, United States Ammonium persulfate, APS, for electrophoresis $\geq 98 \%$, Sigma, Germany

Aprotinin, Sigma, Germany

Bradford reagent, Bio-Rad Laboratories, United States

BSA standard (1 mg/mL), Sigma, Germany

Disposable Cell Lifter, Fisher Scientific, United States

Ethylenediaminetetraacetic acid, EDTA, Fluka, Germany

Leupeptin, Sigma, Germany

Lumilmager, Boehringer Ingelheim, Germany

LumiAnalyst software, Boehringer Ingelheim, Germany

Mini-Protean II System, Bio-Rad Laboratories, United States

N,N,N',N'-Tetramethylethylene-diamine, for electrophoresis, approx. 99\%, TEMED, Sigma, Germany

Nonidet $₫$ P 40 Substitute (NP-40), Sigma, Germany

Phenylmethylsulfonyl fluoride, PMSF, Sigma, Germany 
Polyvinylidene Fluoride Membrane, Roche, Germany

Prestained SDS-PAGE Standards, Broad Range, Bio-Rad Laboratories, United States

Semimicro Disposable Cuvettes, Ratiolab GmbH, Germany

Sodium dodecyl sulfate, SDS, Fluka, Germany

Sodium fluoride, NaF, Sigma, Germany

Sodium orthovanadate, $\mathrm{Na}_{3} \mathrm{VO}_{4}$, Sigma, Germany

Spectronic Genesys ${ }^{\mathrm{TM}} 5$, Spectronic Instruments, U. K.

SuperSignal West Femto, Pierce, Germany

Trizma-Base, Sigma, Germany

Tween 20, Roth, Germany

\section{Solutions}

Tris-buffered saline, TBS:

$30 \mathrm{mM}$ Trizma-Base

$140 \mathrm{mM} \mathrm{NaCl}$

$2.7 \mathrm{mM} \mathrm{KCl}$

$\mathrm{pH} 7.4-7.6$

\section{Lysis buffer $P$ :}

$50 \mathrm{mM}$ Tris- $\mathrm{HCl}, \mathrm{pH} 8$

$120 \mathrm{mM} \mathrm{NaCl}$

5 mM EDTA

$0.5 \%$ NP-40

$\mathrm{w} / \mathrm{ddH} 2 \mathrm{O}$, store at $4^{\circ} \mathrm{C}$

prior to use add the following proteinase and phosphatase inhibitors to $1 \mathrm{~mL}$ lysis buffer $P$ :

$\begin{array}{lcll}\text { inhibitor } & \text { working concentrations } & \boldsymbol{\mu L} & \text { stock solution } \\ \text { Aprotinin } & 20 \mu \mathrm{g} / \mathrm{mL} & 2 & 10 \mathrm{mg} / \mathrm{mL} \text { in } 0.01 \mathrm{M} \mathrm{Hepes,} \mathrm{pH} 8 \\ \text { Leupeptin } & 10 \mu \mathrm{g} / \mathrm{mL} & 2 & 5 \mathrm{mg} / \mathrm{mL} \text { in H2O } \\ \mathrm{PMSF} & 100 \mu \mathrm{g} / \mathrm{mL} & 5.7 & 100 \mathrm{mM} \text { in Isopropanol } \\ \mathrm{NaF} & 50 \mathrm{mM} & 50 & 1 \mathrm{M} \mathrm{in} \mathrm{H} 2 \mathrm{O} \\ \mathrm{Na}_{3} \mathrm{VO}_{4} & 200 \mu \mathrm{M} & 10 & 20 \mathrm{mM} \text { in H2O }\end{array}$

\section{Antibodies}

Primary antibodies:

Phospho-Synapsin (Ser9), Cell Signaling, United States; rabbit polyclonal $\beta$-Actin (I-19), Santa Cruz, United States; goat polyclonal 
Epac1, GeneTex, United States; rabbit polyclonal

Epac2 (M-18), Santa Cruz, United States; goat polyclonal

Synapsin I, BD Transduction Laboratories ${ }^{\mathrm{TM}}$, mouse monoclonal

\section{Secondary antibodies:}

goat anti-rabbit IgG-HRP, Santa Cruz, United States

donkey anti-goat IgG-HRP, Santa Cruz, United States

donkey or goat anti-mouse IgG-HRP, Santa Cruz, United States

\section{Preparation of cytosolic neuronal protein lysates}

Prior to protein lysate preparation the cultures were left untreated (mock pretreatment with external solution used for electrophysiological recordings containing $2 \mathrm{mM} \mathrm{Ca}^{2+} / 1 \mathrm{mM} \mathrm{Mg}^{2+}$ ) for control lysates or were pretreated for 2 minutes with either $\mathrm{ESCA}_{1}$ (8-pCPT-2'-O-Me-cAMP), forskolin, or 6-Bnz-cAMP. The duration of the drug treatment and the drug concentrations were chosen as indicated for the electrophysiological experiments. Protein lysates were generated on day in vitro 10 to 11 (DIV10/11) under maintenance of a working temperature of $4{ }^{\circ} \mathrm{C}$. The neuronal cultures were washed three times with ice-cold Tris-buffered saline (TBS) (30 mM TrizmaBase, $140 \mathrm{mM} \mathrm{NaCl}, 2.7 \mathrm{mM} \mathrm{KCl}$ ) of $\mathrm{pH}$ 7.4-7.6 to stop the pretreatment of the cells and remove the drugs applied. The cells were mechanically detached in TBS containing $100 \mathrm{mM}$ phenylmethylsulfonyl fluoride (PMSF) and subjected to centrifugation for 10 minutes at $600-800 \mathrm{xg}$ and $4^{\circ} \mathrm{C}$. The cell precipitate was lysed for 15 minutes on ice with a Tris-HCl-based buffer (50 $\mathrm{mM}, \mathrm{pH}$ 8) containing $\mathrm{NaCl}(120 \mathrm{mM})$, EDTA (5 mM), Nonidet $₫ \mathrm{P} 40$ Substitute (NP-40) $(0.5 \%, v / v)$, and to which protease- and phosphataseinhibitors like Aprotinin $(20 \mu \mathrm{g} / \mathrm{mL})$, Leupetin $(10 \mu \mathrm{g} / \mathrm{mL})$, PMSF $(100 \mu \mathrm{g} / \mathrm{mL})$, $\mathrm{NaF}(50 \mathrm{mM})$, and $\mathrm{Na}_{3} \mathrm{VO}_{4}(200 \mu \mathrm{M})$ were added. Cytosolic protein extracts were obtained by centrifugation at $13000 \mathrm{xg}\left(4^{\circ} \mathrm{C}, 15\right.$ minutes $)$.

\section{Determination of protein concentration - Bradford assay}

Protein content was determined by a standard Bradford assay. This assay is based on the color change of Coomassie Brilliant Blue G-250 dye in response to various protein concentrations. The dye binds primarily basic and aromatic 
amino acid residues. Small protein lysate samples $(2-5 \mu \mathrm{L})$ were incubated for 45 minutes in the presence of diluted Bradford reagent (BioRad, Germany). The total assay volume was $1 \mathrm{~mL}: 100 \mu \mathrm{L}$ sample and water plus $900 \mu \mathrm{L}$ of the 1:5 diluted Bradford reagent. Presence of NP-40 in the lysis buffer does not affect the protein binding of the Coomassie Brilliant Blue G-250 dye. The absorption of the blue protein-dye complex was measured at $595 \mathrm{~nm}$. For every set of experiments the sample protein content was determined using a calibration curve constructed from the absorption values of various BSAprotein standard concentrations (ranging from 0 to $10 \mu \mathrm{g}$ ).

\section{SDS-PAGE}

Proteins were separated according to their electrophoretic mobility (a function of the polypeptide chain length or the molecular weight as well as of higher order protein folding, posttranslational modifications and other factors) by sodium dodecyl sulfate polyacrylamide gel electrophoresis (SDS-PAGE). Prior to sample application to the stacking gel the proteins were denaturated for 5 minutes at $95{ }^{\circ} \mathrm{C}$ in the presence of SDS and $6 \% \beta$-Mercaptoethanol. SDSPAGE was performed using a tris-glycine buffering system (Lämmli, 1970) either on a $7 \%$ resolving gel with each lane containing $8 \mu \mathrm{g}$ of protein (Fig. $9 \mathrm{~A}$ ) or on a $7.5 \%$ resolving gel with each lane containing $3 \mu \mathrm{g}$ of protein (Fig. 9B1).

\section{Western Blot}

For Western blot analysis, proteins were transfered to polyvinylidene fluoride membranes (Roche, Germany). We generally used TBS solution containing either $0.05 \%(\mathrm{v} / \mathrm{v})$ (for blocking and antibody solutions) or $0.1 \%(\mathrm{v} / \mathrm{v})$ ( for wash steps) Tween-20 during the analysis of the Western blots. When monitoring phosphorylation levels of synapsin we blocked or probed the membranes in the presence of $3.5 \%(\mathrm{w} / \mathrm{v})$ bovine serum albumine (Fraction $\mathrm{V}$, Sigma, Germany) instead of non-fat dry milk. The blocking and antibody solutions were applied for one hour, respectively. Washing steps lasted 10 
minutes and were performed in triplicate after membrane blocking or primary or secondary antibody application.

\section{Detection of proteins - ECL}

Antigen-antibody complexes were visualized by species specific horseradishperoxidase-conjugated sencondary antibodies and the enhanced chemoluminescence system (ECL, SuperSignal West Femto, Pierce, Germany). Signal intensities were quantified densitometrically (Lumilmager, LumiAnalyst software, Boehringer Ingelheim, Germany). The antibodies (polyclonal) were applied in the following dilutions: Phospho-Synapsin (Ser9) (Cell Signaling, U.S.A.), 1:1000; $\beta$-Actin (I-19) (Santa Cruz, U.S.A.), 1:500 ; Epac1 (GeneTex, U.S.A.), 1:500 ; Epac2 (M-18) (Santa Cruz, U.S.A.), 1:500. Secondary HRP-conjugated antibodies were used at a dilution of 1:1000. 


\section{RESULTS}

\section{Cultured autaptic neurons express both Epac $(1,2)$ isoforms}

Electrophysiological experiments performed at the calyx of Held have shown that the rate of vesicle recruitment is modulated by the intracellular level of cAMP and that this modulation involves Epac activity [Sakaba and Neher, 2003; Kaneko and Takahashi, 2004]. In the murine and rat brain both Epac isoforms were detected at the mRNA expression level [Kawasaki et al., 1998; Ozaki et al., 2000]. In this study, protein expression of Epac1 and Epac2 was determined from murine and rat neurons of the Dentate Gyrus (DG) and the CA1 region of the hippocampal formation (CA1; see Experimental Methods and Materials). Western blot analysis of the corresponding neuronal protein lysates demonstrated that cultured murine and rat hippocampal neurons express both Epac isoforms (Epac1,2; Fig. 9A).

\section{$E S C A_{1}$ is a specific activator of Epac in autaptic neurons}

Christensen et al. (2003) showed that ESCA ${ }_{1}$ is a specific activator of the novel cAMP-binding protein in vitro. Under in vitro conditions Epac activation is maximal after application of $50 \mu \mathrm{M} \mathrm{ESCA}{ }_{1}$, while PKA activity is barely ( 5$7 \%$ ) affected at this concentration of the cAMP-analog [Christensen et al., 2003]. Epac-specificity of $\mathrm{ESCA}_{1}$ was confirmed by quantifying the amount of phosphorylation at the PKA phosphorylation site (Ser9) of synapsin I [Johnson et al., 1972; Menegon et al., 2006]. Fig. 9B1 shows the amount of synapsin I phosphorylation at Ser9 after treatment of neuronal DG-cultures with either ESCA $_{1}[50 \mu \mathrm{M}$ ], forskolin [50 $\mu \mathrm{M}$ ], or 6-Bnz-cAMP [100 $\mu \mathrm{M}$ ] (see Experimental Methods and Materials). Forskolin and the PKA activating CAMP-analog, 6Bnz-cAMP, increased synapsin I phosphorylation at Ser9 (Fig. 9B1,2). Forskolin enhanced synapsin I phosphorylation significantly by $120 \pm 20 \%$ (mean \pm SEM, $N=5$ ), 6-Bnz-cAMP only by $29 \%(N=1)$ (Fig. 9B2) under the growth conditions given. Application of $\mathrm{ESCA}_{1}(\mathrm{~N}=3)$ did not increase the phosphorylation level of the synapsin I-PKA site compared to control condition. 


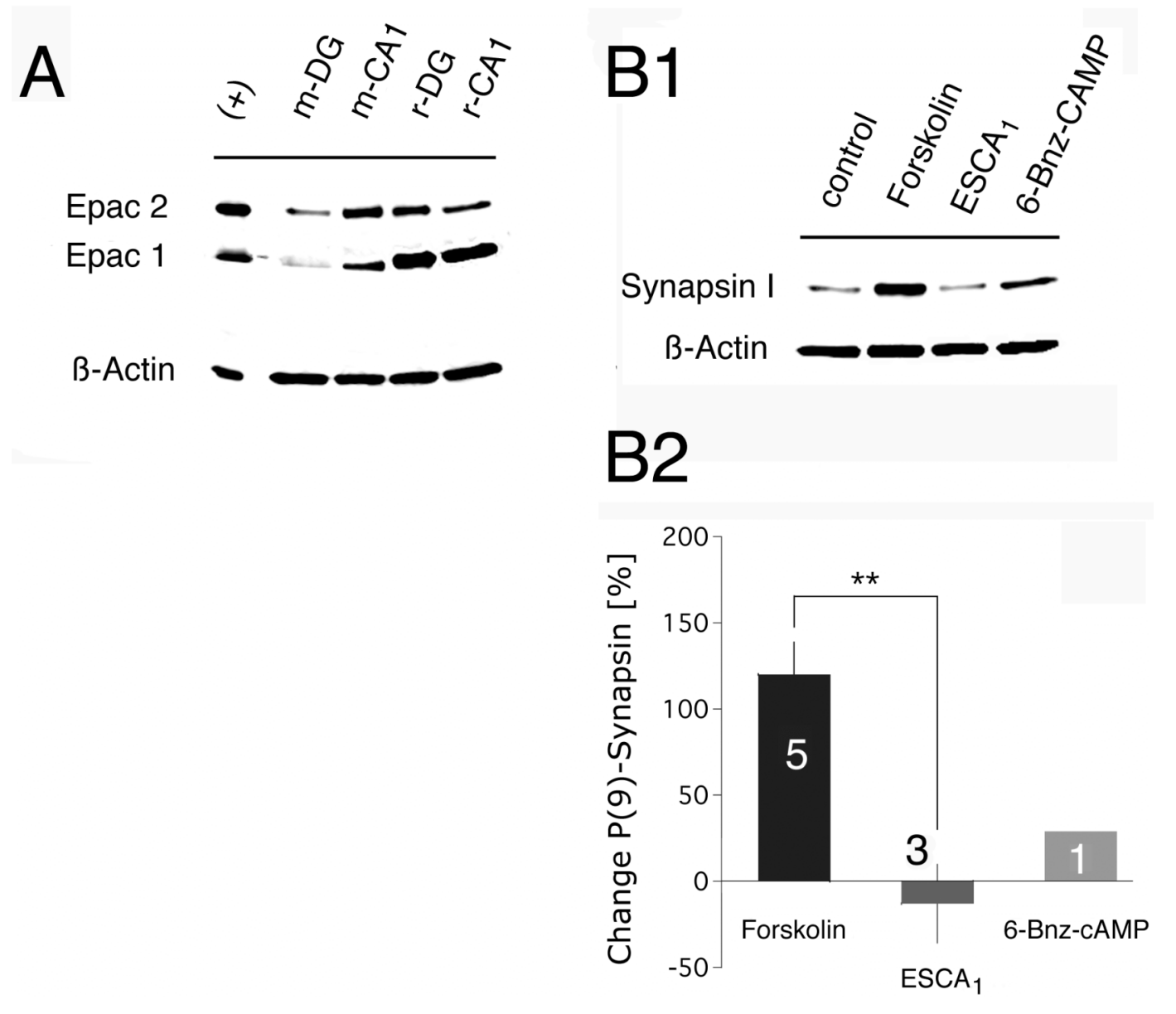

Figure 9

Fig. 9 Epac expression in neuronal cell cultures and its specific activation by the CAMP analog ESCA 1 . A. Western blot showing that cultured autaptic neurons express both Epac isoforms. lanes: rat cerebellum lysate, positive control $(+)$, murine Dentate Gyrus neurons (m-DG), murine CA1 neurons (m-CA1), rat Dentate Gyrus neurons (r-DG), rat CA1 neurons ( $r$-CA1). Protein bands were detected at the following molecular weights: $126 \mathrm{kDa}$ for Epac2, $100 \mathrm{kDa}$ for Epac1, and $43 \mathrm{kDa}$ for $\beta$-Actin. Epac1 experiments were performed in triplicate. B1. Drug-induced synapsin I phosphorylation at its PKA phosphorylation site (Ser9) was detected by western blot analysis. For drug treatment see Methods. $\beta$-Actin controls for equal protein loading. B2. Quantitative change in the phosphorylation level of the PKA site of synapsin I. To correct for nonspecific effects (unrelated to drug treatment), which might have been introduced by variability in protein loading, P-Ser9 synapsin I chemoluminescence intensities were first normalized to the intensities of the corresponding $\beta$-actin values. These values were further normalized to the control intensity value to determine the increase or decrease in P-Ser9 levels upon drug-treatment. Values are shown as mean \pm SEM. Statistical significance was tested by an unpaired two-tailed Student's t-test assuming unequal variances (see Methods). Numbers within histogram bars represent the number of measurements. 


\section{$E S C A_{1}$ enhances neurotransmitter release}

Excitatory cultured autaptic neurons from Dentate Gyrus were chosen to analyse how Epac function regulates neurotransmitter release. Ozaki et al. (2000) presented evidence for pronounced mRNA expression of Epac in the Dentate Gyrus. Epac activation by $\mathrm{ESCA}_{1}$ increased excitatory postsynaptic current (EPSC) amplitudes from DG-neurons during low stimulation frequency $(0.2 \mathrm{~Hz})$. On average, EPSC amplitudes were potentiated by a factor of $1.23 \pm$ 0.03 (mean \pm SEM, $N=60$ ) (Fig. 10A). In a second set of experiments, forskolin was used as a positive control. Forskolin is generally believed to enhance intracellular cAMP levels by activation of adenylyl cyclases [Willoughby and Cooper, 2006; Vincent and Brusciano, 2001]. Forskolin significantly increased EPSC amplitudes on average by a factor of $1.60 \pm 0.06$ (mean \pm SEM, $N=46$ ) (Fig. 10A). Thus, Epac activation can explain on average about $38 \%$ of the forskolin-induced increase in evoked EPSC amplitudes. A contribution of Epac activity to the observed forskolin-response is further supported by the analysis of the decay of the EPSC amplitudes during washout of both the $\mathrm{ESCA}_{1}$ - and the forskolin-response (Fig. 10B1,2). After Epac activation the decay of the EPSC amplitudes during washout was fitted by a monoexponential function with a decay time constant of $13 \pm 1$ seconds (mean \pm S.D.) (Fig. 10B1). In case of forskolin application the decay of the EPSC amplitudes during washout was best decribed by a biexponential function, where the fast decay time constant was $18 \pm 3$ seconds (mean \pm S.D.) followed by a much slower decay with a time constant of $192 \pm 23$ seconds (Fig. 10B2). Therefore, the forskolin-induced changes of EPSC amplitudes can be attributed to complex cAMP-signaling. An increase in intracellular cAMP levels by the general adenylyl cyclase activator forskolin not only results in PKA activation, but leads moreover to Epac activity. Epac function is involved in the fast mode of the forskolin-response.

Both PKA- and Epac-dependent pathways may be constitutively active. In fact, experiments performed by Chevaleyre et al. (2007) suggest that both PKA-dependent and PKA-independent CAMP-mediated signaling pathways are involved in the maintenance of synaptic transmission during low frequency stimulation. 
Autaptic responses are preceeded by action potential (AP)-related sodium $\left(\mathrm{Na}^{+}\right)$and potassium $\left(\mathrm{K}^{+}\right)$currents (Fig. 10C, top left panel). Analysis of these currents revealed that they were differently inhibited by the two pharmacological agents (Fig. 10C). ESCA 1 depressed only the $\mathrm{Na}^{+}$-current significantly, whereas forskolin reduced both, the $\mathrm{Na}^{+}$- and the $\mathrm{K}^{+}$-current. In contrast to the $\mathrm{Na}^{+}$-current, forskolin-mediated inhibition of $\mathrm{K}^{+}$-current was reversible. Neither $\mathrm{Na}^{+}$- nor $\mathrm{K}^{+}$-currents showed a significant rundown during control EPSC amplitude recordings. These observations provide further evidence that ESCA ${ }_{1}$ specifically targets Epac at the concentration used. The inhibition of $\mathrm{K}^{+}$-current can be attributed to PKA activity [Siegelbaum et al., 1982].

Fig. $10 \mathrm{ESCA}_{1}$ enhances neurotransmitter release at excitatory autaptic neurons from Dentate Gyrus. A. Average EPSC amplitude potentiation by $50 \mu \mathrm{M} \mathrm{ESCA}_{1}\left(\mathrm{EPSC}_{0}=5.43 \pm\right.$ $0.51 \mathrm{nA}$, mean $\pm \mathrm{SEM}$ ) and $50 \mu \mathrm{M}$ forskolin $\left(\mathrm{EPSC}_{0}=4.95 \pm 0.48 \mathrm{nA}\right.$, mean $\left.\pm \mathrm{SEM}\right)$. Values are shown as mean \pm SEM. Statistical significance of the individual drug-induced EPSC potentiations was analysed by the paired $t$-test. For comparison between the $\mathrm{ESCA}_{1}$ - and the forskolin-effect the KS-test was used. B1. Average time course of EPSC amplitudes in the presence and absence of $\mathrm{ESCA}_{1}$ (mean $\left.\pm \mathrm{SEM}\right)$. $-\mathrm{ESCA}_{1}$ stimulation, $\mathrm{N}=27, \mathrm{n}=5\left(\mathrm{EPSC}_{0}\right.$ $=7.01 \pm 0.94 \mathrm{nA}$, mean \pm SEM); $\square$ average EPSC amplitude rundown under control condition $\mathrm{N}=17, \mathrm{n}=2\left(\mathrm{EPSC}_{0}=9.2 \pm 1.5 \mathrm{nA}\right.$, mean $\left.\pm \mathrm{SEM}\right)$. The onset and duration of drug application is represented by a bar. B2. Average time course of EPSC amplitudes in the presence and absence of forskolin (mean \pm SEM). Markers were used in analogy to the top panel. $\mathrm{N}=13, \mathrm{n}=1$ (EPSC ${ }_{0}=4.76 \pm 0.81 \mathrm{nA}$, mean $\left.\pm \mathrm{SEM}\right)$. C. Analysis of the changes in the action potential (AP)-related $\mathrm{Na}^{+}$- and $\mathrm{K}^{+}$-current peaks. Prior to every EPSC AP-related sodium and potassium currents were observed. A typical waveform is shown in the top left panel: The first inward current represents $\mathrm{Na}^{+}$influx $\left(\mathrm{Na}^{+}\right)$, the following outward current occurs due to $\mathrm{K}^{+}$efflux $\left(\mathrm{K}^{+}\right)$. Peak current changes were analysed for the control rundown condition (top right panel) and for both drug conditions (middle panel: $\mathrm{ESCA}_{1}$ - bottom panel: forskolin). Both, the changes during the steady state phase of drug application and 3 minutes after drug removal are shown. In the control rundown experiment the time intervals for analysis were chosen to match those used in the drug experiments. The peak current changes are shown as mean \pm SEM. Significance was tested by a paired $t$-test. The numbers within the figure's histogram bars are $\mathrm{N}$-values, representing the number of cells. For the control rundown condition 13 cells were analysed. 
A

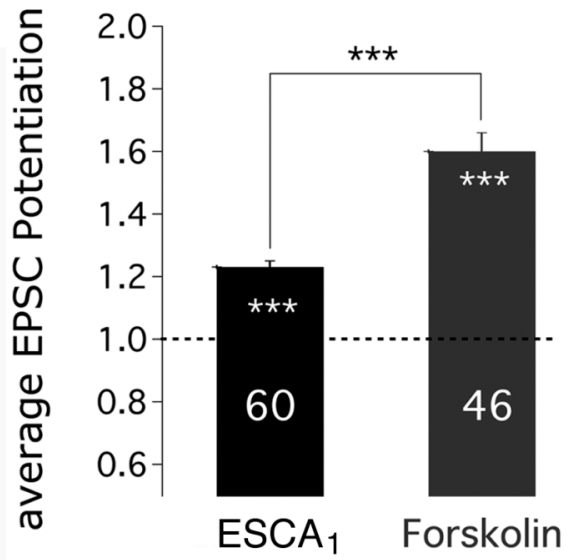

\section{C}

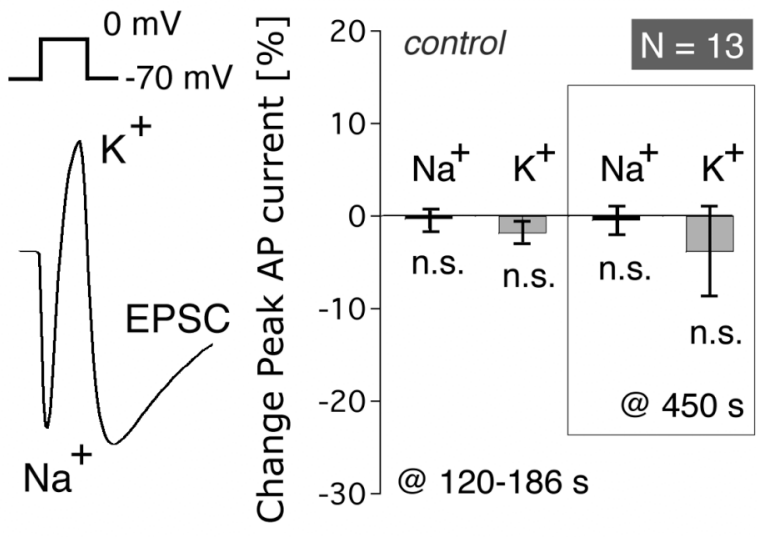

\section{B1}
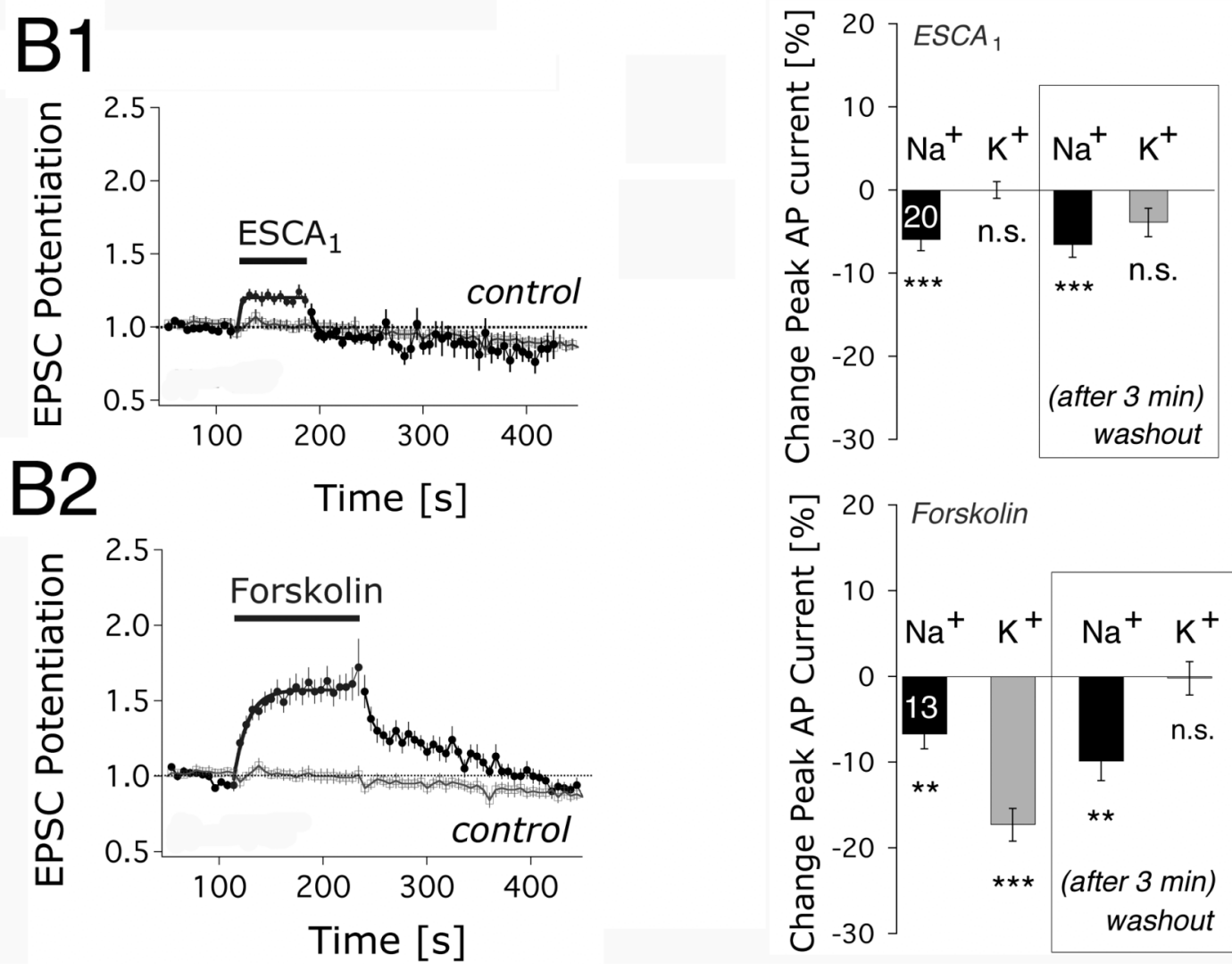

Figure 10 


\section{Structurally related ESCAs mimick the ESCA 1 effect}

The action of $\mathrm{ESCA}_{1}$ on neurotransmitter release from cultured excitatory autaptic neurons of the Dentate Gyrus was mimicked by structurally-related ESCAs (Fig. 11).

Previous studies from cultures of Trypanosoma brucei showed that $E S_{1} A_{1}$ is susceptibel to hydrolysis by cyclic nucleotide phosphodiesterases (PDEs) [Laxman et al., 2006]. Moreover, it inhibits the hydrolysis of endogeneous CAMP by its interaction with PDEs, possibly leading to indirect activation of PKA. Sp-8'-pCPT-2'-O-Me-cAMPS (ESCA $)$, a phosphorothioate derivative of CAMP which is resistant to enzymatic hydrolysis catalyzed by PDEs, was applied to the neuronal cultures to test whether hydrolysis of $E S C A_{1}$ also affects the drug-induced enhancement of neurotransmitter release in mammalian cells during $0.2 \mathrm{~Hz}$ stimulation. The mean EPSC amplitude enhancement for $\mathrm{ESCA}_{2}(20 \pm 2 \%$, mean $\pm \mathrm{SEM}, \mathrm{N}=17)$ was not significantly different from the one for $\mathrm{ESCA}_{1}(25 \pm 2 \%$, mean $\pm \mathrm{SEM}, \mathrm{N}=49)$ (Fig. 11A). To further validate that $\mathrm{ESCA}_{1}$ acted via Epac, a second experiment was performed with the structurally-related 8'-pMeOPT-2'-O-Me-cAMP (ESCA $\left.)_{3}\right)$. ESCA ${ }_{3}$ was shown to displace the binding of $\left[{ }^{3} \mathrm{H}\right] \mathrm{CAMP}$ to Epac with a higher potency than $\mathrm{ESCA}_{1}$ (7.1-fold versus 4.6-fold) [Christensen et al., 2003]. Although $\mathrm{ESCA}_{3}$ combines the highest affinity towards Epac with the highest Epac/PKA selectivity of all ESCAs, it exhibits only a 50-fold higher lipophilicity than CAMP when compared to $\mathrm{ESCA}_{1}$ (70-fold) or to $\mathrm{ESCA}_{2}$ (90-fold) (Biolog, Bremen, Germany). On average $\mathrm{ESCA}_{3}$ led to an EPSC amplitude enhancement of 22 $\pm 5 \%(\mathrm{~N}=19)$ (Fig. 10B). The corresponding $\mathrm{ESCA}_{1}$-effect was $28 \pm 3 \%(\mathrm{~N}$ $=34$ ). These results suggest that neither the rapid intracellular hydrolysis, nor insufficient membrane permeation affected our estimates for $\mathrm{ESCA}_{1}$-induced potentiation of EPSC amplitudes during low frequency stimulation. 


\section{A}
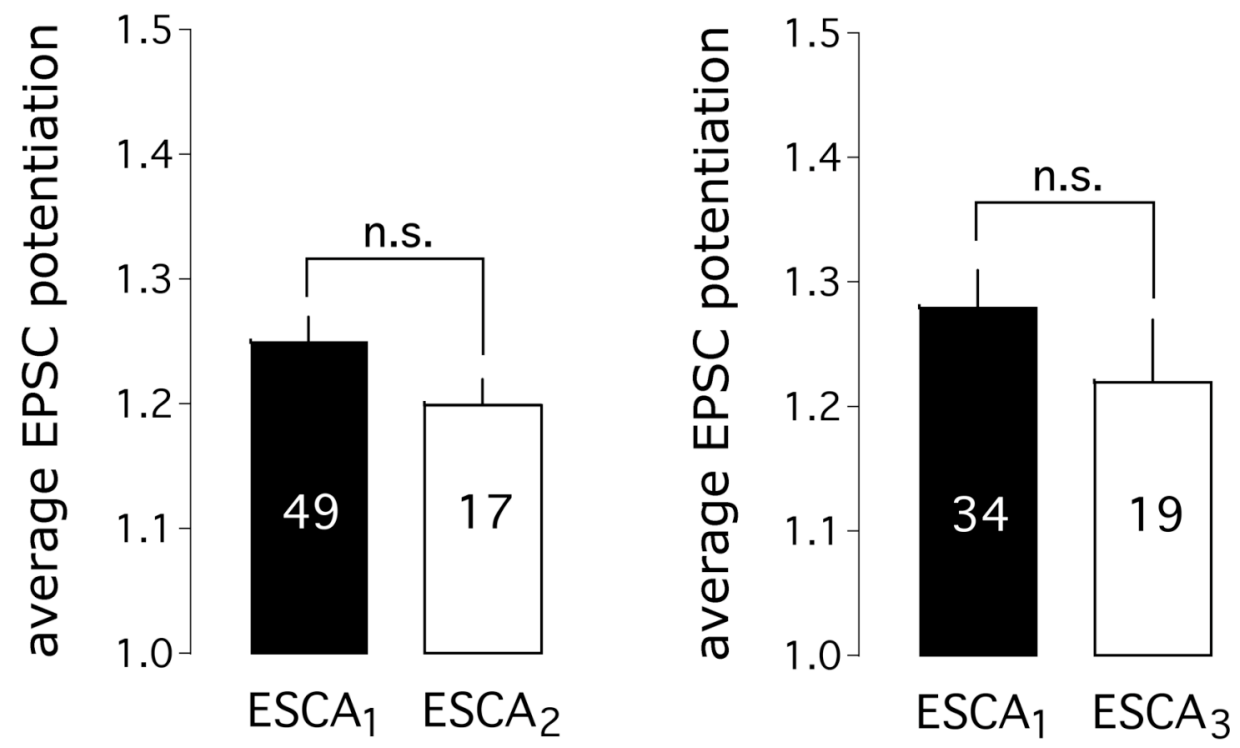

Fig. 11 Effects of $\mathrm{ESCA}_{2}$ and $\mathrm{ESCA}_{3}$ on neurotransmitter release at excitatory autaptic neurons from Dentate Gyrus. A. Average EPSC amplitude potentiation by $50 \mu \mathrm{M}$ $\mathrm{ESCA}_{1}$ and $50 \mu \mathrm{M}$ ESCA ${ }_{2}$ (Sp-8'-pCPT-2'-O-Me-cAMPS, hydrolysis-resistant ESCA analogue). $\mathrm{ESCA}_{1}: \mathrm{N}=49, \mathrm{n}=10\left(\mathrm{EPSC}_{0}=3.68 \pm 0.45 \mathrm{nA}\right.$, mean $\left.\pm \mathrm{SEM}\right) ; \mathrm{ESCA}_{2}: \mathrm{N}=17, \mathrm{n}$ $=1\left(\mathrm{EPSC}_{0}=3.68 \pm 0.29 \mathrm{nA}\right.$, mean $\left.\pm \mathrm{SEM}\right)$. B. Average EPSC amplitude potentiation by 50

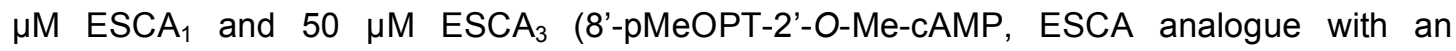
aproximately 1.5-fold higher affinity towards Epac than $\left.\mathrm{ESCA}_{1}\right) . \mathrm{ESCA}_{1}: \mathrm{N}=34, \mathrm{n}=8\left(\mathrm{EPSC}_{0}\right.$ $=2.53 \pm 0.21 \mathrm{nA}$, mean $\pm \mathrm{SEM}) ; \mathrm{ESCA}_{3}: \mathrm{N}=19, \mathrm{n}=2\left(\mathrm{EPSC}_{0}=2.35 \pm 0.30 \mathrm{nA}\right.$, mean \pm SEM). Similar $\mathrm{EPSC}_{0}$ amplitude distributions were considered for $\mathrm{ESCA}_{1}$-treated and $\mathrm{ESCA}_{2}-/ \mathrm{ESCA}_{3}$-treated cells. Statistical significance of the individual drug-induced EPSC potentiations was analysed by the paired t-test. For comparison between the $\mathrm{ESCA}_{1}$ - \& the $\mathrm{ESCA}_{2}$ - or the $\mathrm{ESCA}_{3}$-effect the KS-test was used. The numbers within the histogram bars are $\mathrm{N}$-values, representing the number of cells. 
Potentiation of synaptic strength by various pharmacological agents depends on the initial EPSC amplitude, the type of neuronal preparation, and the animal species

The magnitude of EPSC amplitude potentiation induced by short-term application of forskolin $(2 \mathrm{~min})$ or $\mathrm{ESCA}_{1}(1.2 \mathrm{~min})$ was dependent on the

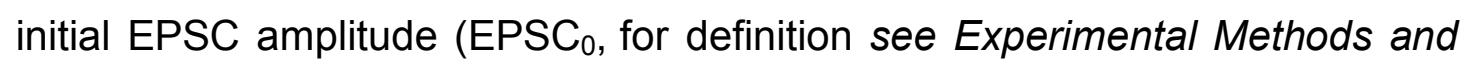

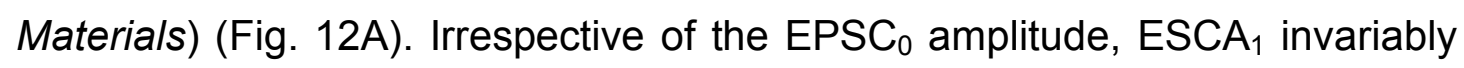
caused less potentiation than forskolin. The forskolin effect was particularly pronounced for $\mathrm{EPSC}_{0}<1 \mathrm{nA}$, a property not shared by the $\mathrm{ESCA}_{1}$-mediated

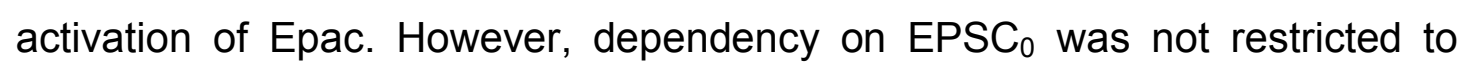
pharmacological agents modulating cAMP signaling. Similarly, an increase in EPSC amplitudes induced by PDBu, a phorbol ester known to presynaptically enhance neurotransmitter release (Malenka et al., 1986), was more pronounced for small EPSC $\mathrm{ES}_{0}$ than for larger ones (Fig. 12B). In Fig. 12C the drug-induced EPSC amplitude potentiation is correlated with the age of the Dentate Gyrus culture (day in vitro, DIV) to account for a possible maturation aspect that may underly the observed effect-dependency on EPSC 0 . Overall, the EPSC potentiation effects were larger for younger (DIV 8-10) than for older (DIV 11-15) cell cultures (Fig. 12C1).

The age of the culture not only determined the amount of EPSC amplitude potentiation, it additionally influenced the mean $\mathrm{EPSC}_{0}$ amplitude. The increase in the mean $\mathrm{EPSC}_{0}$ amplitude with age could be described by a power-law (Fig. 12C2). However, the variation in $\mathrm{EPSC}_{0}$ was large for any given age. To reduce this experimental variability, the $\mathrm{EPSC}_{0}$ amplitude was chosen as reference for further analysis of the drug-mediated EPSC amplitude potentiation.

Dependency on EPSC $\mathrm{ES}_{0}$ extended to properties beyond those of the evoked EPSCs. Under control condition both mEPSC amplitudes and frequency increased in size with larger $\mathrm{EPSC}_{0}$ values (Fig. 14A). Mean frequency of quantal events covered a 22.6-fold range (from $0.18 \pm 0.06 \mathrm{~Hz}$ at an $\mathrm{EPSC}_{0}$ of $0.4 \mathrm{nA}$ to $4.06 \pm 1.12 \mathrm{~Hz}$ at an $\mathrm{EPSC}_{0}$ of $12 \mathrm{nA}$, mean $\pm \mathrm{SEM}$ ) (Fig. 14D). Correlation of control mEPSC amplitudes and frequency with the age of the culture showed that both increased with age, being significantly 
larger for DIV 11-14 than for DIV 8-10 (Fig. 14B). Gottman et al. (1994) reported a similar effect of culture age on mEPSC frequency and amplitude.

In summary, these results suggest that a maturation aspect may underly the $\mathrm{EPSC}_{0}$ amplitude and needs to be considered as a normalizing factor. Therefore, the $\mathrm{EPSC}_{0}$ will be used as a reference throughout the entire analysis of drug-induced changes in evoked excitatory postsynaptic currents. $\mathrm{EPSC}_{0}$ reflects a certain initial functional state of a neuron, which is determined by the number of synapses, the quantal size, and the vesicular release probability.

Differences in-between species or neuronal preparations additionally influenced the drug-induced enhancement of neurotransmitter release. Unlike in murine DG- and CA1-neurons, ESCA $_{1}$ application did not elicit an acute response in rat CA1-neurons (data not shown). In contrast, the PDBu-induced potentiation showed no significant species difference when comparing rat and murine CA1-neurons. However, the PDBu-induced potentiation was more pronounced for murine DG-neurons than for murine/rat CA1-neurons (Fig. 12B). When considering an $\mathrm{EPSC}_{0}$ of $3.33 \pm 0.51 \mathrm{nA}$ (mean $\pm \mathrm{SEM}$ ) the PDBu-induced steady-state EPSC amplitude potentiation in rat CA1-neurons was only half the steady-state potentiation observed for murine DG-neurons (Fig. 12B, right).

Fig. 12 The initial EPSC amplitude (EPSC $)_{0}$ ) determines the amount of EPSC amplitude potentiation. Electrophysiological recordings of excitatory DG-neurons. A. left: cAMP-related EPSC amplitude potentiation versus the $\mathrm{EPSC}_{0}$ amplitude. $\mathrm{ESCA}_{1}[50 \mu \mathrm{M}], \mathrm{N}=60, \mathrm{n}=13$; $\triangle$ forskolin [50 $\mu \mathrm{M}], N=46, n=3$. Individual datapoints were binned in classes of $1 \mathrm{nA}$ for EPSC $_{0}>0.5 \mathrm{nA}$ and are shown as mean \pm S.D.. A monoexponential fit is applied to the $E_{S C A}$-values. The forskolin-data were fitted by a biexponential function. right: Representative EPSC sample traces before and after $\mathrm{ESCA}_{1}$ or forskolin application for both, small (a) and large (b) $\mathrm{EPSC}_{0}$, as marked by arrows in the left panel. AP-related currents were blanked out. B. left: EPSC amplitude potentiation induced by PDBu $[1 \mu \mathrm{M}]$ versus the EPSC $_{0}$ amplitude. $O$ murine DG, $N=35, \mathrm{n}=7 ; \diamond$ murine CA1, $N=5 ; \diamond$ rat $\mathrm{CA} 1, \mathrm{~N}=16, \mathrm{n}=$ 3. Data binning and layout of the figure is as in part A. The PDBu-data were fitted by a biexponential function. right: The time-course of the PDBu-effect on EPSC amplitudes (values: mean \pm SEM) depends on the hippocampal region used for the preparation of neuronal cultures. $O$ murine $D G, N=7, n=1\left(\right.$ EPSC $_{0}=3.33 \pm 0.51 \mathrm{nA}$, mean $\left.\pm \mathrm{SEM}\right) ;-$ rat $\mathrm{CA} 1, \mathrm{~N}=6, \mathrm{n}=1\left(\mathrm{EPSC}_{0}=3.37 \pm 0.7 \mathrm{nA}\right.$, mean $\left.\pm \mathrm{SEM}\right) \mathrm{C} 1$. Drug-induced EPSC amplitude 
potentiation as a function of culture age (day in vitro, DIV; mean \pm SEM). A: DIV 8-10, B: DIV 11-15. The numbers within the histogram bars are $\mathrm{N}$-values, representing the number of cells. Significance was tested by a KS-test. C2. Dependency of the $\mathrm{EPSC}_{0}$ on the age of the culture

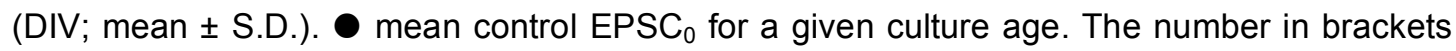
indicates the number of cells measured for a given culture age. $\bigcirc$ individual EPSC 0 datapoints measured at a certain culture age; $\square, \triangle, \bigcirc$ mean $\mathrm{EPSC}_{0}$ values of the cells from the figure's part $\mathrm{C} 1$ which were treated with $\mathrm{ESCA}_{1}$, forskolin, and PDBu, respectively. These mean values are presented for both culture age ranges, DIV 8-10 and DIV 11-15.
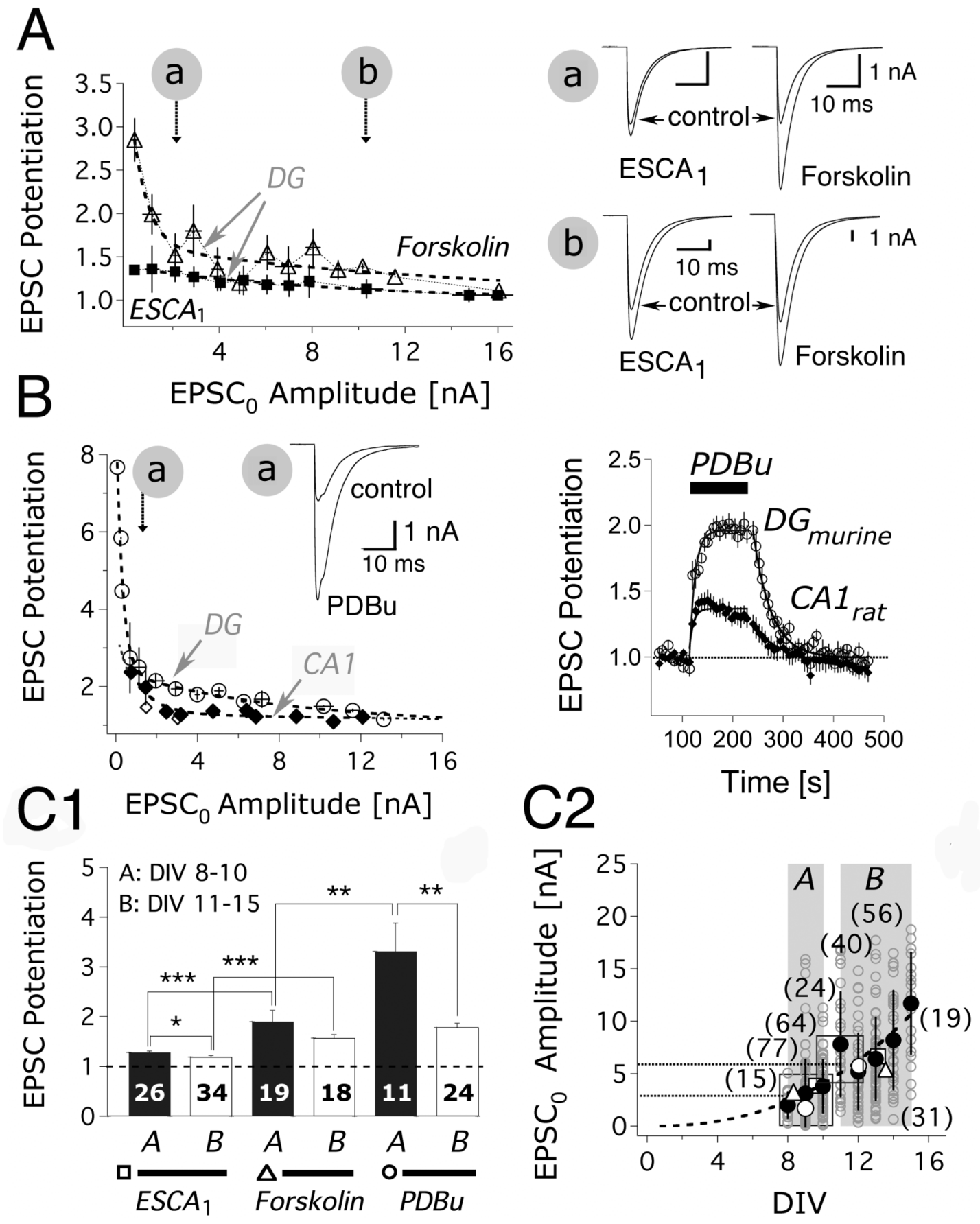

Figure 12 


\section{Variability in-between cell cultures}

For experimental reasons average changes in a parameter of interest were analysed by taking into consideration the total number of recorded cells $(\mathrm{N})$ instead of the number of cell cultures (n). However, variability in-between cell cultures may affect the pharmacologically-induced changes in EPSC size. Therefore, statistical analysis was used to show that the variance of the sample means $\left(\mathrm{n}_{\mathrm{i}}\right)$ from a population $(N)$ equals the variance of this population. Here, the standard error of the mean (SEM) was used as the measure of the variance. The SEM equals the square root of the variance divided by the square root of the sample size.

For two different cell culture ages (DIV9 and DIV13) it was exemplary tested whether the SEM of the mean EPSC $_{0}$ amplitude from a total of seven cultures $(n=7)$ equals the corresponding SEM calculated for the total number of individual datapoints in these cultures (Fig. 13A). Prior to the calculation of the mean $\mathrm{EPSC}_{0}$ amplitude and the SEM from a total of seven cultures, the average $\mathrm{EPSC}_{0}$ amplitude of an individual cell culture was weighted by the variance of that culture (for equation see legend of Fig. 13).

The SEM values of the mean $\mathrm{EPSC}_{0}$ amplitudes of the population of individual datapoints $\mathrm{EPSC}_{0}(\mathrm{~N})$ and the single cell culture $\mathrm{EPSC}_{0}$ amplitudes $\mathrm{EPSC}_{0}(\mathrm{n})$ were comparable in size for any of the analysed cell culture ages: $\mathrm{EPSC}_{0}(\mathrm{~N})_{\text {DIV9 }}=2.4 \pm 0.3 \mathrm{nA}$ versus $\mathrm{EPSC}_{0}(\mathrm{n})_{\mathrm{DIV}_{9}}=2.2 \pm 0.4 \mathrm{nA}(\mathrm{N}=56, \mathrm{n}=$ 7 ), and $\mathrm{EPSC}_{0}(\mathrm{~N})_{\mathrm{DIV} 13}=5.4 \pm 0.4 \mathrm{nA}$ versus $\mathrm{EPSC}_{0}(\mathrm{n})_{\mathrm{DIV} 13}=5.4 \pm 0.4 \mathrm{nA}(\mathrm{N}$ $=38, \mathrm{n}=7$ ) (mean \pm SEM; Fig. 13B). EPSC 0 amplitudes are largely independent on variabilities introduced by differences in-between cultures.

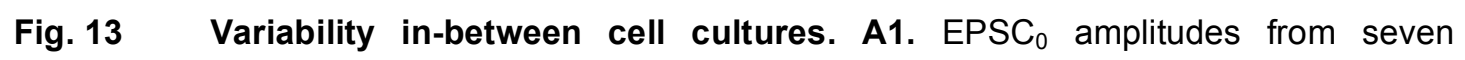
different cell cultures $\left(n_{i}\right.$, with $\left.i=1-7\right)$ for DIV9. Individual datapoints $(N=56)$ and their corresponding culture mean values ( \pm S.D.) are presented. $\bullet$, alternating colour code emphasizes the individual datapoints of consecutively following cell cultures. The solid line represents the mean $\mathrm{EPSC}_{0}$ amplitude of all individual datapoints $(\mathrm{N}=56)$. Dotted lines show the corresponding standard deviation (S.D.) range of this mean $\mathrm{EPSC}_{0}$ amplitude. A2. EPSC amplitudes from seven different cell cultures for DIV13 $(\mathrm{N}=38)$. Graph description as in part

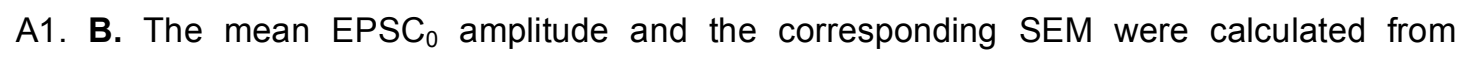
individual datapoints $(\mathrm{N})$ or from the average EPSC $\mathrm{ES}_{0}$ amplitudes of single cell cultures $\left(\mathrm{n}_{\mathrm{i}}\right)$. The average $\mathrm{EPSC}_{0}$ amplitude of a given cell culture was weighted by the variance of that 
culture

according to the

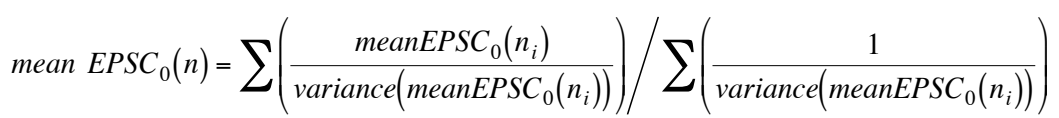

following equation:
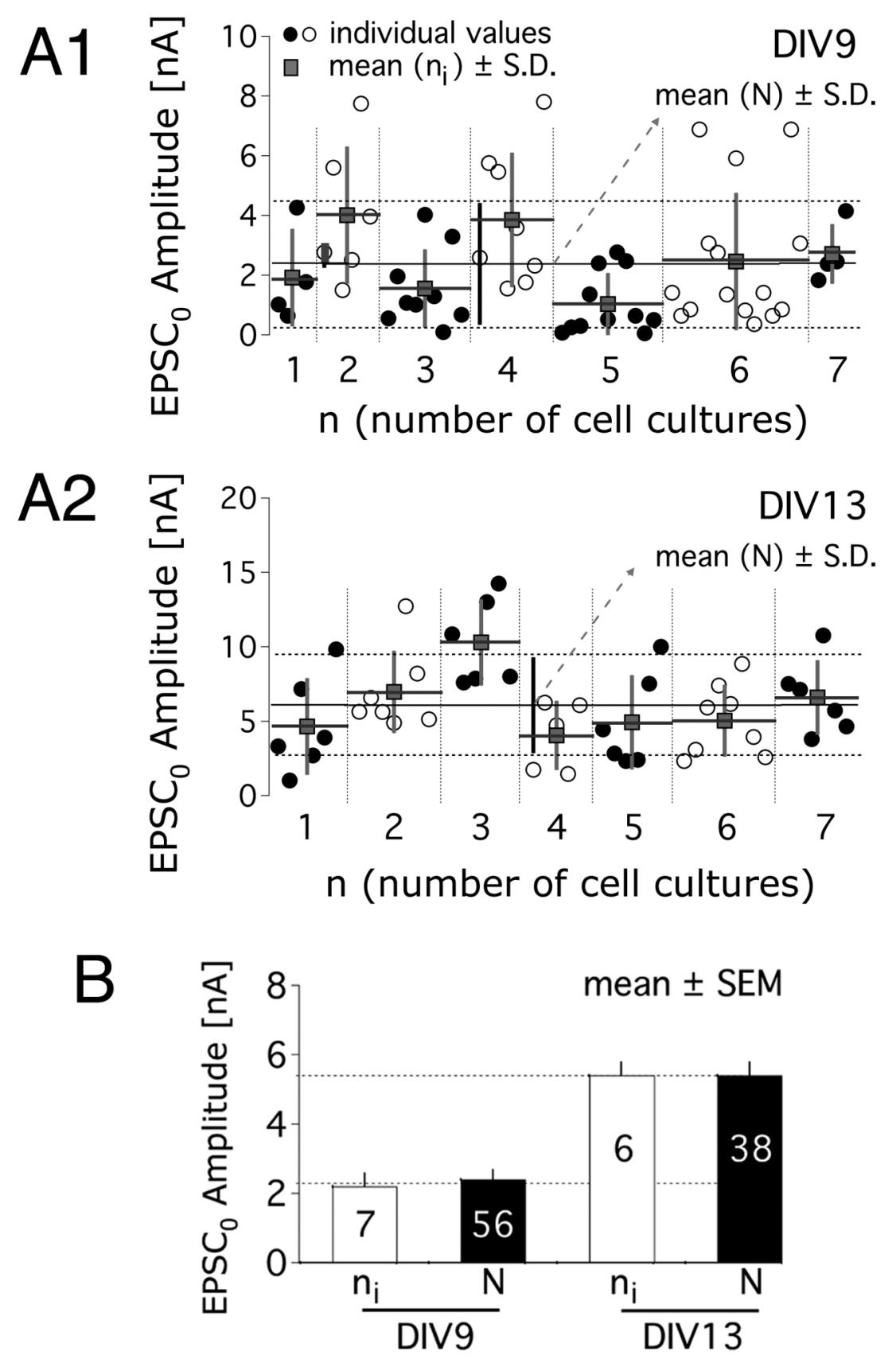

Figure 13 


\section{Epac activation is presynaptic in origin and increases the release probability for a vesicle}

Both, forskolin and $E_{S C A}$ enhanced mEPSC frequency (Fig. 14A,D) without changing mEPSC amplitudes (Fig. 14C). The ESCA $_{1}$-induced increase in mEPSC frequency was prominent for the $E \mathrm{PSC}_{0}$ amplitude interval of $[2 ; 10] \mathrm{nA}$. For $\mathrm{EPSC}_{0}<0.5 \mathrm{nA}$ no potentiation was detectable during Epac activation by $\mathrm{ESCA}_{1}$. The average potentiation of mEPSC frequency by application of forskolin (3.4 \pm 0.4 , mean $\pm S E M, N=10)$ was not significantly different from the one induced by $\operatorname{ESCA}_{1}(2.7 \pm 0.6$, mean \pm SEM, $N=15)$. Similar distributions of $\mathrm{EPSC}_{0}$ values and the same cell culture ages (DIV11-14) were considered for both drug treatments. For younger ages (DIV8-10) ESCA $_{1}$ similarly increased mEPSC frequency by a factor of $2.9 \pm$ 0.5 (mean \pm SEM, $N=20$ ). Therefore, Epac activation can account for $100 \%$ of the forskolin effect on mEPSC frequency. The lack of an effect on mEPSC amplitudes suggests that ESCA 1 acted presynaptically.

Fig. 14 Activation of Epac increases mEPSC frequency in murine DG-neurons. For every individual cell mEPSC events were recorded for at least one minute in the absence or presence of cAMP-related pharmacological agents. To prevent AP-related calcium influx, sodium channels were blocked by co-application of $300 \mathrm{nM}$ TTX. A. Representative mEPSC sample traces for the control (DIV10 and DIV14) condition and the corresponding ESCA $_{1}[50$ $\mu \mathrm{M}]$ or forskolin $[50 \mu \mathrm{M}]$ treatment. B. Significant increase of the mean control mEPSC amplitude (left) and the mean mEPSC frequency (right) with culture age. Values are shown as mean \pm SEM. Significance was tested by an unpaired $t$-test in both cases. The numbers within the histogram bars are $\mathrm{N}$-values, representing the number of cells. C. mEPSC amplitude versus the $\mathrm{EPSC}_{0}$ amplitude. control; $\square \mathrm{ESCA}_{1}, \mathrm{~N}=47, \mathrm{n}=3$; $\bigcirc$ forskolin, $\mathrm{N}=$ $11, n=2$. inset: mean mEPSC sample traces are shown for control and $\mathrm{ESCA}_{1}$ treatment. Arrows indicate their corresponding datapoints in the curve. D. mEPSC frequency versus the $\mathrm{EPSC}_{0}$ amplitude. Significance was tested by a paired t-test. 0 control, $N=101, n=9$; ESCA $_{1}, N=47, n=3$; 9 forskolin $[50 \mu \mathrm{M}], N=11, n=2$. In $C$ and $D$ mEPSC data are pooled over the following $\mathrm{EPSC}_{0}$ intervals: from $>0 \mathrm{nA}$ to $<1 \mathrm{nA}$, from $1 \mathrm{nA}$ to $<2 \mathrm{nA}$, from $2 \mathrm{nA}$ to $<$ $4 \mathrm{nA}$, from $4 \mathrm{nA}$ to $<10 \mathrm{nA}$, and $\geq 10 \mathrm{nA}$. The values are presented as mean $\pm \mathrm{SEM}$. The number of measurements in the $\mathrm{EPSC}_{0}$-classes is given in round brackets. 

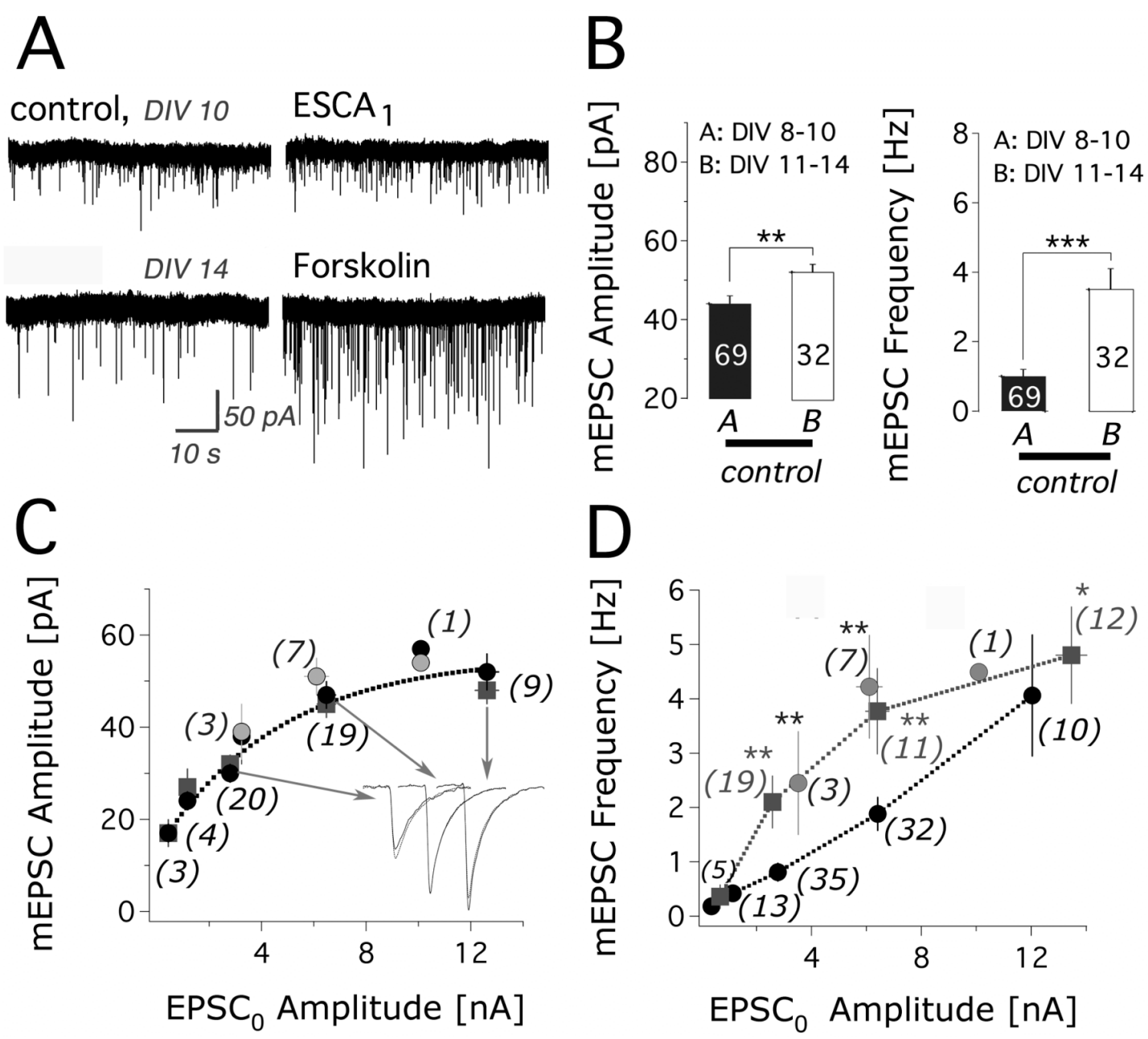

Figure 14

Next, the question was addressed whether the number of vesicles that can be released with a brief pulse of hypertonic sucrose solution is modulated by $\mathrm{ESCA}_{1}$ (Fig. 15). Application of $500 \mathrm{mM}$ sucrose solution nearly depletes all vesicles in close proximity to the active zone [Rosenmund and Stevens, 1996]. The number of vesicles released by sucrose under control condition and in the presence of ESCA $E_{1}$ was calculated as described in the Experimental Methods and Materials section. ESCA Eas $_{1}$ applied for 72 seconds prior to sucrose-stimulation. For any given $\mathrm{EPSC}_{0}$ value no significant difference between the number of released vesicles in the absence or presence of $\mathrm{ESCA}_{1}$ could be detected (Fig. 15B). This shows that the average number of sucrose-releasable vesicles is not changed during application of $\mathrm{ESCA}_{1}$. Given the finding that $\mathrm{ESCA}_{1}$ increases action potential- 
evoked EPSCs and that quantal size is unchanged upon Epac activation, one can conclude that the drug increases the mean release probability. In view of the heterogeneity in release probability [Moulder and Mennerick, 2005] this change can be either a general increase in $p$ or else a shift between different populations of vesicles.

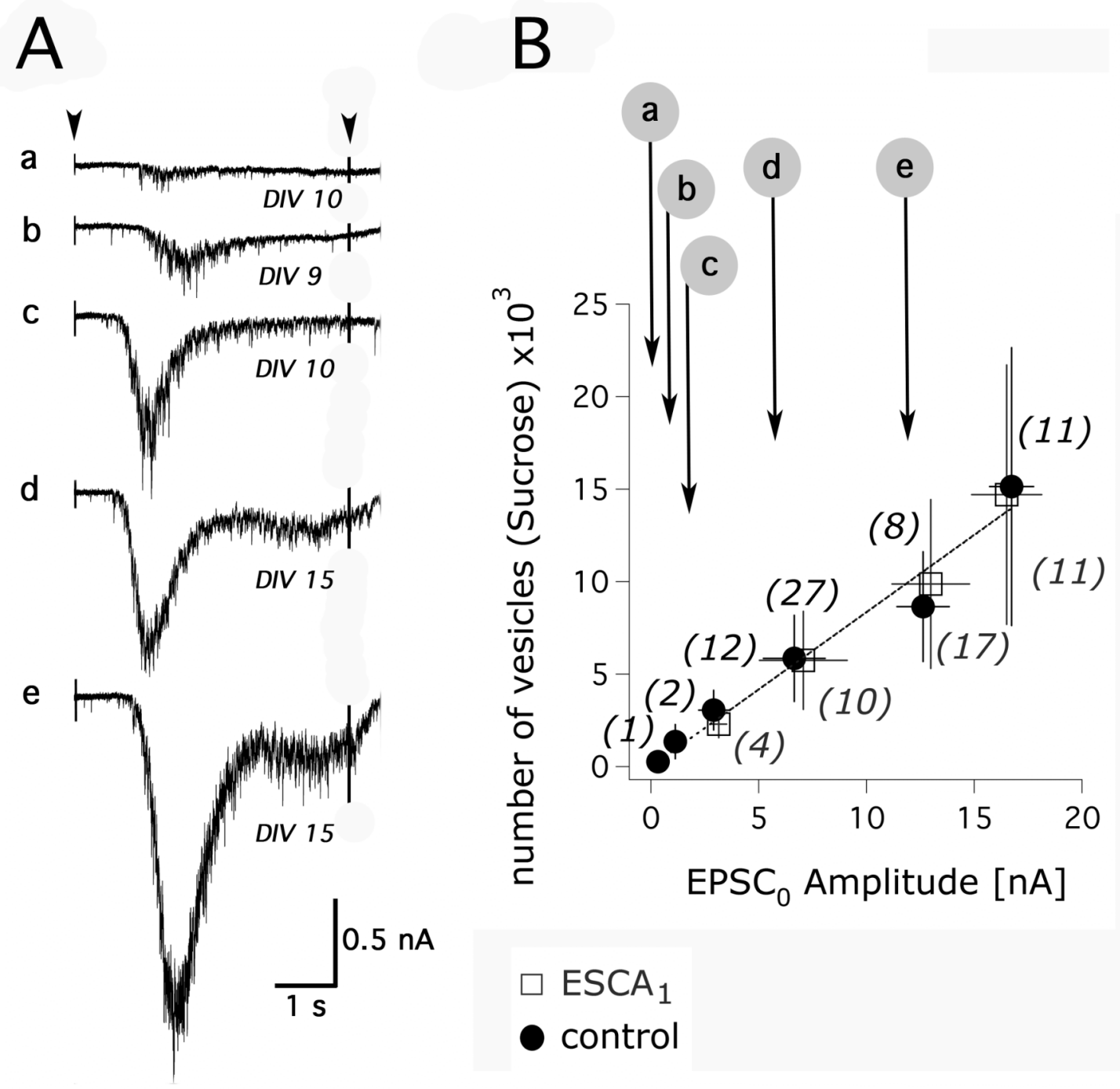

Figure 15

Fig. 15 The number of sucrose-releasable vesicles is a characteristic function of the initial EPSC amplitude and does not change upon application of ESCA $A_{1}$. A.

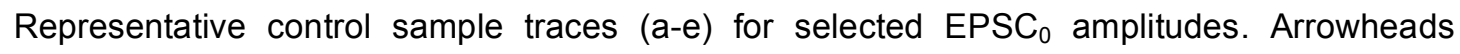
indicate onset and end of sucrose application (500 mM). B. Linear dependency of vesicle 
numbers on the $\mathrm{EPSC}_{0}$ amplitude. control; $\mathrm{N}=50, \mathrm{n}=6 \square \mathrm{ESCA}_{1}[50 \mu \mathrm{M}] ; \mathrm{N}=44, \mathrm{n}=3$. Datapoints were binned for the following $\mathrm{EPSC}_{0}$ intervals: $<0.5 \mathrm{nA}$, from $0.5 \mathrm{nA}$ to $1 \mathrm{nA}$, from $>1 \mathrm{nA}$ to $<4 \mathrm{nA}$, from $4 \mathrm{nA}$ to $<10 \mathrm{nA}$, from $10 \mathrm{nA}$ to $<15 \mathrm{nA}$, and $>15 \mathrm{nA}$. The values are presented as mean \pm S.D. The number of measurements in the EPSC ${ }_{0}$-classes is given in round brackets. The arrows (a-e) indicate the corresponding $\mathrm{EPSC}_{0}$ values for the control sample traces shown in part $A$.

\section{$E S C A_{1}$ enhanced mEPSC frequency during $0.2 \mathrm{~Hz}$ stimulation}

For young cell culture ages (DIV9-10) mEPSC frequency was also enhanced in the last $900 \mathrm{~ms}$ of EPSC traces (Fig. 16A) recorded every five seconds $(0.2$ $\mathrm{Hz}$ ), albeit to a lesser extent (1.9-fold on average). The degree of mEPSC frequency enhancement depended on calcium ion influx (Fig. 16B). Only recordings from young cell culture ages were considered to assure that the values from different cell cultures belong to the same distribution. After ESCA application the effect on mEPSC frequency decayed monoexponentially with a time constant of $\tau \sim 25 \pm 1$ seconds (mean \pm SD; Fig. 16A) during $0.2 \mathrm{~Hz}$ stimulation, whereas it was previously shown that the $\mathrm{ESCA}_{1}$-effect on EPSC amplitudes decreased with a time constant of $\tau \sim 13 \pm 1$ seconds (mean $\pm S D$ ) (Fig. 10B1).

Fig. 16 Washout of $E \mathrm{SCA}_{1}$ and its effect on mEPSC frequency during $0.2 \mathrm{~Hz}$ stimulation. A. Dependency of the normalized mEPSC frequency (mean \pm SEM) on time: The number of mEPSC events from the last $900 \mathrm{~ms}$ of three subsequent traces (each of $1 \mathrm{~s}$ length) recorded at $0.2 \mathrm{~Hz}$ were counted and grouped together (to reduce the number of datapoints and to increase in parallel the number of detected mEPSC events) (exception: the first point during $E_{S C A}$ application was calculated only from the first trace). From the number of mEPSC events the mEPSC frequency was calculated for three stimulation conditions (prior, during and after $E_{S C A_{1}}$ stimulation). The mEPSC frequency values were normalized to the average mEPSC frequency $\left(2.6 \pm 0.6 \mathrm{~Hz}\right.$, mean \pm SEM) determined prior to $\mathrm{ESCA}_{1}$ stimulation. To assure that the values from different cultures belong to the same distribution we considered only recordings performed on DIV 9 and 10 (average DIV =9.4). $\mathrm{N}=25, \mathrm{n}=6$ $\left(\mathrm{EPSC}_{0}=3.5 \pm 0.4 \mathrm{nA}\right.$, mean $\left.\pm \mathrm{SEM}\right)$. For the cells analysed the average EPSC amplitude potentiation by $\mathrm{ESCA}_{1}$ was $28 \pm 3 \%$ (mean \pm SEM) $\mathbf{B}$. Timecourse of the mEPSC frequency in the presence $(0.2 \mathrm{~Hz})$ or absence (TTX) of action potential-stimulated calcium ion influx from the same cell. During treatment with TTX no depolarization pulses were elicited. The mEPSC frequency values were normalized to the average mEPSC frequency $(0.5 \pm 0.1 \mathrm{~Hz}$, 
mean \pm SEM) measured during tetrodotoxin (TTX) treatment only. For the TTX treatment a single mEPSC frequency datapoint contains the mEPSC events detected within a time window of 15 seconds. mEPSC frequency from $0.2 \mathrm{~Hz}$ recordings was determined as described in part A. We considered only recordings performed on DIV 9 and 10 (average DIV $=9.6) . \mathrm{N}=18, \mathrm{n}=2\left(\mathrm{EPSC}_{0}=2.4 \pm 0.2 \mathrm{nA}\right.$, mean $\left.\pm \mathrm{SEM}\right)$.

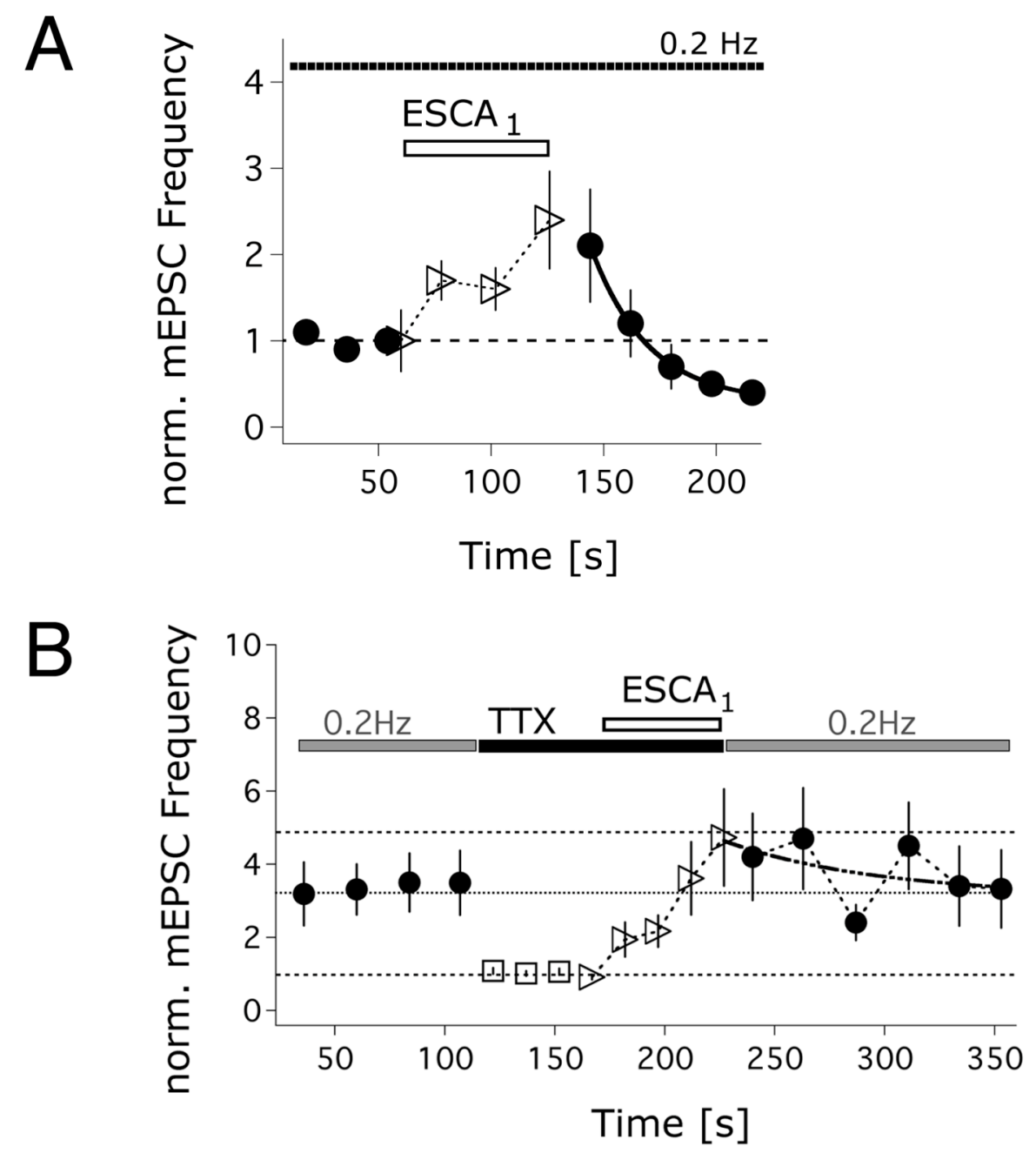

Figure 16

\section{cAMP-to-PKC signaling occurs upon Epac activation}

Phorbol esters were shown to enhance evoked and spontaneous neurotransmitter release in various nervous preparations [Malenka et al., 1986; Parfitt and Madison, 1993; Chen and Roper, 2003; Searl and Silinsky, 
2003]. Phorbol esters seem to modulate both the number of readily releasable vesicles [Stevens and Sullivan, 1998; Waters and Smith, 2000] as well as the vesicular release probability [Rhee et al., 2002; Basu et al., 2007]. To test whether Epac activation and application of phorbol esters may affect similar signaling pathways, neurons were stimulated with $\mathrm{ESCA}_{1}$ prior to application of phorbol-12,13-dibutyrate (PDBu) (see Fig. 17 for details), and the PDBumediated changes in EPSC amplitudes were recorded at $0.2 \mathrm{~Hz}$. A prominent interaction between the two stimuli was observed.

This interaction was detected in murine DG-neurons, which so far proved to be susceptible to Epac activation. In addition, rat CA1-neurons were chosen to serve as a negative control for a putative interaction of the PDBuand the $\mathrm{ESCA}_{1}$-activated pathways, since application of $\mathrm{ESCA}_{1}$ did not elicit an acute increase in EPSC amplitudes (data not shown). The changes of the PDBu-effect induced by prestimulation with $\mathrm{ESCA}_{1}$, were analysed by differentiating between different classes of $\mathrm{EPSC}_{0}$. Prestimulation with the cAMP-analog increased a subsequent PDBu effect in murine DG-neurons, but not in rat CA1-neurons (Fig. 17B). The difference is detectable for all EPSC 0 values below $10 \mathrm{nA}$. Statistical analysis of the PDBu potentiation values for

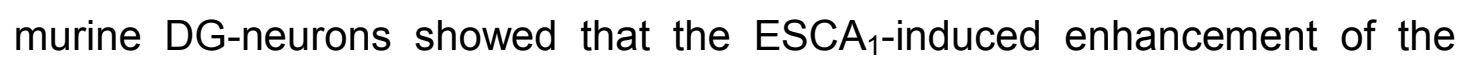
PDBu-effect is significant $(p<0.0001)$. Thus, a modulation of the PDBu-effect occurs only for neurons, which also show an increase of neurotransmitter release during prestimulation with the Epac-specific cAMP-analog (see above). Sample traces from murine DG-neurons show the Epac-induced enhancement of the PDBu effect (Fig. 17A). The amount of potentiation depended on the time interval between Epac activation and PDBu application. The resulting time-course of relative EPSC amplitude potentiation peaked at the inter-application interval of three minutes (Fig. 17C), with the enhancement of the PDBu-effect developping slowly and decaying over several minutes. For murine CA1 neurons the degree of PDBu-effect enhancement at an inter-application interval of one minute was comparable to that observed for murine DG neurons (other IAls were not analysed). Rat CA1 neurons showed an Epac-induced PDBu-effect enhancement neither at an inter-application interval of one minute nor at one of two minutes.

These data demonstrate that for murine DG and CA1 neurons activation 
of Epac exhibits a slow mode of action in addition to its rapid enhancement of EPSC amplitude during low frequency stimulation. Considering the fast washout of the $\mathrm{ESCA}_{1}$-effect $(\tau \sim 13 \pm 1 \mathrm{~s}$, mean \pm S.D., Fig. 10B1), the ESCA $_{1}$-mediated enhancement of the PDBu-effect over a timescale of minutes presumably involves a complex signaling cascade either converging to or complementing PDBu-activated signaling pathways.

Fig. 17 Activation of Epac enhances a subsequently induced PDBu effect. A. Stimulation protocol and sample traces. Prior to PDBu $[1 \mu \mathrm{M}]$ application for 2 minutes cultured neurons were stimulated at various inter-application intervals (IAls) for 1.2 minutes with $\mathrm{ESCA}_{1}[50 \mu \mathrm{M}]$. EPSCs were recorded at $0.2 \mathrm{~Hz}$. Average traces of one complete experiment (numbered 1-4) are shown for IAI = 2 min. AP-related currents were blanked. The reference PDBu trace was calculated from the basal EPSC (3) according to the fit of the PDBu reference curve shown in Fig.3B left. B. Dependency of the PDBu-effect on $\mathrm{EPSC}_{0}$ in the presence (+) or absence (-) of neuronal prestimulation with $\mathrm{ESCA}_{1}$ for both, murine $\mathrm{DG}$ neurons $\left[D G_{(+)}\right.$or $\left.D G_{(-)}\right]$and rat $C A 1$ neurons $\left[C A 1_{( \pm)}\right]$. O murine $D G(-)$, control value; murine $\mathrm{DG}(+), \mathrm{ESCA}_{1}$ prestimulation, $\mathrm{N}=21, \mathrm{n}=5 . \diamond$ rat $\mathrm{CA} 1(-)$, control value; $\diamond$ rat $\mathrm{CA} 1(+), \mathrm{ESCA}_{1}$ prestimulation, $N=11, \mathrm{n}=2$. In case of the murine $\mathrm{DG}$ neurons the PDBu-effects for the IAIs 0 and 1 minutes were pooled to increase the number of datapoints. Similarly, for rat CA1 neurons the PDBu-effects corresponding to the IAls 1 and 2 minutes were pooled. For all curves individual datapoints were binned in classes of $1 \mathrm{nA}$ for $\mathrm{EPSC}_{0}>$ $0.5 \mathrm{nA}$. The PDBu-generated EPSC potentiation values are shown as mean \pm SEM for murine DG neurons and as mean \pm S.D. for rat CA1 neurons. C. Time dependency of the Epac-induced enhancement of the PDBu-effect. murine DG; murine CA1; rat CA1. Values from different age- and $\mathrm{EPSC}_{0}$-classes were pooled by averaging for each IAI the relative difference of EPSC amplitude potentiations. These are defined by $\frac{f(\text { measured })-f(\text { reference })}{f(\text { reference })-1} \times 100 \%$, with $\mathrm{f}=$ potentiation factor for a given amplitude class.

The values are shown as mean \pm SEM. Statistical significance was tested by a KS-test. The number of measurements for distinct IAls is given in round brackets. 


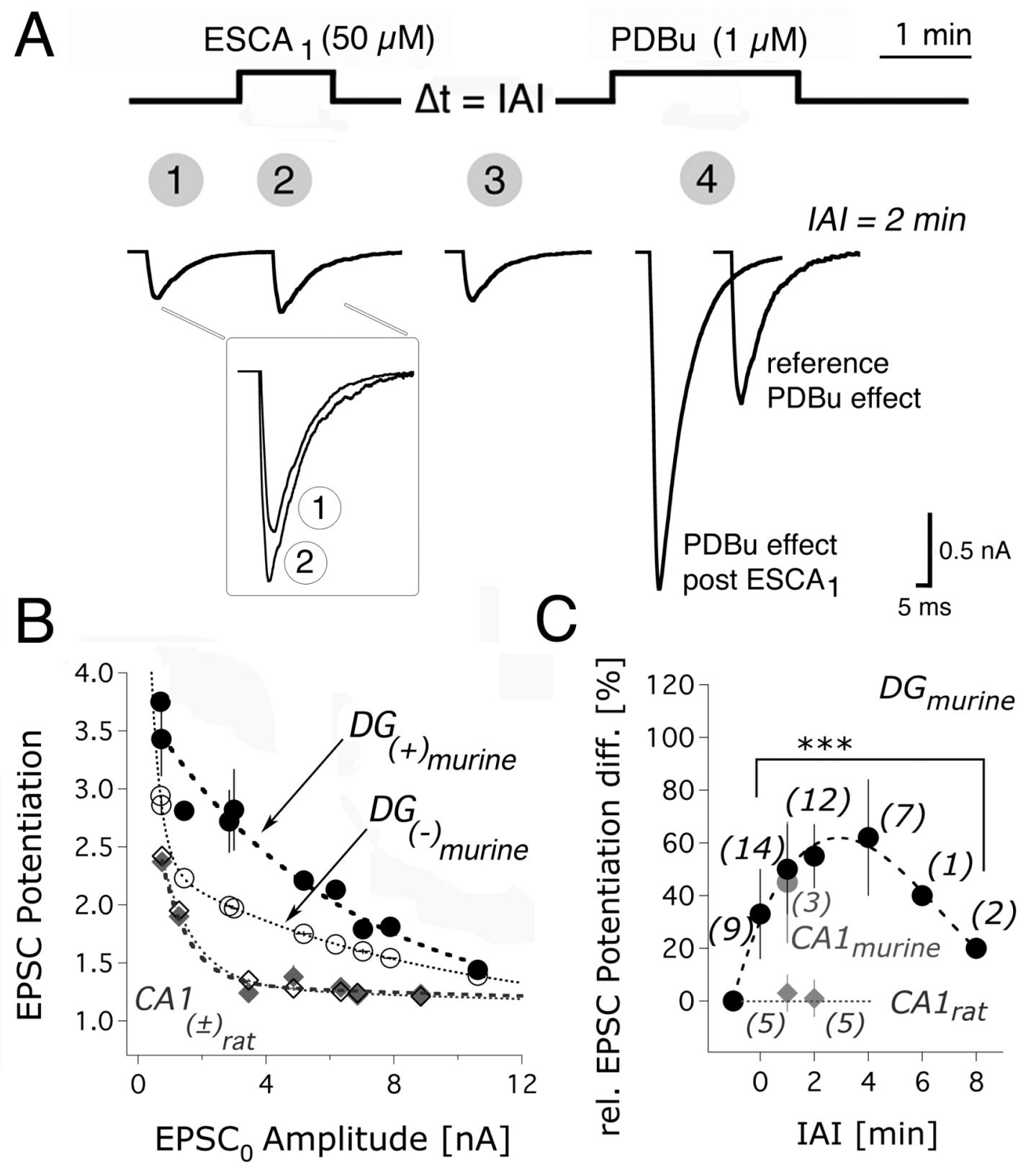

Figure 17

In order to define the role of the classical phorbol ester receptor, PKC, for the observed cAMP-to-PDBu effect its enzymatic kinase function was inhibited in situ in the absence of direct Epac stimulation. During electrophysiological 
recordings, preapplication of the PKC-antagonist bisindolylmaleimide I (1.2 $\mu \mathrm{M}, \mathrm{BIS}-\mathrm{I})$ significantly $(\mathrm{p}<0.0001)$ inhibited the PDBu-mediated potentiation of EPSC amplitudes on average by $60 \pm 19 \%$ (mean \pm S.D., $N=31, n=3$ ) (Fig. 18). In addition, it led to a long-lasting suppression of EPSCs (Fig. 18A) as reported by Rhee et al. (2002). Betz et al. (1998) showed that in vitro BIS-I does not inhibit the activity of Munc13, another putative presynaptic PDBu target crucial for neurotransmitter release. Thus, the non-blocked PDBu effect may be due to activation of Munc13. However, an incomplete kinase-block may as well explain the remaining PDBu-effect in this experimental design. Moreover, application of BIS-I reduced AP-related potassium- and sodium-currents by $12.4 \pm 1.6 \%$ (mean \pm SEM) and $14 \pm 1.7 \%$ (mean \pm SEM, $N=18, n=2$ ) respectively. Both current type changes are significant at the $1 \%$ level.

Fig. 18 Inhibition of PKC activity by bisindolylmaleimide I reduces the PDBu-effect. A. Time course of the EPSC amplitude potentiation of Dentate Gyrus autapses by $1 \mu \mathrm{M}$ $\mathrm{PDBu}$ in the absence or presence of $1.2 \mu \mathrm{M}$ bisindolylmaleimide I (Bis I) during $0.2 \mathrm{~Hz}$ stimulation. Horizontal bars show the onset and the duration of drug application. - reference PDBu effect (-Bis I), $N=24, n=6\left(\right.$ EPSC $_{0}=4.35 \pm 0.51 \mathrm{nA}$, mean \pm SEM); $\diamond$ PDBu effect in the presence of Bis I (+Bis I), N = 31, $n=3\left(\right.$ EPSC $_{0}=4.69 \pm 0.49 \mathrm{nA}$, mean \pm SEM). The values are shown as mean \pm SEM. B. PDBu-mediated EPSC amplitude potentiation in the absence (-) or presence (+) of Bis I versus $E$ PSC $_{0}$. Individual datapoints were binned in classes of $1 \mathrm{nA}$ for $\mathrm{EPSC}_{0}>0.5 \mathrm{nA}$ and mean drug-effects were calculated for each class. The values are shown as mean \pm S.D. The continuous line is the fit to the values from Fig. $3 B$ left; $\boldsymbol{\nabla}$ expected reference PDBu-effect calculated from the $\mathrm{EPSC}_{0}$ amplitudes of the Bis I experiment and the potentiation curve (continuous line); mean PDBu-effect measured in the presence of Bis I; $\diamond$ individual, datapoints measured in the presence of Bis I. 
A

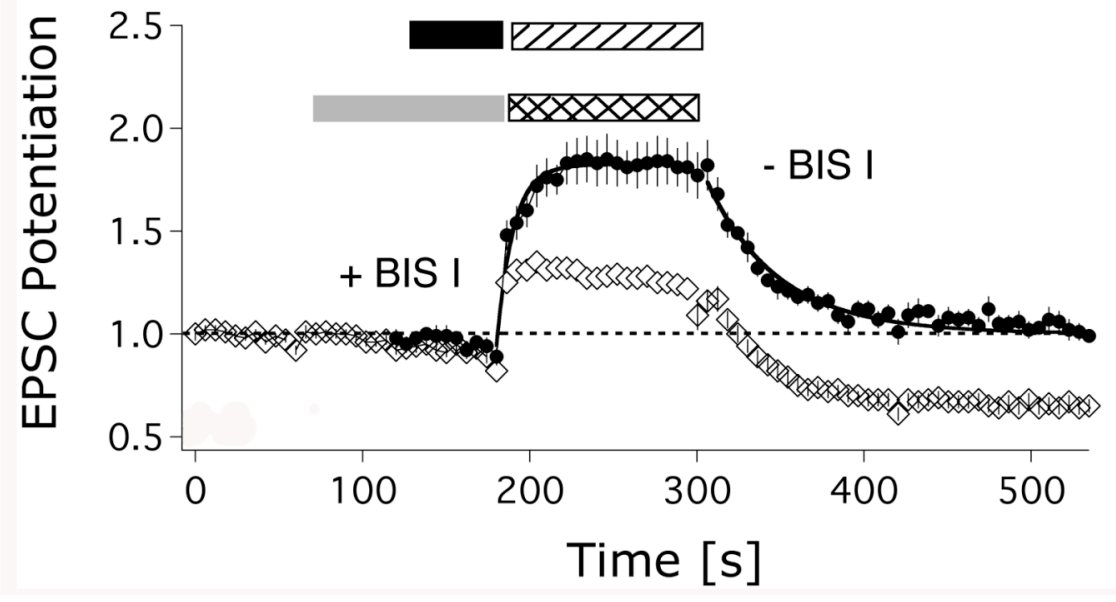

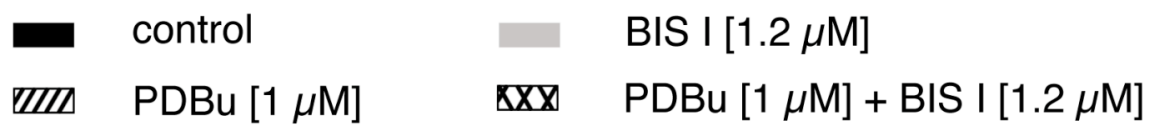

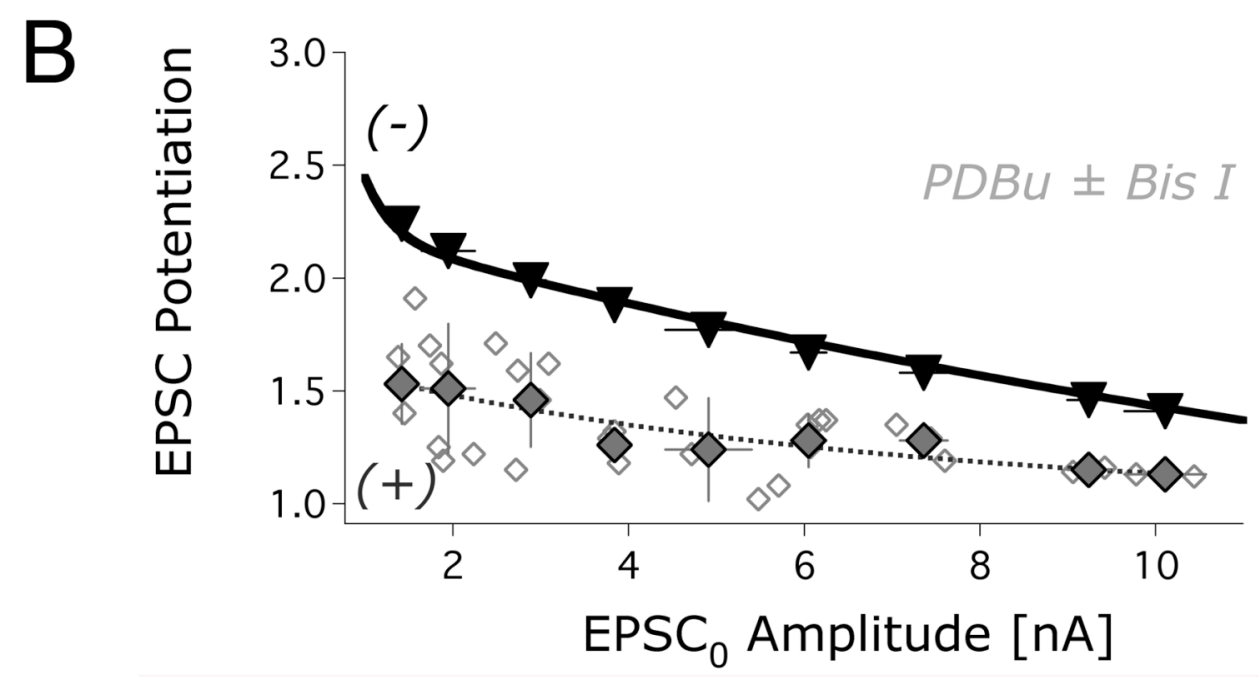

Figure 18

Given the partial action of the PKC-antagonist, the involvement of PKC was tested using an alternative approach. Matthies et al. (1987) presented evidence that prolonged stimulation of cells with PDBu $(1 \mu \mathrm{M})$ down-regulates PKC activity in differentiated PC12 cells and sympathetic neurons. The biochemical basis for the observed downregulation involves proteolysis of the enzyme [Lee et al., 1997]. Murine DG-neurons were preincubated with $1 \mu \mathrm{M}$ PDBu for $16 \mathrm{~h}$ and tested for the PDBu effect on EPSC amplitudes after a 5 
minutes wash. This was considered to be a sufficient time for the washout of $\mathrm{PDBu}$, given the washout time constant for the acute PDBu effect of $\tau_{\text {washout }}(\mathrm{PDBu})=35.7 \pm 4.1 \mathrm{~s}$ (mean \pm S.D., see Fig. 12B, right). The PDBu-

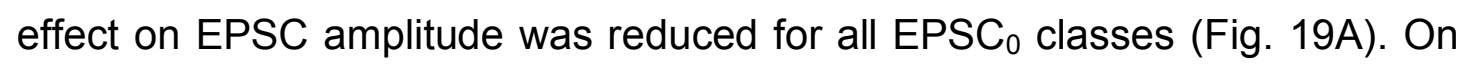
average the PDBu-effect was significantly ( $p<0.0001$ ) reduced by $93 \pm 12 \%$ (mean \pm S.D., $N=19$ ). Mean $\mathrm{EPSC}_{0}$ values were not significantly different between control measurements $(1.88 \pm 0.36 \mathrm{nA}$, mean $\pm \mathrm{SEM}, \mathrm{N}=15)$ and those after PDBu pretreatment (1.87 $\pm 0.42 \mathrm{nA}$, mean $\pm \mathrm{SEM}, \mathrm{N}=19)$. Similarly, mEPSC frequency was not changed when comparing control $(0.29$ $\pm 0.15 \mathrm{~Hz}$, mean \pm S.D., $N=6)$ and PDBu-pretreated $(0.31 \pm 0.09 \mathrm{~Hz}$, mean \pm S.D., $N=5)$ neurons for a given class of $E$ SSC $_{0}$-values $(0.83 \pm 0.48 \mathrm{nA})$ (Fig. 19C,D). From the occurrence of mEPSCs at normal rates one can conclude, that longterm pretreatment with PDBu did not cause a major loss of Munc13 protein function, since Varoqueaux et al. (2002) presented evidence that neurons lacking Munc13 show neither evoked nor spontaneous release, in spite of forming a normal number of synapses with typical ultrastructural features. Moreover, PKC activity is required for the enhancement of EPSC amplitudes by PDBu.

Fig. 19 Downregulation of PKC activity by prolonged preincubation of neuronal cultures with PDBu abolishes the PDBu-effect. Dentate Gyrus neurons were incubated either with PDBu $[1 \mu \mathrm{M}]$ or with DMSO (control) for 16 hours prior to electrophysiological recordings. A. EPSC amplitude potentiation \pm preincubation with PDBu for $16 \mathrm{~h}$. Individual datapoints were binned in classes of $1 \mathrm{nA}$ for $\mathrm{EPSC}_{0}>0.5 \mathrm{nA}$. - mean PDBu-effect reference values from Fig. $3 \mathrm{~B}$ left, $\mathrm{N}=21, \mathrm{n}=6\left(\mathrm{EPSC}_{0}=2.18 \pm 0.28 \mathrm{nA}\right.$, mean $\left.\pm \mathrm{SEM}\right)$;

mean PDBu-effect datapoints after preincubation with $\mathrm{PDBu} \diamond$ individual PDBu-effect datapoints after preincubation with PDBu. B. Average (ave.) potentiation of the EPSC amplitudes by PDBu in the presence or absence of preincubation with PDBu (mean \pm SEM, significance tested by a KS-test). The recordings for both conditions were not obtained from identical cells. Therefore, we generated three different control values for the mean PDBu effect. $m$ : potentiation values measured in the absence of PDBu preincubation $(N=21, n=5)$. $c$ : potentiation values generated from the biexponential curve fit of the PDBu-reference curve

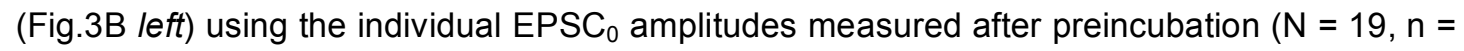
2). $d$ : potentiation values after preincubation with DMSO for $16 \mathrm{~h}$ (volume of application corresponded to the one used for pretreatment with $\mathrm{PDBu} ; \mathrm{N}=11, \mathrm{n}=3$ ). The average EPSC $_{0} \pm \operatorname{SEM}(2.10 \pm 0.59 \mathrm{nA})$ for the initial amplitude distribution used for $d$ in part $\mathrm{B}$ is 
indicated by a light gray bar in part A. C. top two traces: Sample traces for control and preincubation condition. lowest traces: Superimposed traces of detected mEPSC events (24 events for control; 29 events for the preincubation condition). D. Dependency of the mEPSC frequency on the preincubation condition. mean control frequency, $\mathrm{N}=6\left(\mathrm{EPSC}_{0}=0.83 \pm\right.$ $0.48 \mathrm{nA}$, mean \pm S.D.); $\diamond$ individual control datapoints; $\bigcirc$ mean frequency after $16 \mathrm{~h}$ preincubation with $\mathrm{PDBu}, \mathrm{N}=5\left(\mathrm{EPSC}_{0}=0.81 \pm 0.82 \mathrm{nA}\right.$, mean \pm S.D.); $\bigcirc$ individual preincubation datapoints.

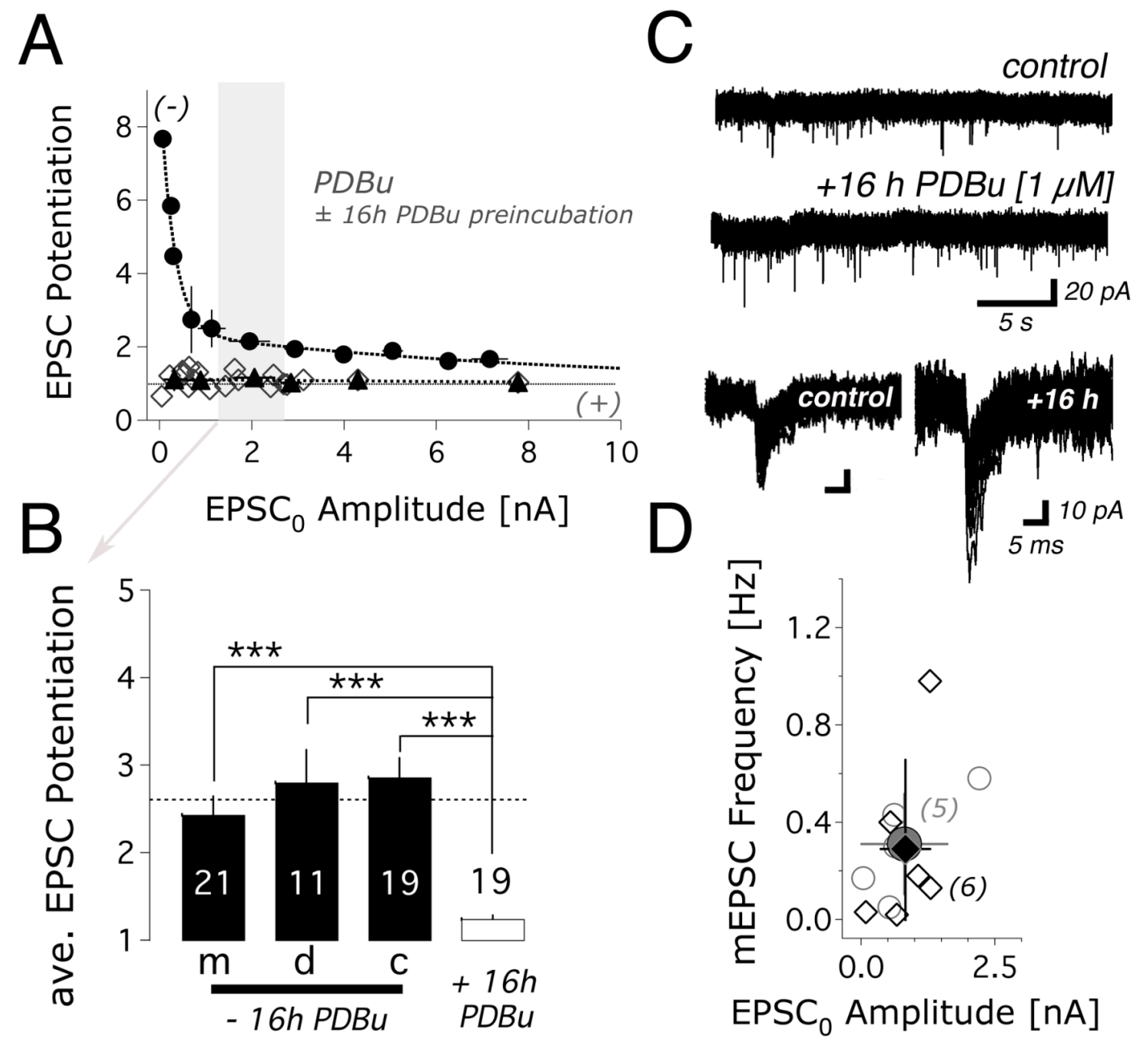

Figure 19 


\section{Persistence of the ESCA ${ }_{1}$ effect post prolonged PDBu treatment}

Although prolonged preincubation with $\mathrm{PDBu}$ abolished a subsequent PDBu-induced enhancement of neurotransmitter release, potentiation of neurotransmitter release by acute ESCA $_{1}$ application persisted (Fig. 20). After control preincubation with DMSO only, ESCA ${ }_{1}$ enhanced EPSC amplitudes on average by $21 \pm 4 \%$ (mean \pm SEM, $N=9$ ). After preincubation with PDBu for at least 16 hours the potentiation by $\mathrm{ESCA}_{1}$ was $18 \pm 4 \%$ (mean $\pm \mathrm{SEM}, \mathrm{N}=$ 14). In contrast, the PDBu effect on EPSC amplitudes was significantly ( $p<$ 0.001 ) reduced by $101 \pm 2 \%$ (mean $\pm \mathrm{SEM}, \mathrm{N}=8$ ). Mean $\mathrm{EPSC}_{0}$ values were not different between control measurements $(1.88 \pm 0.36 \mathrm{nA}$, mean $\pm \mathrm{SEM}, \mathrm{N}$ $=15)$ and those after PDBu pretreatment $(1.54 \pm 0.36 \mathrm{nA}$, mean $\pm \mathrm{SEM}, \mathrm{N}=$ 8). Moreover, $\mathrm{ESCA}_{1}$ did not lead to a PDBu effect upon subsequent PDBu application in PDBu pretreated neurons (IAI = $2 \mathrm{~min}$; data not shown).

Therefore, Epac function itself does not rely on PKC activity, which can be downregulated by prolonged preincubation with PDBu.

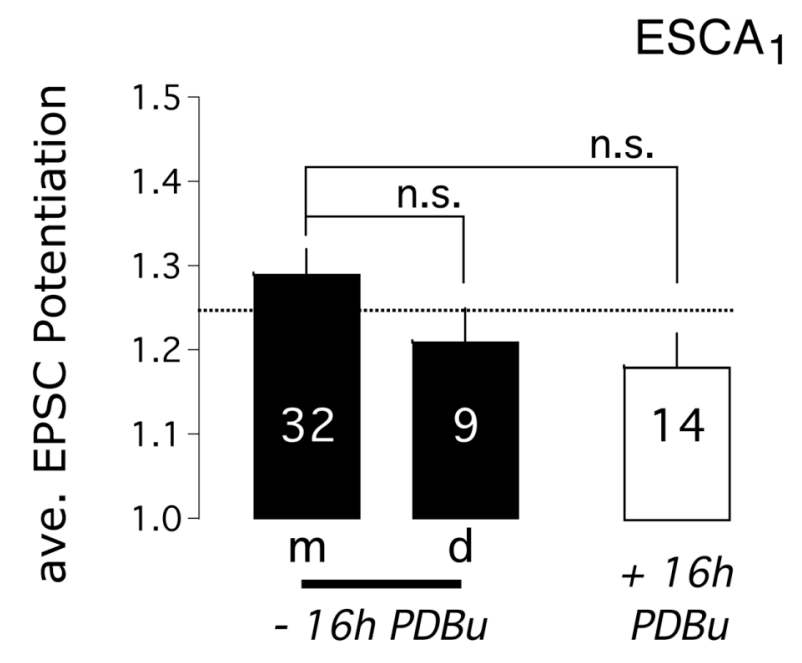

Figure 20

Fig. 20 ESCA $_{1}$ effect on neurotransmitter release after downregulation of PKC activity. Average (ave.) potentiation of the EPSC amplitudes by $\mathrm{ESCA}_{1}$ in the presence or absence of preincubation with PDBu for 16 hours. Potentiation values are shown as mean \pm SEM. Significance was tested by a KS-test. The recordings for both conditions were not obtained from identical cells. Therefore, we generated two different control values for the mean ESCA 
effect. $m: E_{1 S A}$ potentiation values measured in the absence of PDBu preincubation $(N=$ $32, \mathrm{n}=6$ ). $d$ : $\mathrm{ESCA}_{1}$ potentiation values after preincubation with DMSO for $16 \mathrm{~h}$ (volume of application corresponded to the one used for pretreatment with PDBu; $N=9, n=2$ ). For the pretreatment condition $(+16 h P D B u): \mathrm{N}=14, \mathrm{n}=2$. Both, the control and the PDBu preincubation condition show similar mean $\mathrm{EPSC}_{0}$ values $(2.6 \pm 0.3 \mathrm{nA}$ versus $1.9 \pm 0.4 \mathrm{nA}$, mean $\pm \mathrm{SEM}$ ). The numbers within the histogram bars are $\mathrm{N}$-values, representing the number of cells. 


\section{DISCUSSION}

The contribution of the novel cAMP-target Epac to the CAMP-mediated enhancement of glutamate release from presynaptic terminals at excitatory hippocampal synapses was investigated. Epac modulates neurotransmitter release by increasing the mean vesicular release probability, either due to a general increase in $p$, or due to a shift between different populations of vesicles. Moreover, brief Epac activation leads to presynaptic changes persisting for several minutes during low stimulation frequency. Epac- and PKC-mediated signaling pathways interact. Both, PKA-dependent and PKAindependent signaling pathways may shape neurotransmitter release at excitatory mammalian central synapses.

\section{Epac function complements PKA activity}

Specific activation of Epac by ESCA $_{1}$ (8-pCPT-2'-O-Me-cAMP) presynaptically increased synaptic transmission in cultured excitatory neurons from murine Dentate Gyrus (Fig. 9B1,2 \& Fig. 10). Previous publications considering the calyx of Held [Sakaba and Neher, 2003; Kaneko and Takahashi, 2004] and the crayfish neuromuscular junction [Zhong and Zucker, 2005] reported similar PKA-independent presynaptic effects. In cultured excitatory DG-neurons Epac activation enhances EPSC amplitudes on average by $23 \pm 3 \%$ (mean \pm SEM, $N=60$ ). This effect can explain on average $38 \%$ of a forskolin-induced increase in evoked EPSC amplitudes (60 $\pm 6 \%$, mean \pm SEM, $N=46$ ). In slices of layer $V$ cortical neurons $E_{S C A}$ or forskolin potentiated EPSP slopes to a comparable extent [Huang and Hsu, 2006]. However, in contrast to the findings presented here and to results from the crayfish neuromuscular junction [Zhong and Zucker, 2005], Huang and Hsu (2006) concluded that Epac activity does not contribute to the forskolinmediated increase of EPSC slopes.

Traditionally, PKA was believed to be the key player when modulating plasticity at central excitatory synapses. Considering its short-term actions, PKA not only inhibits potassium channel function [Siegelbaum et al., 1982], 
but additionally phosphorylates synapsins, SNAP-25, and voltage-dependent calcium channels [Menegon et al., 2006; Nagy et al., 2004; Hell et al., 1995]. In this study, potassium currents were indeed reduced after forskolin application but not by specific Epac activation.

Acute application of pharmacological agents modified neurotransmitter release from cultured autaptic excitatory neurons depending on the initial EPSC amplitude (EPSC 0 ) (Fig. 12A,B) and the age of the culture (Fig. 12C). The forskolin-mediated potentiation of EPSC amplitudes suggests that notably

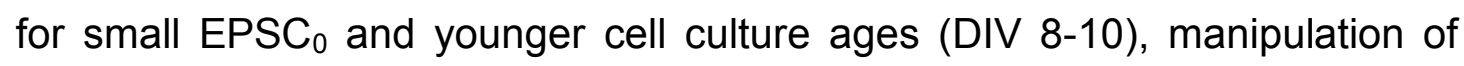
cAMP-signaling pathways other than that via Epac have a high impact on neurotransmission (Fig. 12A,C1,2). In slices of layer $V$ cortical neurons, potentiation of neurotransmitter release by forskolin exihibited a dependency on the age of the animal, being more pronounced for younger than for older animal ages [Huang and $\mathrm{Hsu}, 2006]$. The age of the analysed animals determines, moreover, mEPSC amplitude and frequency. mEPSC amplitude and frequency increase with the animal age [Yamashita et al., 2003]. In autaptic hippocampal cultures similar observations were made with regard to the influence of the cell culture age on mEPSC amplitude and frequency [Gottman et al., 1994]. This property is shared by the control mEPSC recordings. Therefore, the observed dependency of pharmacological effects on $\mathrm{EPSC}_{0}$ likely occurs due to a developmental change. In order to eliminated heterogeneity between experiments resulting from such an effect, short-term pharmacological effects were analysed with respect to the initial state of a neuron. This revealed features of second messenger-initiated molecular interactions underlying the developmentally determined neuronal plasticity.

Activation of Epac accounts solely for the observed increase in mEPSC frequency after a forskolin-induced elevation of intracellular cAMP-levels. Quantal size was affected neither by application of forskolin nor by ESCA (Fig. 14C). Recently it was shown that in the presence of cannabinoid receptor antagonist-induced PKA-inhibition, forskolin enhances mIPSC frequency without affecting quantal size [Chevaleyre et al., 2007]. Therefore, this study is compatible with previously presented results.

Although increasing AP-evoked neurotransmitter release, ESCA $_{1}$ mediated Epac activation did not change the number of releasable vesicles as 
measured by the application of $500 \mathrm{mM}$ sucrose solution [Rosenmund and Stevens, 1996] (Fig. 15). However, this result does not necessarily reflect a general increase in $p$. In the past years, several studies provided evidence that kinetically distinct components contribute to release during presynaptic depolarization in diverse model systems, such as the neuromuscular junction, chromaffin cells, hippocampal neurons, and the Calyx of Held [Rahamimoff and Yaari, 1973; Neher and Zucker, 1993; Goda and Stevens, 1994; Moulder and Mennerick, 2005; Sakaba and Neher, 2001]. Therefore, the Epac-induced change in mean $p$ may as well represent a shift between different populations of vesicles.

\section{Epac function involves Epac-to-PKC signaling}

PDBu has been reported to modulate both the number of readily releasable vesicles [Stevens and Sullivan, 1998; Waters and Smith, 2000] as well as the vesicular release probability [Rhee et al., 2002; Basu et al., 2007]. Epac activation enhanced a subsequent PDBu-effect on EPSC amplitudes (Fig. 17). The amount of enhancement depended on the time interval between Epac activation and PDBu application, and developped slowly over several minutes. Synergistic interaction of the forskolin- and PDBu-mediated modulation of excitatory synaptic transmission was previously observed in granule cells of the human Dentate Gyrus: Prior application of forskolin occludes the effects of PDBu on mEPSC frequency [Chen and Roper, 2003].

Downregulation of PKC activity by prolonged pretreatment of the cell cultures with PDBu [Matthies et al., 1987] revealed that PKC activity is required for the presynaptic PDBu-effect (Fig. 8). Recently, Wierda et al. (2007) demonstrated that the PDBu-effect is abolished in autaptic munc18-1 null mutant neurons expressing a PKC-insensitive Munc18-1 protein. In chromaffin cells Munc18-1 facilitates vesicle docking in a PKC phosphorylation-independent manner, and phosphorylation by PKC enhances vesicle pool replenishment following a depleting stimulation at a post-docking stage [Nili et al., 2006]. However, at present little is known about the contribution of PKC-mediated regulation of VDCCs and calcium influx [DeRiemer et al., 1985; Swartz, 1993] to the observed PDBu-effect. The 
results presented here do not allow to distinguish if and to what extent the observed Epac-to-PKC signaling involves changes of VDCC function and calcium influx.

After downregulation of PKC activity ESCA 1 application still elicited its typical response, but did not lead to a subsequent PDBu sensitivity (Fig. 20). Therefore, Epac function itself does not rely on PKC activity which can be downregulated by prolonged pretreatment with PDBu.

Since Epac activation increases the PDBu-effect (Fig. 17), and since the PDBu-effect is dependent on PKC/Munc18-1 interaction (Wierda et al., 2007) Epac activity may enhance the PKC/Munc18-1-mediated vesicle pool replenishment by directly stimulating $\mathrm{PKC} /$ Munc18-1 activity or indirectly by regulating Munc13 function and vesicle priming. Two mechanisms can be proposed for this action of Epac: Plasmamembrane-associated Epac1 [DiPilato et al., 2004] targets PLC $\varepsilon$ via Rap2B [Evellin et al., 2002] generating diacylglycerol. This may lead to the activation and translocation of $\mathrm{PKC} \varepsilon$ to the plasmamembrane [Hucho et al., 2005] or else to the activation of Munc13 via its $\mathrm{C} 1$ domain. Moreover, Rap2B activates the Cdc25 domain function of PLC $\varepsilon$ generating the active GTP-form of Rap1 [Wing et al., 2003]. Alternatively, Epac2 was shown to interact N-terminally with the PDZ domain of the active zone protein RIM1 [Ozaki et al., 2000]. The currently available data establish that RIM1 has a central function in the regulation of neurotransmitter release [Lonart, 2002]. It organizes the docking and priming of vesicles for exocytosis, by regulating the recruitment of Munc13-1 to the active zone [Andrews-Zwilling et al., 2006], thereby enabling the formation of a Munc13/RIM/Rab3 tripartite complex [Dulubova et al., 2005]. 


\section{GENERAL SUMMARY}

In this study electrophysiological, pharmacological and biochemical tools were applied to analyse
A. the contribution of the novel cAMP-binding protein Epac to neurotransmitter release from central synapses
B. the step of exocytosis regulated by Epac activity
C. Epac's mechanisms of action.

(1) Specific activation of Epac by extracellularly applied cAMP-analogues enhanced both spontaneous and evoked neurotransmitter release in wild-type dissociated autaptic neuronal cultures of the murine Dentate Gyrus. Potentiation of evoked EPSCs and mEPSC frequency was dependent on the initial EPSC amplitude (EPSC ${ }_{0}$ ) of a neuron, and could be related to the state of maturation of a culture.

(2) On average, Epac function accounts for $38 \%$ of a forskolin-induced increase in evoked EPSC amplitudes during low frequency $(0.2 \mathrm{~Hz})$ electrophysiological recordings and for $100 \%$ of a forskolin-induced increase in mEPSC frequency. The number of sucrose-releasable vesicles was unchanged upon Epac activation. These observations suggest that Epac activity enhances mean release probability or else leads to the shift between different populations of vesicles.

(3) Moreover, Epac activity augmented a subsequent enhancement of evoked EPSC amplitudes by phorbol ester (PDBu). This effect was maximal when Epac activation occured three minutes prior to PDBu application. Since the PDBu effect required PKC function, Epac activation leads to presynaptic changes involving Epac-to-PKC signaling. This interaction may stimulate vesicle pool replenishment (docking) either directly or indirectly by enhancing vesicle priming.

(4) Finally, calcium ion influx regulates the size of the Epac effect in wild-type neurons. An increase in calcium ion influx decreases the $\mathrm{ESCA}_{1}$-induced Epac effect on mEPSC frequency. Inhibition of calcium ion influx reduces the duration of the Epac-mediated EPSC amplitude enhancement (Appendix). 



\section{REFERENCES}

Abel T, Nguyen PV, Barad M, Deuel TAS, Kandel ER, Bourtchouladze R (1997) Genetic demonstration of a role for PKA in the late phase of LTP and in the hippocampus-based long-term memory. Cell 88:615-626.

Aivatiadou E, Brunetti F, Berruti G (2005) cAMP promotes an Epac2 redistribution where Rap-1 is located in differentiating male germ cells. FEBS J 272 (s1), E4-008P.

Andrews-Zwilling YS, Kawabe H, Reim K, Varoqueaux F, Brose N (2006) Binding to Rab3A-interacting molecule RIM regulates the presynaptic recruitment of Munc13-1 and ubMunc13-2. J Biol Chem 281:19720-19731.

Aravamudan B, Fergestad T, Davis WS, Rodesch CK, Broadie K (1999) Drosophila UNC-13 is essential for synaptic transmission. Nat Neurosci 2:965-971.

Arunachalam L, Han L, Tassew NG, He Y, Wang L, Xie L, Fujita Y, Kwan E, Davletov B, Monnier PP, Gaisano HY, Sugita S (2007) Munc18-1 is critical for plasma membrane localization of syntaxin1 but not of SNAP-25 in PC12 cells. Mol Biol Cell - ahead of print

Augustin I, Rosenmund C, Südhof TC, Brose N (1999) Munc13-1 is essential for fusion competence of glutamatergic synaptic vesicles. Nature 400:457461.

Augustine I, Betz A, Herrmann C, Jo T, Brose N (1999) Differential expression of two novel Munc13 proteins in rat brain. Biochem J 337:363-371.

Bankir L, Ahloulay M, Devreotes PN, Parent CA (2002) Extracellular cAMP inhibits proximal reabsorption: are plasma membrane cAMP receptors involved? Am J Physiol Renal Physiol 282:376-392.

Barg S, Eliasson L, Renström E, Rorsman P (2002) A subset of 50 secretory granules in close contact with L-type $\mathrm{Ca}^{2+}$ channels accounts for first-phase insulin secretion in mouse beta-cells. Diabetes Suppl1:S74-82.

Basu J, Betz A, Brose N, Rosenmund C (2007) Munc13-1 C1 domain lowers the energy barrier for synaptic vesicle fusion. J Neurosci 27:1200-1210.

Beavo JA, Hardman JG, Sutherland EW (1970) Hydrolysis of cyclic guanosine and adenosine 3',5'-monophosphates by rat and bovine tissues. J Biol Chem 245:5649-5655.

Beavo JA, Bechtel PJ, Krebs EG (1975) Mechanisms of control for cAMPdependent protein kinase from skeletal muscle. Adv Cyclic Nucleotide Res 5:241-51.

Béguin P, Nagashima K, Nishimura M, Gonoi T, Seino S (1999) PKA-mediated phosphorylation of the human K(ATP) channel: separate roles of KIR6.2 and SUR1 subunit phosphorylation. EMBO J 18:4722-4732. 
Bekkers JM, Stevens CF (1991) Excitatory and inhibitory autaptic currents in isolated hippocampal neurons maintained in cell culture. Proc Natl Acad Sci USA 88:7834-7838.

Bernstein BW, Bamburg JR (1989) Cycling of actin assembly in synaptosomes and neurotransmitter release. Neuron 3:257-265.

Betz A, Okamoto M, Benseler F, Brose N (1997) Direct interaction of the rat unc-13 homologue Munc13-1 with the $\mathrm{N}$ terminus of syntaxin. $\mathrm{J}$ Biol Chem 272:2520-2526.

Betz A, Ashery U, Rickmann M, Augustin I, Neher E, Südhof TC, Rettig J, Brose N (1998) Munc13-1 is a presynaptic phorbol ester receptor that enhances neurotransmitter release. Neuron 21:123-136.

Birks R, Maclntosh FC (1961) Acetylcholine metabolism of a sympathetic ganglion. Canad J Biochem Physiol 39:787-827.

Blasi J, Chapman ER, Yamasaki S, Binz T, Niemann H, Jahn R (1993a) Botulinum neurotoxin $\mathrm{C} 1$ blocks neurotransmitter release by means of cleaving HPC-1/syntaxin. EMBO J 12:4821-4828.

Blasi J, Chapman ER, Link E, Binz T, Yamasaki S, De Camilli P, Südhof TC, Niemann H, Jahn R (1993b) Botulinum neurotoxin A selectively cleaves the synaptic protein SNAP-25. Nature 365:160-163.

Bliss TVP, Lømo T (1973) Long-lasting potentiation of synaptic transmission in the dentate area of the anaesthetized rabbit following stimulation of the perforant path. J Physiol 232:331-356.

Boeckers TM (2006) The postsynaptic density. Cell Tissue Res 326:409-422.

Boriack-Sjodin PA, Margarit SM, Bar-Sagi D, Kuriyan J (1998) The structural basis of the activation of Ras by Sos. Nature 394:337-343.

Bos JL (2003) Epac: a new cAMP target and new avenues in the cAMP research. Nat Rev Mol Cell Biol 4:733-738.

Bos JL (2005) Linking Rap to cell adhesion. Curr Opin Cell Biol 17:123-4.

Bos JL (2006) Epac proteins: multi-purpose cAMP targets. Trends Biochem Sci 31:680-686.

Bos JL, Rehmann H, Wittinghofer A (2007) GEFs and GAPs: critical elements in the control of small $G$ proteins. Cell 129:865-877.

Bräuer AU, Savaskan NE, Kole MHP, Plaschke M, Monteggia LM, Nestler EJ, Simbürger E, Deisz RA, Ninnemann O, Nitsch R (2001) Molecular and functional analysis of hyperpolarization-activated pacemaker channels in the hippocampus after entorhinal cortex lesion. FASEB J 15:2689-2701.

Bradley J, Zhang Y, Bakin R, Lester HA, Ronnett GV, Zinn K (1997) Functional expression of the heteromeric "olfactory" cyclic nucleotide-gated channel in the hippocampus: a potential effector of synaptic plasticity in brain neurons. J Neurosci 17:1993-2005. 
Brandon EP, Zhuo M, Huang Y-Y, Qi M, Gerhold KA, Burton KA, Kandel ER, McKnight GS, Idzerda RL (1995) Hippocampal long-term depression and depotentiation are defective in mice carrying a targeted disruption of the gene encoding the RI $\beta$ subunit of cAMP-dependent protein kinase. Proc Natl Acad Sci USA 92:8851-8855.

Brandon EP, Idzerda RL, McKnight GS (1997) PKA isoforms, neural pathways, and behaviour: making the connection. Curr Opin Neurobiol 7:397-403.

Bratanova-Tochkova TK, Cheng H, Daniel S, Gunawardana S, Liu YJ, Mulvaney-Musa J, Schermerhorn T, Straub SG, Yajima H, Sharp GW (2002) Triggering and augmentation mechanisms, granule pools, and biphasic insulin secretion. Diabetes Suppl1:S83-90.

Britsch S, Krippeit-Drews P, Lang F, Gregor M, Drews G (1995) Glucagon-like peptide-1 modulates $\mathrm{Ca}^{2+}$ current but not $\mathrm{K}^{+}$ATP current in intact mouse pancreatic B-cells. Biochem Biophys Res Commun 207:33-39.

Brose N, Hofmann K, Hata Y, Südhof TC (1995) Mammalian homologues of Caenorhabditis elegans unc-13 gene define novel family of $\mathrm{C}_{2}$-domain proteins. J Biol Chem 270:25273-25280.

Brose N, Rosenmund C, Rettig J (2000) Regulation of transmitter release by Unc-13 and its homologues. Curr Opin Cell Neurobiol 10:303-311.

Bruel-Jungerman E, Davis S, Laroche S (2007) Brain plasticity mechanisms and memory: a party of four. Neuroscientist 13:492-505.

Butcher RW, Sutherland EW (1962) Adenosine 3',5'-phosphate in biological materials. I. Purification and properties of cyclic 3',5'-nucleotide phosphodiesterase and use of this enzyme to characterize adenosine 3',5'phosphate in human urine. J Biol Chem 237:1244-1250.

Castellucci VF, Kandel ER, Schwartz JH, Wilson FD, Nairn AC, Greengard P (1980) Intracellular injection of the catalytic subunit of cyclic AMPdependent protein kinase stimulates facilitation of transmitter release underlying behavioral sensitization in Aplysia. Proc Natl Acad Sci USA 77:7492-7496.

Castellucci VF, Nairn A, Greengard P, Schwartz JH, Kandel ER (1982) Inhibitor of adenosine 3',5'-monophosphate-dependent protein kinase blocks presynaptic facilitation in Aplysia. J Neurosci 2:1673-1681.

Cecarelli B, Hurlbut WP, Mauro A (1972) Depletion of vesicles from frog neuromuscular junctions by prolonged tetanic stimulation. J Cell Biol 54:3038.

Cedar H, Kandel ER, Schwartz JH (1972) Cyclic adenosine monophosphate in the nervous system of Aplysia californica. I. Increased synthesis in response to synaptic stimulation. J Gen Physiol 60:558-569. 
Charles MA, Fanska R, Schmid FG, Forsham PH, Grodsky GM (1973) Adenosine 3',5'-monophosphate in pancreatic islets: glucose-induced insulin release. Science 179:569-571.

Charles MA, Lawecki J, Pictet R, Grodsky GM (1975) Insulin secretion. Interrelationships of glucose, cyclic adenosine 3',5'-monophosphate, and calcium. J Biol Chem 250:6134-6140.

Chavez-Noriega LE, Stevens CF (1994) Increased transmitter release at excitatory synapses produced by direct activation of adenylate cyclase in rat hippocampal slices. J Neurosci 14:310-317.

Chen X-H, Roper SN (2003) PKA and PKC enhance excitatory synaptic transmission in human dentate gyrus. J Neurophysiol 89:2482-2488.

Chevaleyre V, Heifets BD, Kaeser PS, Südhof TC, Castillo PE (2007) Endocannabinoid-mediated long-term plasticity requires cAMP/PKA signaling and RIM1 $\alpha$. Neuron 54:801-812.

Chi P, Greengard P, Ryan TA (2001) synapsin dispersion and reclustering during synaptic activity. Nat Neurosci 4:1187-1193.

Christensen AE, Selheim F, de Rooij J, Dremier S, Schwede F, Dao KK, Martinez A, Maenhaut C, Bos JL, Genieser H-G, Døskeland SO (2003) cAMP analog mapping of Epac1 and cAMP kinase. 278:35394-35402.

Clements JD, Bekkers JM (1997) Detection of spontaneous synaptic events with an optimally scaled template. Biophys J 73:220-229.

Collingridge GL, Isaac JTR, Wang YT (2004) Receptor trafficking and synaptic plasticity. Nat Rev Neurosci 5:952-962.

Cullere X, Shaw SK, Andersson L, Hirahashi J, Luscinskas FW, Mayadas TN (2005) Regulation of vascular endothelial barrier function by Epac, a cAMPactivated exchange factor for Rap GTPase. Blood 105:1950-1955.

Curry DL, Bennett LL, Richard A (1968) Dynamics of insulin secretion by the perfused rat pancreas. Endocrinology 83:572-582.

Daniel S, Noda M, Straub SG, Sharp GW (1999) Indentification of the docked granule pool responsible for the first phase of glucose-stimulated insulin secretion. Diabetes 48:1686-1690.

Dao KK, Teigen K, Kopperud R, Hodneland E, Schwede F, Christensen AE, Martinez A, Døskeland SO (2006) Epac1 and cAMP-dependent protein kinase holoenzyme have similar cAMP affinity, but their cAMP domains have distinct structural features and cyclic nucleotide recognition. J Biol Chem 281:21500-21511.

del Castillo J, Katz B (1954) Quantal components of the end-plate potential. J Physiol 124:560-573.

DeRiemer SA, Strong JA, Albert KA, Greengard P, Kaczmarek LK (1985) Enhamcement of calcium current in Aplysia neurons by phorbol ester and protein kinase C. Nature 313:313-316. 
de Rooij J, Zwartkruis FJT, Verheijen MHG, Cool RH, Nijman SMB, Wittinghofer A, Bos JL (1998) Epac is a Rap1 guanine-nucleotideexchange factor directly activated by cyclic AMP. Nature 396:474-477.

de Rooij J, Boenink NM, van Triest M, Cool RH, Wittinghofer A, Bos JL (1999) PDZ-GEF1, a guanine nucleotide exchange factor specific for Rap1 and Rap2. J Biol Chem 274:38125-38130.

de Rooij J, Rehmann H, van Triest M, Cool RH, Wittinghofer A, Bos JL (2000) Mechanism of regulation of the Epac family of cAMP-dependent RapGEFs. J Biol Chem 275:20829-20836.

Diamond JS, Jahr CE (1997) Transporters buffer synaptically released glutamate on a submillisecond time scale. J Neurosci 17:4672-4687.

Dingledine R, Borges K, Bowie D, Traynelis SF (1999) The glutamate receptor ion channels. Pharmacol Rev 51:7-61.

DiPilato LM, Cheng X, Zhang J (2004) Fluorescent indicators of cAMP and Epac activation reveal differential dynamics of CMP signaling within discrete subcellular compartments. Proc Natl Acad Sci USA 101:16513-16518.

Dobrunz LE, Stevens CF (1997) Heterogeneity of release probability, facilitation, and depletion at central synapses. Neuron 18:995-1008.

Dobrunz LE (2002) Release probability is regulated by the size of the readily releasable vesicle pool at excitatory synapses in hippocampus. Int J Dev Neurosci 20:225-236.

Dodge-Kafka KL, Soughayer J, Pare GC, Michel JJC, Langeberg LK, Kapiloff MS, Scott JD (2005) The protein kinase A anchoring protein mAKAP coordinates two integrated cAMP effector pathways. Nature 437:574-578.

Dodge-Kafka KL, Kapiloff MS (2006) The mAKAP signaling complex: integration of cAMP, calcium, and MAP kinase signaling pathways. Eur $\mathrm{J}$ Cell Biol 85:593-602.

Dulubova I, Lou X, Lu J, Huryeva I, Alam, A., Schneggenburger R, Südhof TC, Rizo J (2005) A Munc13/RIM/Rab3 tripartite complex: from priming to plasticity? EMBO J 24:2839-2850.

Eccles JC (1964) The physiology of the synapses. Academic Press, New York.

Edwards FA (1995) LTP - astructural model to explain the inconsistencies. TINS 18:250-255.

Eliasson L, Ma X, Renström E, Barg S, Berggren PO, Galvanovskis J, Gromada J, Jing X, Lundquist I, Salehi A, Sewing S, Rorsman P (2003) SUR1 regulates PKA-independent CAMP-induced granule priming in mouse pancreatic B-cells. J Gen Physiol 121:181-197.

Elmquist D, Quastel DM (1965) A quantitative study of end-plate potentials in isolated human muscle. J Physiol 178:505-529. 
Evellin S, Nolte J, Tysack K, vom Dorp F, Thiel M, Weernink PAO, Jakobs $\mathrm{KH}$, Webb EJ, Lomasney JW, Schmidt M (2002) Stimulation of phospholipase $\mathrm{C}-\varepsilon$ by the $\mathrm{M}_{3}$ muscarinic acetylcholine receptor mediated by cyclic AMP and the GTPase Rap2B. J Biol Chem 277:16805-16813.

Fasshauer D, Antonin W, Subramaniam V, Jahn R (2002) SNARE assembly and disassembly exhibit a pronounced hysteresis. Nat Struct Biol 9:144151.

Fasshauer D, Margittai M (2004) A transient N-terminal interaction of SNAP-25 and syntaxin nucleates SNARE assembly. J Biol Chem 279:7613-7621.

Fisher SA, Fischer TM, Carew TJ (1997) Multiple overlapping processes underlying short-term synaptic enhancement. TINS 20:170-177.

Fujimoto K, Shibasaki T, Yokoi N, Kashima Y, Matsumoto M, Sasaki T, Tajima N, Iwanaga T, Seino S (2002) Piccolo, a $\mathrm{Ca}^{2+}$ sensor in pancreatic $\beta$-cells. J Biol Chem 277:50497-50502.

Fukuhara S, Sakurai A, Sano H, Yamagishi A, Somekawa S, Takakura N, Saito Y, Kangawa K, Mochizuki N (2005) Cyclic AMP potentiates vascular endothelial cadherin-mediated cell-cell contact to enhance endothelial barrier function through an Epac-Rap1 signaling pathway. Mol Cell Biol 25:136-146.

Genoux D, Montgomery JM (2007) Glutamate receptor plasticity at excitatory synapses in the brain. Clin Exp Pharmacol Physiol 34:1058-1063.

Gesellchen F, Prinz A, Zimmermann B, Herberg FW (2006) Quantification of cAMP antagonist action in vitro and in living cells. Eur J Cell Biol 85:663672.

Goda Y, Stevens CF (1994) Two components of transmitter release at a central synapse. Proc Natl Acad Sci USA 91:12942-12946.

Goldberg AL, Singer JJ (1969) Evidence for a role of cyclic AMP in neuromuscular transmission. Proc Natl Acad Sci USA 64:134-141.

Gottmann K, Pfrieger FW, Lux HD (1994) The formation of glutamatergic synapses in cultured central neurons: selective increase in miniature synaptic currents. Dev Brain Res 81:77-88.

Gray EG (1963) Electron microscopy of presynaptic organelles of the spinal cord. J Anat 97:101-106.

Greengard P, Kuo JF, Miyamoto E (1970) Studies on the mechanism of action of cyclic AMP in nervous and other tissues. Adv Enzym Regul 9:113-125.

Greengard P, Valtorta F, Czernik AJ, Benfenati F (1993) Synaptic vesicle phosphoproteins and regulation of synaptic function. Science 259:780-785.

Guan R, Dai H, Rizo J (2008) Binding of the Munc13-1 MUN domain to membrane-anchored SNARE complexes. Biochemistry - ahead of print 
Gundelfinger ED, Kessels MM, Qualmann B (2003) Temporal and spatial coordination of exocytosis and endocytosis. Nat Rev Mol Cell Biol 4:127139.

Hamilton M, Liao J, Cathcart MK, Wolfman A (2001) Constitutive association of $\mathrm{c}-\mathrm{N}-\mathrm{R}$ as with $\mathrm{c}-\mathrm{Raf}-1$ and $\mathrm{PKC} \varepsilon$ in latent signalling modules. J Biol Chem 276:29079-29090.

Hanson PI, Heuser JE, Jahn R (1997) neurotransmitter release - four years of SNARE complexes. Curr Opin Neurobiol 7:310-315.

Hebb D (1949) The organization of behavior. Wiley, New York.

Heidelberger R, Heinemann C, Neher E, Matthews G (1994) Calcium dependence of the rate of exocytosis in a synaptic terminal. Nature 371 : 513-515.

Hell JW, Yokoyama CT, Breeze LJ, Chavkin C, Catterall WA (1995) Phosphorylation of presynaptic and postsynaptic calcium channels by cAMP-dependent protein kinase in hippocampal neurons. EMBO J 14:3036-3044.

Herman MA, Jahr CE (2007) Extracellular glutamate concentration in hippocampal slice. J Neurosci 27:9736-9741.

Heuser JE, Reese TS (1973) Evidence for recycling of synaptic vesicle membrane during transmitter release at the frog neuromuscular junction. 57:313-344.

Hilfiker S, Pieribone VA, Czernik AJ, Kao H-T, Augustine GJ, Greengard P (1999) Synapsins as regulators of neurotransmitter release. Phil Trans $R$ Soc Lond 354:269-279.

Hollmann M, Hartley M, Heinemann S (1991) $\mathrm{Ca}^{2+}$ permeability of KA-AMPAgated glutamate receptor channels depends on subunit composition. Science 252:851-853.

Holz GG (2004) Epac: A new cAMP-binding protein in support of glucagonlike peptide-1 receptor-mediated signal transduction in the pancreatic $\beta$ cell. Diabetes 53:5-13.

Holz GG, Kang G, Harbeck M, Roe MW, Chepurny OG (2006) Cell physiology of cAMP sensor Epac. J Physiol 577:5-15.

Holz GG, Chepurny OG, Schwede F (2008) Epac-selective cAMP analogs: New tools with which to evaluate the signal transduction properties of cAMP-regulated guanine nucleotide exchange factors. Cell Signal 20:10-20.

Houslay MD (1998) Adaptation in cyclic AMP signalling processes: a central role for cyclic AMP phosphodiesterases. Sem Cell Dev Biol 9:161-167.

Howe DG, Wiley JC, McKnight GS (2002) Molecular and behavioral effects of a null mutation in all PKA C $\beta$ isoforms. Mol Cell Neurosci 20:515-524. 
Howell SL, Jones PM, Persaud SJ (1994) Regulation of insulin secretion: the role of second messengers. Diabetologia 37 Suppl1:S30-35.

Hu H-J, Glauner KS, Gereau IV RW (2003a) ERK integrates PKA and PKC signaling in superficial dorsal horn neurons. I. Modulation of A-type $\mathrm{K}^{+}$ currents. J Neurophysiol 90:1671-1679.

Hu H-J, Gereau IV RW (2003b) ERK integrates PKA and PKC signaling in superficial dorsal horn neurons. II. Modulation of neuronal excitability. J Neurophysiol 90:1680-1688.

Huang C-C, Hsu K-S (2006) Presynaptic mechanism underlying cAMP-induced synaptic potentiation in medial prefrontal cortex pyramidal neurons. Mol Pharmacol 69:846-856.

Huang YY, Kandel ER, Varshavsky L, Brandon EP, Qi M (1995) A genetic test of the of mutations in PKA on mossy fiber LTP and its relation to spatial and contextual learning. Cell 83:1211-1222.

Hucho TB, Dina OA, Levine JD (2005) Epac mediates a cAMP-to-PKC signaling in inflammatory pain: an isolectin $B 4(+)$ neuron-specific mechanism. J Neurosci 25:6119-6126.

lezzi M, Escher G, Meda P, Charollais A, Baldini G, Darchen F, Wollheim CB, Regazzi R (1999) Subcellular distribution and function of Rab3A, B, C, and $D$ isoforms in insulin-secreting cells. Mol Endocrinol 13:202-212.

Jahn R, Grubmüller H (2002) Membrane fusion. Curr Opin Cell Biol 14:488495.

Jahn R, Lang T, Südhof TC (2003) Membrane fusion. Cell 112:519-533.

Johnson EM, Ueda T, Maeno H, Greengard P (1972) Adenosine 3',5monophosphate-dependent phosphorylation of a specific protein in synaptic membrane fractions from rat cerebrum. J Biol Chem 247:56505652.

Jovanovic JN, Sihra TS, Nairn AC, Hemmings Jr HC, Greengard P, Czernik AJ (2001) Opposing changes in phosphorylation of specific sites in synapsin I during $\mathrm{Ca}^{2+}$-dependent glutamate release in isolated nerve terminals. J Neurosci 21:7944-7953.

Kaczmarek L, Kossut M, Skangiel-Kramska J (1997) Glutamate receptors in cortical plasticity: molecular and cellular biology. Pharmacol Rev 77:217255.

Kakiuchi S, Rall TW, Mcllwain H (1969) The effect of electrical stimulation upon the accumulation of adenosine 3',5'-phosphate in isolated cerebral tissue. J Neurochem 16:485-491.

Kamp TJ, Hell JW (2000) Regulation of cardiac L-type calcium channels by protein kinase A and protein kinase C. Circ Res 87:1095-1102. 
Kaneko M, Takahashi T (2004) Presynaptic mechanism underlying cAMPdependent synaptic potentiation. J Neurosci 24:5202-5208.

Kang G, Chepurny OG, Malester B, Rindler MJ, Rehmann H, Bos JL, Schwede F, Coetzee WA, Holz GG (2006) cAMP sensor Epac as a determinant of ATP-sensitive potassium channel activity in human pancreatic beta cells and rat INS-1 cells. J Physiol 573:595-609.

Kanno T, Suga S, Wu J, Kimura M, Wakui M (1998) Intracellular cAMP potentiates voltage-dependent activation of L-type $\mathrm{Ca}^{2+}$ channels in rat islet beta-cells. Pflügers Arch 435:578-580.

Kashima Y, Miki T, Shibasaki T, Ozaki N, Miyazaki M, Yano H, Seino S (2001) Critical role of cAMP-GEFII-Rim2 complex in incretin-potentiated insulin secretion. J Biol Chem 276:46046-46053.

Katz B, Miledi R (1968) The role of calcium in neuromuscular facilitation. J Physiol 195:481-492.

Katz B (1969) The release of neural transmitter substances. Liverpool University Press, Liverpool.

Katz B, Miledi (1969) Tetrodotoxin-resistant electric activity in presynaptic terminals. J Physiol 203:459-487.

Kawasaki H, Springett GM, Mochizuki N, Toki S, Nakaya M, Matsuda M, Housman DE, Graybiel AM (1998) A family of cAMP-binding proteins that directly activate Rap1. Science 282:2275-2279.

Kingston PA, Zufall F, Barnstable CJ (1996) Rat hippocampal neurons express genes for both rod retinal and olfactory cyclic nucleotide-gated channels: novel targets for cAMP/cGMP function. Proc Natl Acad Sci USA 93:10440-10445.

Klausner RD, Donaldson JG, Lippincott-Schwartz J (1992) Brefeldin A: Insights into the control of membrane traffic and organelle structure. J Cell Biol 116:1071-1080.

Klein PS, Sun TJ, Saxe CL, Kimmel AR, Johnson RL, Deverotes PN (1988) Science 241:1467-1472.

Klein PS, Sun TJ, Saxe CL, Kimmel AR, Johnson RL, Deverotes PN (1988) A chemoattractant receptor controls development in dictyostelium discoideum. Science 241:1467-1472.

Kooistra MR, Corada M, Dejana E, Bos JL (2005) Epac1 regulates integrity of endothelial cell junctions through VE-cadherin. FEBS Lett 579:4966-4972.

Kopp C, Longordo F, Lüthi A (2007) Experience-dependent changes in NMDA receptor composition at mature central synapses. Neuropharmacology 53:1-9.

Kraemer A, Rehmann HR, Cool RH, Theiss C, de Rooij J, Bos JL, Wittinghofer A (2001) Dynamic interaction of cAMP with the Rap guaninenucleotide exchange factor Epac1. J Mol Biol 306:1167-1177. 
Krebs EG (1983) Historical perspectives on protein phosphorylation and classification system for protein kinases. Philos Trans R Soc Lond B Biol Sci 302:3-11.

Kuo JF, Greengard P (1969) Cyclic nucleotide-dependent protein kinases, IV. Widespread occurrence of adenosine 3',5'-monophosphate-dependent protein kinase in various tissues and phyla of the animal kingdom. Proc Natl Acad Sci USA 64:1349-1355.

Kwan EP, Xie L, Sheu L, Ohtsuka T, Gaisano HY (2007) Interaction between Munc13-1 and RIM is critical for glucagon-like peptide-1 mediated rescue of exocytosis defects in Munc13-1 deficient pancreatic beta-cells. Diabetes 56:2579-2588.

Laemmli UK (1970) Cleavage of structural proteins during the assembly of the head of bacteriophage T4. Nature 227:680-685.

Landa LR Jr, Harbeck M, Kaihara K, Chepurny O, Kitiphongspattana K, Graf O, Nikolaev VO, Lohse MJ, Holz GG, Roe MW (2005) Interplay of $\mathrm{Ca}^{2+}$ and cAMP signaling in the insulin-secreting MIN6 beta-cell line. J Biol Chem 280:31294-31302.

Laxman S, Riechers A, Sadilek M, Schwede F, Beavo JA (2006) Hydrolysis products of cAMP analogs cause transformation of Trypanosoma brucei from slender to stumpy-like forms. Proc Natl Acad Sci USA 103:1919419199.

Lee H-W, Smith L, Pettit GR, Smith JB (1997) Bryostatin 1 and phorbol ester down-modulate protein kinase $\mathrm{C}-\alpha$ and $-\varepsilon$ via the ubiquitin/proteasome pathway in human fibroblasts. Mol Pharmacol 51:439-447.

Leenders AGM, Sheng Z-H (2005) Modulation of neurotransmitter release by the second messenger-activated protein kinases: implications for presynaptic plasticity. Pharmacology \& Therapeutics 105:69-84.

Leßmann V, Heumann R (1997) Cyclic AMP endogenously enhances synaptic strength of developing glutamatergic synapses in serum-free microcultures of rat hippocampal neurons. Brain Res 763:111-122.

Li Y, Asuri S, Rebhun JF, Castro AF, Paranavitana NC, Quilliam LA (2006) The Rap1 guanine nucleotide exchange factor Epac2 couples cyclic AMP and Ras signals at the plasma membrane. J Biol Chem 281:2506-2514.

Lippincott-Schwartz J, Glickman J, Donaldson JG, Robbins J, Kreis TE, Seamon KB, Sheetz MP, and Klausner RD (1991) Forskolin inhibits and reverses the effects of brefeldin A on Golgi morphology by a cAMPindependent mechanism. J Cell Biol 112:567-577.

Littleton JT (2006) Mixing and matching during synaptic vesicle endocytosis. Neuron 51:149-155.

Lonart G (2002) RIM1: an edge for presynaptic plasticity. TINS 25:329-332. 
Ludwig A, Zong X, Jeglitsch M, Hofmann F, Biel M (1998) A family of hyperpolarization-activated mammalian cation channels. Nature 393:587591.

Maillet M, Robert SJ, Cacquevel M, Gastineau M, Vivien D, Bertoglio J, Zugaza JL, Fischmeister R, Lezoualc'h F (2003) Crosstalk between Rap1 and Rac regulates secretion of sAPP $\alpha$. Nat Cell Biol 5:633-639.

Malenka RC, Madison DV, and Nicoll RA (1986) Potentiation of synaptic transmission in the hippocampus by phorbol ester. Nature 321:175-177.

Malenka RC (2003) The long-term potential of LTP. Nat Rev Neurosci 4:923926.

Malinow R, Malenka RC (2002) AMPA receptor trafficking and synaptic plasticity. Annu Rev Neurosci 25:103-126.

Mansuy, I. A constraint on cAMP signaling. Neuron 41, 4-6 (2004).

Margarit SM, Sondermann H, Hall BE, Nagar B, Hoelz A, Pirruccello M, Bar-Sagi D, Kuriyan J (2003) Structural evidence for feedback activation by Ras.GTP of the Ras-specific nucleotide exchange factor SOS. Cell 112:685-695.

Martemyanov KA, Lishko PV, Calero N, Keresztes G, Sokolov M, Strissel KJ, Leskov IB, Hopp JA, Kolesnikov AV, Chen C-K, Lem J, Heller S, Burns ME, Arshavsky VY (2003) The DEP domain determines subcellular targeting of the GTPase activating protein RGS9 in vivo. J Neurosci 23:10175-10181.

Martin TFJ (2003) Tuning exocytosis for speed: fast and slow modes. Biochim Biophys Acta 1641:157-165.

Matteoli M, Takei K, Cameron R, Hurlbut P, Johnston PA, Südhof TC, Jahn R, De Camilli P (1991) Association of Rab3A with synaptic vesicles at late stages of the secretory pathway. J Cell Biol 115:625-633.

Matthies HJG, Palfrey HC, Hirning LD, Miller RJ (1987) Down regulation of protein kinase $\mathrm{C}$ in neuronal cells: effects on neurotransmitter release. $\mathrm{J}$ Neurosci 7:1198-1206.

Matulef K, Zagotta WN (2003) Cyclic nucleotide-gated ion channels. Annu Rev Cell Dev Biol 19:23-44.

Mayford M (2007) Protein kinase signaling in synaptic plasticity and memory. Curr Opin Neurobiol 17:313-317.

McKnight GS, Cadd GG, Clegg CH, Otten AD, Correll LA (1988) Expression of wild-type and mutant subunits of the cAMP-dependent protein kinase. Cold Spring Harb Symp Quant Biol 53:111-119.

McKnight GS, Uhler MD, Clegg CH, Correll LA, Cadd GG (1988) Application of molecular genetic techniques to the cAMP-dependent protein kinase system. Methods Enzymol 159:299-311. 
Medine CN, Rickman C, Chamberlain LH, Duncan RR (2007) Munc18-1 prevents the formation of ectopic SNARE complexes in living cells. J Cell Sci 120:4407-4415.

Melançon P, Glick BS, Malhotra V, Weidman PJ, Serafini T, Rothman JE (1987). Involvement of GTP-binding " $G$ " proteins in transport through the Golgi stack. Cell 51:1053-1062.

Menegon A, Bonanomi D, Albertinazzi C, Lotti F, Ferrari G, Kao H-T, Benfenati F, Baldelli P, Valtorta F (2006) Protein kinase A-mediated synapsin I phosphorylation is a central modulator of $\mathrm{Ca}^{2+}$-dependent synaptic activity. J Neurosci 26:11670-11681.

Miyamoto E, Kuo JF, Greengard P (1969a) Adenosine 3',5'-monophosphatedependent protein kinase from brain. Science 165:63-65.

Miyamoto E, Kuo JF, Greengard P (1969b) Cyclic nucleotide-dependent protein kinases. III. Purification and properties of adenosine 3',5'monophosphate-dependent protein kinase from bovine brain. J Biol Chem 244:6395-6402.

Morales M, Colicos MA, Goda Y (2000) actin-dependent regulation of neurotransmitter release at central synapses. Neuron 27:539-550.

Morgan MR, Humphries MJ, Bass MD (2007) Synergistic control of cell adhesion by integrins and syndecans. Nat Rev Mol Cell Biol 8:957-969.

Moulder KL, Mennerick S (2005) Reluctant vesicles contribute to the total readily releasable pool in glutamatergic hippocampal neurons. J Neurosci 25:3842-3850.

Mozhayeva MG, Sara Y, Liu X, Kavalali ET (2002) Development of vesicle pools during maturation of hippocampal synapses. J Neurosci 22:654-665.

Murthy VN, Schikorski T, Stevens CF, Zhu Y (2001) Inactivity produces increases in neurotransmitter release and synapse size. Neuron 32:673682.

Murthy VN, De Camilli P (2003) Cell biology of the presynaptic terminal. Annu Rev Neurosci 26:701-728.

Nagy G, Reim K, Matti U, Brose N, Binz T, Rettig J, Neher E, Sørensen JB (2004) Regulation of releasable vesicle pool sizes by protein kinase Adependent phosphorylation of SNAP-25. Neuron 41:351-365.

Neher E, Zucker RS (1993) Multiple calcium-dependent processes related to secretion in bovine chromaffin cells. Neuron 10:21-30.

Nguyen PV, Woo NH (2003) Regulation of hippocampal synaptic plasticity by cyclic AMP-dependent protein kinases. Prog Neurobiol 71:401-437.

Nicholson KL, Munson M, Miller RB, Filip TJ, Fairman R, Hughson FM (1998) regulation of SNARE complex assembly by an $\mathrm{N}$-terminal domain of the t-SNARE Sso1p. Nat Struct Biol 5:793-802. 
Nili U, de Wit H, Gulyas-Kovacs A, Toonen RF, Sørensen JB, Verhage M, Ashery $U$ (2006) Munc18-1 phosphorylation by protein kinase $C$ potentiates vesicle pool replenishment in bovine chromaffin cells. Neuroscience 143:487-500.

Nowak L, Bregestovski P, Ascher P (1984) Magnesium gates glutamateactivated channels in mouse central neurons. Nature 307:462-465.

Ozaki N, Shibasaki T, Kashima Y, Miki T, Takahashi K, Ueno H, Sunaga Y, Yano H, Matsuura Y, Iwanaga T, Takai Y, Seino S (2000) cAMP-GEFII is a direct target of cAMP in regulated exocytosis. Nat Cell Biol 2:805-811.

Pak Y, Pham N, Rotin D (2002) Direct binding of the $\beta 1$ adrenergic receptor to the cyclic AMP-dependent guanine nucleotide exchange factor CNrasGEF leads to Ras activation. Mol Cell Biol 22:7942-7952.

Palay SL, Palade GE (1955) The fine structure of neurons. J Biophysic Biochem Cytol 1:69-88.

Palay SL (1956) Synapses in the central nervous system. J Biophys Biochem Cytol 2:193-207.

Parent A, Schrader K, Munger SD, Reed RR, Linden DJ, Ronnett GV (1998) Synaptic transmission and hippocampal long-term potentiation in olfactory cyclic nucleotide-gated channel type 1 null mouse. J Neurophysiol 79:329532301.

Parfitt KD, Madison DV (1993) Phorbol esters enhance synaptic transmission by a presynaptic, calcium-dependent mechanism in rat hippocampus. J Physiol 471:245-268.

Passner JM, Schultz SC, Steitz TA (2000) Modeling the cAMP-induced allosteric transition using the crystal structure of CAP-cAMP at $2.1 \AA$ resolution. J Mol Biol 304:847-859.

Ponsioen B, Zhao J, Riedl J, Zwartkruis F, van der Krogt G, Zaccolo M, Moolenaar WH, Bos JL, Jalink K (2004) Detecting cAMP-induced Epac activation by fluorescence resonance energy transfer: Epac as a novel cAMP indicator. EMBO Reports 5:1176-1180.

Pozzi D, Condliffe S, Bozzi Y, Chikhladze M, Grumelli C, Proux-Gillardeaux V, Takahashi M, Franceschetti S, Verderio C, Matteoli M (2008) activitydependent phosphorylation of Ser187 is required for SNAP-25-negative modulation of neuronal voltage-gated calcium channels. Proc Natl Acad Sci USA 105:323-328.

Prentki M, Matschinsky FM (1987) $\mathrm{Ca}^{2+}$, cAMP, and phospholipid-derived messengers in coupling mechanisms of insulin secretion. Physiol Rev 67:1185-1248.

Quastel DMJ (1997) The binomial model in fluctuation analysis of quantal neurotransmitter release. Biophys J 72:726-753. 
Qi M, Zhuo M, Skålhegg BS, Brandon EP, Kandel ER, McKnight GS, Idzerda $\mathrm{RL}$ (1996) Impaired hippocampal plasticity in mice lacking the $C \beta_{1}$ catalytic subunit of cAMP-dependent protein kinase. Proc Natl Acad Sci USA 93:1571-1576.

Quilliam LA, Rebhun JF, Castro AF (2002) A growing family of guanine nucleotide exchange factors is responsible for activation of Ras-family GTPases. Prog Nucleic Acid Res Mol Biol 71:391-444.

Rahamimoff R, Yaari Y (1973) Delayed release of transmitter at the frog neuromuscular junction. J Physiol 228:241-257.

Rall TW, Sutherland EW (1958) Formation of a cyclic adenine ribonucleotide by tissue particles. J Biol Chem 232:1065-1076.

Rall TW, Sutherland EW (1962) Adenyl cyclase. II. The enzymatically catalyzed formation of adenosine 3',5'-phosphate and inorganic pyrophosphate from adenosine triphosphate. J Biol Chem 237:1228-1232.

Rampe D, Triggle DJ, Brown AM (1987) Electrophysiologic and biochemical studies on the putative $\mathrm{Ca}^{2+}$ channel blocker MDL 12,330A in a endocrine cell. J Pharmacol Exp Ther 243:402-407.

Rangarajan S, Enserink JM, Kuiperij HB, de Rooij J, Price LS, Schwede F, Bos JL (2003) Cyclic AMP induces integrin-mediated cell adhesion through Epac and Rap1 upon stimulation of the $\beta_{2}$-adrenergic receptor. J Cell Biol 4:487-493.

Regehr WG, Delaney KR, Tank DW (1994) The role of presynaptic calcium in short-term enhancement at the hippocampal mossy fiber synapse. J Neurosci 14:523-537.

Rehmann H, Rueppel A, Bos JL, Wittinghofer A (2003) Communication between the regulatory and the catalytic region of the cAMP-responsive guanine nucleotide exchange factor Epac. J Biol Chem 278:23508-23514.

Rehmann H, Schwede F, Døskeland SO, Wittinghofer A, Bos JL (2003b) Ligand-mediated activation of the cAMP-responsive guanine nucleotide exchange factor Epac. J Biol Chem 278:38548-38556.

Renström E, Eliasson L, Rorsman P (1997) Protein kinase A-dependent and independent stimulation of exocytosis by cAMP in mouse pancreatic Bcells. J Physiol 502:105-118.

Rhee J-S, Betz A, Pyott S, Reim K, Varoqueaux F, Augustin I, Hesse D, Südhof TC, Takahashi M, Rosenmund C, Brose N (2002) $\beta$ phorbol esterand diacylglycerol-induced augmentation of transmitter release is mediated by Munc13s and not PKCs. Cell 108:121-133.

Richmond JE, Davis WS, Jorgensen EM (1999) UNC-13 is required for synaptic vesicle fusion in C. elegans. Nat Neurosci 2:959-964. 
Richmond JE, Weimer RM, Jorgensen EM (2001) The open form of syntaxin bypasses the requirement for UNC-13 in vesicle priming. Nature 412:338341.

Rizzoli SO, Betz WJ (2005) Synaptic vesicle pools. Nat Rev Neurosci 6:57-69.

Robert S, Maillet M, Morel E, Launay J-M, Fischmeister R, Mercken L, Lezoualc'h $F$ (2005) regulation of the amyloid precursor protein ectodomain shedding by 5- $\mathrm{HT}_{4}$ receptor and Epac. FEBS Lett 579:1136-1142.

Roscioni SS, Elzinga CRS, Schmidt M (2007) Epac: effectors and biological functions. Naunyn-Schmiedeberg's Arch Pharmacol - ahead of print

Rosenmund C, Clements JD, Westbrook GL (1993) Nonuniform probability of glutamate release at a hippocampal synapse. Science 262:754-757.

Rosenmund C, Feltz A, Westbrook GL (1995) Synaptic NMDA receptor channels have a low open probability. J Neurosci 15:2788-2795.

Rosenmund C, Stevens CF (1996) Definition of the readily releasable pool of vesicles at hippocampal synapses. Neuron 16:1197-1207.

Rosenmund C, Sigler A, Augustin I, Reim K, Brose N, Rhee J-S (2002) Differential control of vesicle priming and short-term plasticity by Munc13 isoforms. Neuron 33:411-424.

Rotenberg A, Abel T, Hawkins RD, Kandel ER, Muller RU (2000) Parallel instabilities of long-term potentiation, place cells, and learning caused by decreased protein kinase A activity. J Neurosci 20:8096-8102.

Ryan TA (2006) A pre-synaptic to-do list for coupling exocytosis to endocytosis. Curr Opin Cell Biol 18:416-421.

Sakaba T, Neher E (2001a) Quantitative relationship between transmitter release an $\mathrm{d}$ calcium current at the calyx of Held synapse. J Neurosci 21:462-476.

Sakaba T, Neher E (2001b) Calmodulin mediates rapid recruitment of fastreleasing synaptic vesicles at a calyx-type synapse. Neuron 32:1119-1131.

Sakaba T, Neher E (2001c) Preferential potentiation of fast-releasing synaptic vesicles by cAMP at the calyx of Held. Proc Natl Acad Sci USA 98:331336.

Sakaba T, Neher E (2003) Direct modulation of synaptic vesicle priming by $\mathrm{GABA}_{B}$ receptor activation at a glutamatergic synapse. Nature 424:775778.

Schikorski T, Stevens CF (1997) Quantitative ultrastructural analysis of hippocampal excitatory synapses. J Neurosci 17:5858-5867.

Schikorski T, Stevens CF (2001) Morphological correlates of functionally defined synaptic vesicle populations. Nat Neurosci 4:391-395. 
Schikorski T, Young SM, Jr, Hu Y (2007) Horseradish peroxidase cDNA as a marker for electron microscopy in neurons. J Neurosci Methods 165:210215.

Schmidt M, Evellin S, Weernink PAO, vom Dorp F, Rehmann H, Lomasney JW, Jakobs KH (2001) A new phospholipase-C-calcium signalling pathway mediated by cyclic AMP and a Rap GTPase. Nat Cell Biol 3:1020-1024.

Searl TJ, Silinsky EM (2003) Phorbol esters and adenosine affect the readily releasable neurotransmitter pool by different mechanisms at amphibian motor nerve endings. J Physiol 553:445-456.

Sedej S, Rose T, Rupnik M (2005) cAMP increases $\mathrm{Ca}^{2+}$-dependent exocytosis through both PKA and Epac2 in mouse melanotrophs from pituitary tissue slices. J Physiol 567:799-813.

Seino S, Shibasaki T (2006) PKA-dependent and Pka-independent pathways for cAMP-regulated exocytosis. Physiol Rev 85:1303-1342.

Sheng M, Hoogenraad CC (2007) The postsynaptic architecture of excitatory synapses: a more quantitative view. Annu Rev Biochem 76:823-847.

Shibasaki T, Sunaga Y, Fujimoto K, Kashima Y, Seino S (2004) Interaction of ATP sensor, cAMP sensor, $\mathrm{Ca}^{2+}$ sensor, and voltage-dependent $\mathrm{Ca}^{2+}$ channel in insulin granule exocytosis. J Biol Chem 279:7956-7961.

Shimizu H, Creveling CR, Daly J (1970) Stimulated formation of adenosine 3',5'-cyclic phosphate in cerebral cortex: synergism between electrical activity and biogenic amines. Proc Natl Acad Sci USA 65:1033-1040.

Siegelbaum SA, Camardo JS, Kandel ER (1982) Serotonin and cyclic AMP close single $\mathrm{K}^{+}$channels in Aplysia sensory neurones. Nature 299:413-417.

Siggins GR, Hoffer BJ, Bloom FE (1969) Cyclic adenosine monophosphate: possible mediator for norepinephrine effects on cerebellar purkinje cells. Science 165:1018-1020.

Silver RA, Traynelis SF, Cull-Candy SG (1992) Rapid-time-course miniature and evoked excitatory currents at cerebellar synapses in situ. Nature 355:163-166.

Skålhegg BS, Tasken K (2000) Specificity in the cAMP/PKA signaling pathway, differential expression, regulation, and subcellular localization of subunits of PKA. Frontiers Biosci 5:678-693.

Slepnev VI, De Camilli P (2000) Accessory factors in clathrin-dependent synaptic vesicle endocytosis. Nat Rev Neurosci 1:161-172.

Soderling TR (2000) CaM-kinases: modulators of synaptic plasticity. Curr Opin Neurobiol 10:375-380.

Solem M, McMahon T, Messing RO (1997) Protein kinase A regulates inhibition of $\mathrm{N}$ - and $\mathrm{P} / \mathrm{Q}$-type calcium channels by ethanol in PC12 cells. J Pharmacol Exp Ther 282:1487-1495. 
Spruston N, Jonas P, Sakmann B (1995) Dendritic glutamate receptor channels in rat hippocampal CA3 and CA1 pyramidal neurons. J Physiol 482:325-352.

Südhof T (1995) The synaptic vesicle cycle: a cascade of protein-protein interactions. Nature 375:645-653.

Südhof T (2004) The synaptic vesicle cycle. Annu Rev Neurosci 27:509-547.

Sudlow LC, Gilette R (1997) Cyclic AMP levels, adenylyl cyclase activity, and their stimulation by serotonin quantified in intact neurons. J Gen Physiol 110:243-255.

Sutherland EW, Rall TW (1958) Fractionation and characterization of a cyclic adenine ribonucleotide formed by tissue particles. J Biol Chem 232:10771091.

Sutherland EW, Rall TW, Menon T (1962) Adenyl cyclase. I. Distribution, preparation, and properties. J Biol Chem 237:1220-1227.

Sutherland EW, Øye I, Butcher RW (1965) The action of epinephrine and the role of the adenyl cyclase system in hormone action. Recent Prog Hormone Res 21:623-646.

Sutherland EW, Robinson GA (1966) The role of cyclic-3',5'-AMP in responses to catecholamines and other hormones. Pharmacol Rev 18:145161.

Stevens CF, Sullivan JM (1998) Regulation of the readily releasable vesicle pool by protein kinase C. Neuron 21:885-893.

Swartz KJ (1993) Modulation of $\mathrm{Ca}^{2+}$ channels by protein kinase $\mathrm{C}$ in rat central and peripheral neurons: Disruption of $G$ protein-mediated inhibition. Neuron 11:305-320.

Takamori S, Holt M, Stenius K, Lemke EA, Grønborg M, Riedel D, Urlaub H, Schenck S, Brügger B, Ringler P, Müller SA, Rammner B, Gräter F, Hub JS, De Groot BL, Mieskes G, Moriyama Y, Klingauf J, Grubmüller H, Heuser J, Wieland F, Jahn R (2006) Molecular anatomy of a trafficking organelle. Cell 127:831-846.

Toonen RFG (2003) Role of munc18-1 in synaptic vesicle and large dense-core vesicle secretion. Biochem Soc Trans 31:848-850.

Trudeau L-E, Emery DG, Haydon PG (1996) Direct modulation of the secretory machinery underlies PKA-dependent synaptic facilitation in hippocampal neurons. Neuron 17:789-797.

Varoqueaux F, Sigler A, Rhee J-S, Brose N, Enk C, Reim K, Rosenmund C (2002) Total arrest of spontaneous and evoked synaptic transmission but normal synaptogenesis in the absence of Munc13-mediated vesicle priming. Proc Natl Acad Sci USA 99:9037-9042.

Verhage M, Maia AS, Plomp JJ, Brussaard AB, Heeroma JH, Vermeer $H$, Toonen RF, Hammer RE, van den Berg TK, Missler M, Geuze HJ, Südhof 
TC (2000) Synaptic assembly of the brain in the absence of neurotransmitter secretion. Science 287:864-869.

Villacres EC, Wong ST, Chavkin C, Storm DR (1998) Type I adenylyl cyclase mutant mice have impaired mossy fibre long-term potentiation. J Neurosci 18:3186-3194.

Vincent P, Brusciano D (2001) Cyclic AMP imaging in neurones in brain slice preparations. J Neurosci Methods 108:189-198.

Voets T, Toonen RF, Brian EC, de Wit H, Moser T, Rettig J, Südhof TC, Neher E, Verhage M (2001) Munc18-1 promotes large dense-core vesicle docking. Neuron 31:581-591.

vom Dorp F, Sari AY, Sanders H, Keiper M, Weernink PAO, Jakobs KH, Schmidt M (2004) Inhibition of phospholipase $C-\varepsilon$ by $\mathrm{G}_{\mathrm{i}}$-coupled receptors. Cell Signal 16:921-928.

Waites CL, Craig AM, Garner CC (2005) Mechanisms of vertebrate synaptogenesis. Annu Rev Neurosci 28:251-274.

Walsh DA, Perkins JP, Krebs EG (1968) An adenosine 3',5'-monophosphatedependant protein kinase from rabbit skeletal muscle. J Biol Chem 13:3763-3774.

Walworth NC, Goud B, Kabcenell K, Novick PJ (1989) Mutational analysis of SEC4 suggests a cyclical mechanism for the regulation of vesicular traffic. EMBO J 8:1685-1693.

Wang M, Ramos BP, Paspalas CD, Shu Y, Simen A, Duque A, Vijayraghavan S, Brennan A, Dudley A, Nou E, Mazer JA, McCormick DA, Arnsten AFT (2007) a2A-Adrenoceptors strengthen working memory networks by inhibiting cAMP-HCN channel signaling in prefrontal cortex. Cell 129:397410.

Waters J, Smith SJ (2000) Phorbol esters potentiate evoked and spontaneous release by different presynaptic mechanisms. J Neurosci 20:7863-7870.

Weber T, Zemelman BV, McNew JA, Westermann B, Gmachl M, Partati F, Söllner TH, Rothman JE (1998) SNAREpins: minimal machinery for membrane fusion. Cell 92:759-772.

Wei JY, Roy DS, Leconte L, Barnstable CJ (1998) Molecular and pharmacological analysis of cyclic nucleotide-gated channel function in the central nervous system. Prog Neurobiol 56:37-64.

Weisskopf MG, Zalutsky RA, Nicoll RA (1993) The opioid peptide dynorphin mediates heterosynaptic depression of hippocampal mossy fiber synapses and modulates long-term potentiation. Nature 362:423-427.

Weisskopf MG, Castillo PE, Zalutsky RA, Nicoll RA (1994) Mediation of hippocampal mossy fiber long-term potentiation by cyclic AMP. Science 265:1878-1882. 
Wennerberg K, Rossman KL, Der CJ (2005) The Ras superfamily at a glance. J Cell Sci 118:843-846.

Wierda KDB, Toonen RFG, de Wit H, Brussaard AB, Verhage M (2007) Interdependence of PKC-dependent and PKC-independent pathways for presynaptic plasticity. Neuron 54:275-290.

Willoughby D, Cooper DM (2006) $\mathrm{Ca}^{2+}$ stimulation of adenylyl cyclase generates dynamic oscillations in cyclic AMP. J Cell Sci 119:828-836.

Wing MR, Bourdon DM, Harden TK (2003) PLC- $\varepsilon$ : A shared effector protein in Ras-, Rho-, and G $\alpha \beta \gamma$-mediated signaling. Mol Interv 3:273-280.

Wong ST, Athos J, Figueroa XA, Pineda VV, Schaefer ML, Chavkin CC, Muglia LJ, Storm DR (1999) Calcium-stimulated adenylyl cyclase activity is critical for hippocampus-dependent long-term memory and late phase LTP. Neuron 23:787-798.

Wu ZL, Thomas SA, Villacres EC, Xia Z, Simmons ML, Chavkin C, Palmiter RD, Storm DR (1995) Altered behaviour and long-term potentiation in type I adenylyl cyclase mutant mice. Proc Natl Acad Sci USA 92:220-224.

Yaekura K, Julyan R, Wicksteed BL, Hays LB, Alarcon C, Sommers S, Poitout V, Baskin DG, Wang Y, Philipson LH, Rhodes CJ (2003) J Biol Chem Insulin secretory deficiency and glucose intolerance in Rab3A null mice. J Biol Chem 278:9715-9721.

Yamashita T, Ishikawa T, Takahashi T (2003) Developmental increase in vesicular glutamate content does not cause saturation of AMPA receptors at the Calyx of Held synapse. J Neurosci 23:3633-3638.

Yarwood SJ (2005) Microtubule-associated proteins (MAPs) regulate cAMP signalling through exchange protein directly activated by cAMP (Epac). Biochem Soc Trans 33:1327-1329.

Yau KW (1994) Cyclic nucleotide-gated channels: an expanding new family of ion channels. Proc Natl Acad Sci USA 91:3481-3.

Yeckel MF, Kapur A, Johnston D (1999) Multiple forms of LTP in hippocampal CA3 neurons use a common postsynaptic mechanism. Nat Neurosci 2:625633.

Zaccolo M, Magalhaes P, Pozzan T (2002) Compartmentalisation of cAMP and $\mathrm{Ca}^{2+}$ signals. Curr Opin Cell Biol 14:160-166.

Zakharenko SV, Zablow L, Siegelbaum SA (2001) Visualization of changes in presynaptic function during long-term synaptic plasticity. Nat Neurosci 4:711-717.

Zalutsky RA, Nicoll RA (1990) Comparison of two forms of long-term potentiation in single hippocampal neurons. Science 248:1619-1624.

Zhong N, Zucker RS (2005) cAMP acts on exchange protein activated by cAMP/cAMP-regulated guanine nucleotide exchange protein to regulate 
transmitter release at the crayfish neuromuscular junction. $\mathrm{J}$ Neurosci 25:208-214.

Zucker RS, Regehr WG (2002) Short-term synaptic plasticity. Annu Rev Physiol 64:355-405.

Zufall F, Shepherd GM, Barnstable CJ (1997) Cyclic nucleotide gated channels as regulators of CNS development and plasticity. Curr Opin Neurobiol 7:404-412. 


\section{APPENDIX}

\section{A. Parameters of the Perfusion System}

Table 2 Flow rates of the perfusion system. Diameter of a single flow tube $\sim 404 \mu \mathrm{m}$. A: measured from the valve center; B: measured from the bottom of the reservoir

length [m]

\begin{tabular}{|c|c|c|c|c|c|c|c|}
\hline tube & repeat & time [s] & $\mathrm{H} 2 \mathrm{O}[\mathrm{g}]$ & $m L / m i n$ & $\mathrm{~m} / \mathrm{sec}$ & $A$ & $B$ \\
\hline \multirow[t]{3}{*}{1} & 1 & 241 & 2.08 & 0.52 & 0.07 & 1.15 & 1.34 \\
\hline & 2 & 424 & 3.71 & 0.53 & 0.07 & & \\
\hline & 3 & 403 & 3.67 & 0.55 & 0.07 & & \\
\hline \multirow[t]{3}{*}{2} & 1 & 269 & 2.22 & 0.50 & 0.06 & 1.18 & 1.35 \\
\hline & 2 & 334 & 2.94 & 0.53 & 0.07 & & \\
\hline & 3 & 249 & 2.14 & 0.52 & 0.07 & & \\
\hline \multirow[t]{3}{*}{3} & 1 & 263 & 2.34 & 0.53 & 0.07 & 1.17 & 1.33 \\
\hline & 2 & 325 & 2.79 & 0.51 & 0.07 & & \\
\hline & 3 & 240 & 2.10 & 0.53 & 0.07 & & \\
\hline \multirow[t]{3}{*}{4} & 1 & 297 & 2.54 & 0.51 & 0.07 & 1.18 & 1.33 \\
\hline & 2 & 259 & 2.21 & 0.51 & 0.07 & & \\
\hline & 3 & 213 & 1.82 & 0.51 & 0.07 & & \\
\hline \multirow[t]{3}{*}{5} & 1 & 369 & 3.33 & 0.54 & 0.07 & 1.17 & 1.35 \\
\hline & 2 & 300 & 2.69 & 0.54 & 0.07 & & \\
\hline & 3 & 402 & 3.75 & 0.56 & 0.07 & & \\
\hline \multirow[t]{3}{*}{6} & 1 & 585 & 5.44 & 0.56 & 0.07 & 1.15 & 1.35 \\
\hline & 2 & 266 & 2.13 & 0.48 & 0.06 & & \\
\hline & 3 & 371 & 2.84 & 0.46 & 0.06 & & \\
\hline
\end{tabular}

\section{B. PKA-Epac interaction}

PKA activation by the specific cAMP analog 6-Bnz-cAMP $(50 \mu \mathrm{M})$ increased EPSC amplitudes from DG-neurons during $0.2 \mathrm{~Hz}$ stimulation frequency. On average EPSC amplitudes were potentiated by a factor of $1.21 \pm 0.07$ (mean \pm SEM, $N=10$; Fig. 21A1). This effect was comparable in size to the EPSC amplitude potentiation induced by $\mathrm{ESCA}_{1}$-mediated Epac activation (factor $=$ $1.25 \pm 0.02$, mean \pm SEM, $N=53$ ). From these observations and the size of the forskolin effect on EPSC amplitudes (factor $=1.76 \pm 0.13$, mean \pm SEM, $N$ = 35) one can conclude that PKA- and Epac-signaling do not show a simple additive behaviour (Fig.21A2). Experiments performed in the presence of PKA-inhibitors and forskolin or the Epac activator $E_{S C A}$ suggest a synergistic interaction of PKA-dependent and PKA-independent signaling pathways. 

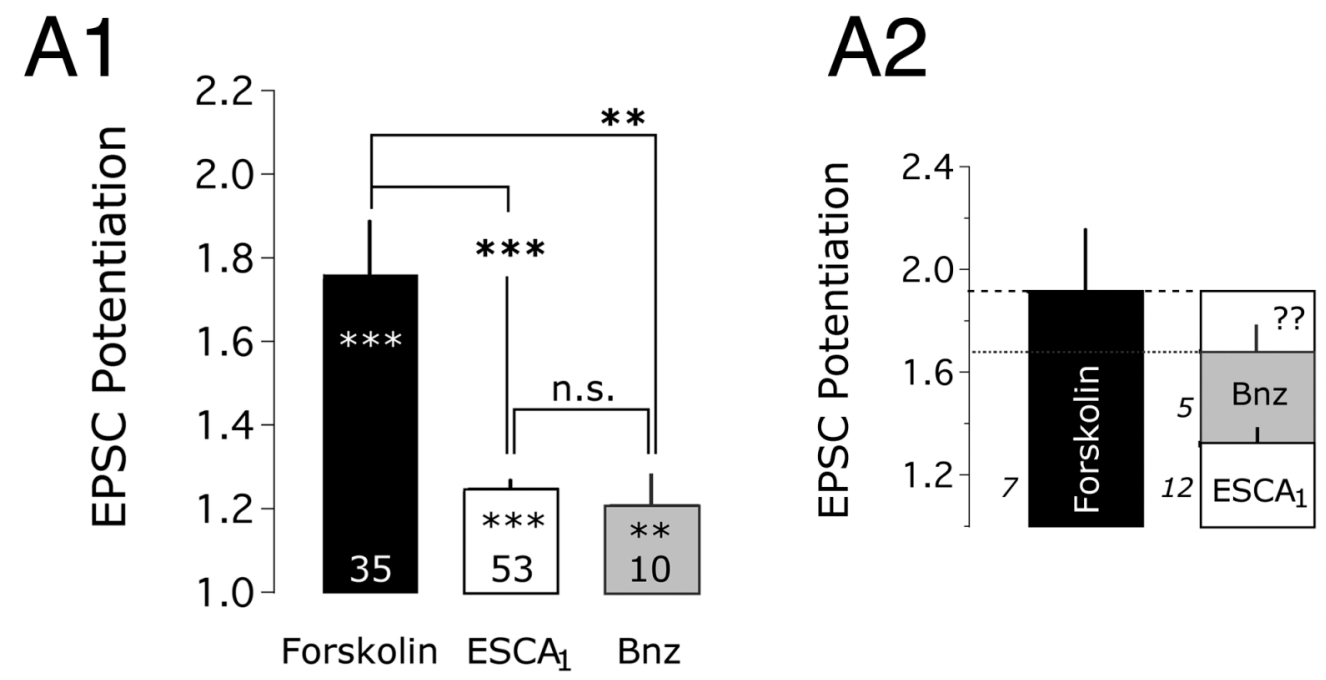

Figure 21

Fig. 21 6-Bnz-cAMP enhances neurotransmitter release at excitatory autaptic neurons from Dentate Gyrus. A1. Average EPSC amplitude potentiation by $50 \mu \mathrm{M}$ forskolin $\left(\mathrm{EPSC}_{0}=\right.$ $3.90 \pm 0.42 \mathrm{nA}$, mean \pm SEM), $50 \mu \mathrm{M}$ 6-Bnz-cAMP $\left(B n z\right.$, EPSC $_{0}=3.38 \pm 1.01 \mathrm{nA}$, mean \pm $\mathrm{SEM})$ and $50 \mu \mathrm{M} \mathrm{ESCA}{ }_{1}\left(\mathrm{EPSC}_{0}=4.30 \pm 0.34 \mathrm{nA}\right.$, mean $\left.\pm \mathrm{SEM}\right)$. Values are shown as mean \pm SEM. Statistical significance of the individual drug-induced EPSC potentiations was analysed by the paired $t$-test. Significance in-between the different drug-effects was analysed by the KS-test. A2. Schematic presentation of the contribution of the individual effects of 6-

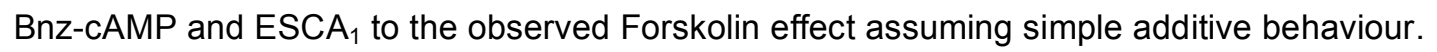

The forskolin effect is not inhibited by application of the PKAantagonists KT5720 (1 $\mu \mathrm{M}$ and $4 \mu \mathrm{M}, \mathrm{K}_{\mathrm{i}} \sim 56 \mathrm{nM}$; Fig. 22A1,A3) and Rp-8-BrcAMPS (100 $\mu \mathrm{M}$; Fig. 22B). The PKA-inhibitors were previously shown to inhibit cellular PKA function at the concentrations used here [Nagy et al., 2004; Huang and Hsu, 2006; Gesellchen et al., 2006]. Western blot analysis of the phosphorylation level of synapsin I at its PKA/CaMKII-site showed that $4 \mu \mathrm{M}$ KT5720 does not block the forskolin-mediated increase in

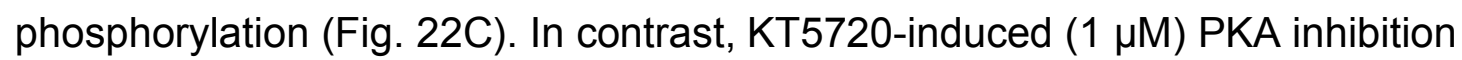
enhanced a simultaneous effect of $\mathrm{ESCA}_{1}$ on EPSC amplitudes on average by $100 \%$ (Fig. 22A2, A3).

Therefore, compensatory PKA-independent signaling pathways exist and maintain neurotransmitter release. Under low stimulation frequency conditions PKA activity is rather restrictive to Epac function. 

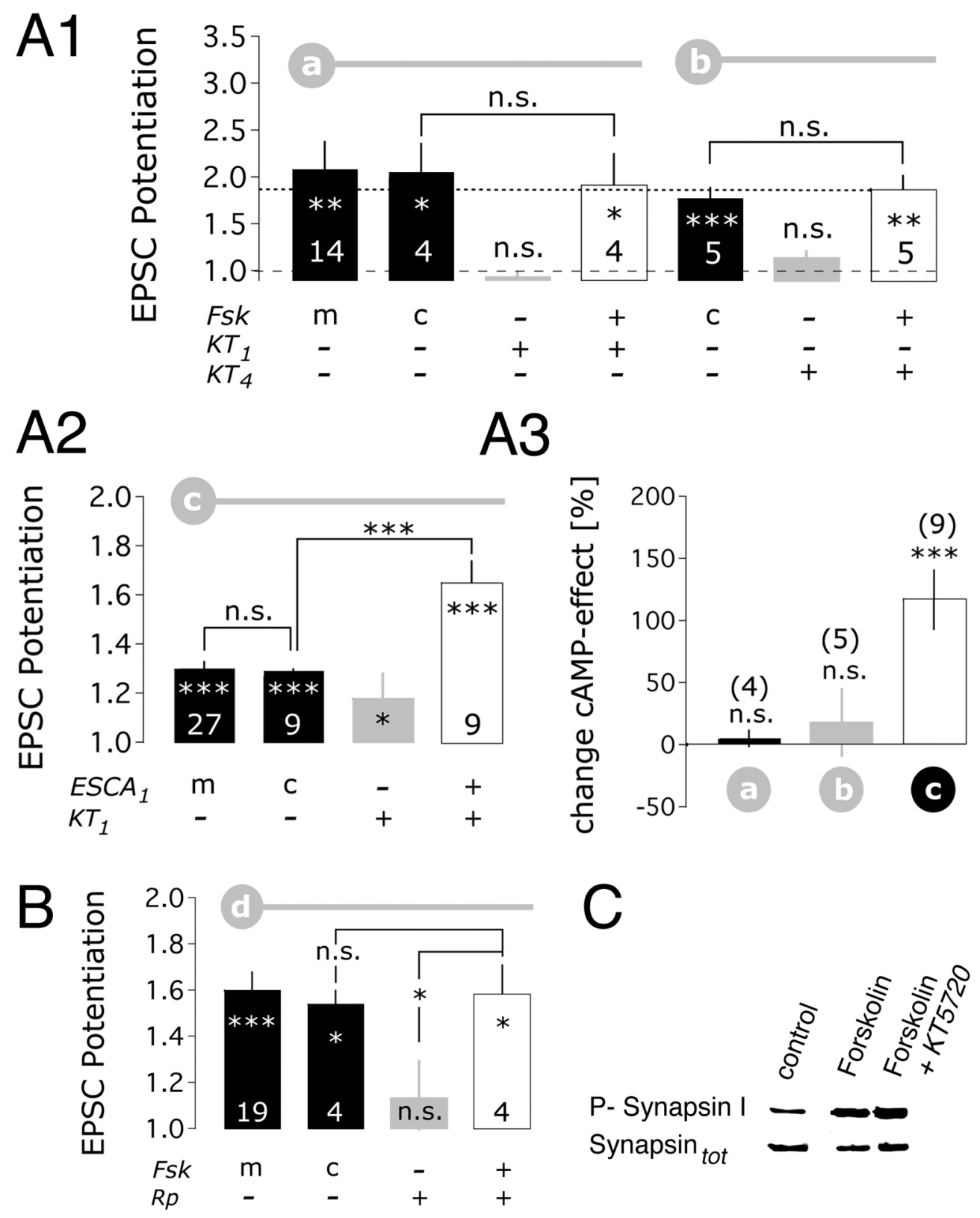

Figure 22

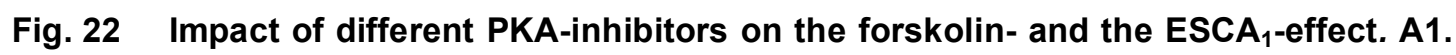
Average EPSC amplitude potentiation by $50 \mu \mathrm{M}$ forskolin in the presence or absence of $1 \mu \mathrm{M}$ $\left(\mathrm{KT}_{1}\right)$ or $4 \mu \mathrm{M}\left(\mathrm{KT}_{4}\right) \mathrm{KT} 5720\left(\mathrm{EPSC}_{0}=1.91 \pm 0.65 \mathrm{nA}\right.$, mean $\left.\pm \mathrm{SEM}\right)$. The numbers within the histogram bars are $\mathrm{N}$-values, representing the number of cells. A2. Average EPSC amplitude potentiation by $50 \mu \mathrm{M} E S C A_{1}$ in the presence or absence of $1 \mu \mathrm{M}\left(\mathrm{KT}_{1}\right) \mathrm{KT} 5720\left(\mathrm{EPSC}_{0}=\right.$ $2.45 \pm 0.34 \mathrm{nA}$, mean \pm SEM). A3. \% change in the cAMP-effect by the PKA inhibitor KT5720. B. Average EPSC amplitude potentiation by $50 \mu \mathrm{M}$ forskolin in the presence or

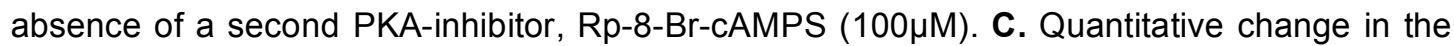
phosphorylation level of the PKA site of synapsin I (P-Synapsin I) by forskolin $(50 \mu \mathrm{M})$ in the absence or presence of $4 \mu \mathrm{M} \mathrm{KT5720.} \mathrm{Synapsin}{ }_{\text {tot }}$ controls for total synapsin expression. $5 \mu \mathrm{g}$ protein per lane. 


\section{Epac activity and presynaptic $\mathrm{Ca}^{2+}$ influx interact synergistically to maintain neurotransmission during high frequency stimulation}

To further examine the effect of CAMP on neurotransmitter release adenylyl cyclase activity was inhibited by extracellular application of MDL 12,330A. Autaptic neurons of the Dentate Gyrus were stimulated for twenty seconds at $10 \mathrm{~Hz}$. Prior to application of the AC-inhibitor the readily releasable pool of vesicles was released for five seconds by $500 \mathrm{mM}$ sucrose solution.

MDL 12,330A inhibited the regeneration of neurotransmission after pool-depletion in a characteristic way (Fig. 23A,B phase II and Fig. 23C). This inhibitory effect can be attributed to a disturbance of the equilibrium between vesicle refilling and vesicle consumption either by directly or indirectly affecting vesicular dynamics. The indirect effects on vesicular dynamics may result from changes of the action potential shape. Possible explanations for changes of the action potential shape are inhibitory effects on VDCCs or the modulation of $\mathrm{K}^{+}$- and $\mathrm{Na}^{+}$-influx.

Different concentrations of the AC-inhibitor were tested to exclude indirect effects of MDL 12,330A on vesicle dynamics as a consequence of $\mathrm{K}^{+}$and $\mathrm{Na}^{+}$-influx modulation. The degree of inhibition of the regeneration of neurotransmission depended on the concentration of the general AC-antagonist. $30 \mu \mathrm{M}$ MDL 12,330A barely affected AP-realted peak sodium and potassium currents, whereas $150 \mu \mathrm{M}$ of the inhibitor severely reduced both current types with increasing duration of MDL 12,330A application (Fig. 23D1,D2).

Application of $\mathrm{ESCA}_{1}(50 \mu \mathrm{M})$ partially rescues the inhibitory effect of $30 \mu \mathrm{M}$ MDL 12,330A on EPSC amplitudes in the regeneration phase of the $10 \mathrm{~Hz}$ train (Fig. 24A). AP-related sodium and potassium currents were barely affected by the drug combination used (Fig. 24C1,C2). Similarly, ESCA 1 (50 $\mu \mathrm{M})$ can partially compensate for the negative effects of $150 \mu \mathrm{M} M D L$ 12,330A (Fig. 24B). ESCA 1 can not remove the inhibitory constraints imposed to AP-related potassium currents by $150 \mu \mathrm{M}$ of the AC-inhibitor (Fig. $24 \mathrm{C} 1, \mathrm{C} 2)$. In contrast AP-related sodium currents were largely rescued by this $\mathrm{ESCA}_{1}$ concentration. 
Since $E \mathrm{SCA}_{1}$ cannot completely compensate for the observed inhibitory effect of MDL 12,330A, different cAMP-targets and their signaling pathways may be negatively affected. Not only Epac but also PKA and even CNG channels may be involved in the regulation of vesicular dynamics. However, mechanistical or spatial and temporal information about the concerted signaling actions of all these so far known cAMP-targets and their exact contribution to neurotransmission and synaptic plasticity are largely unknown today.

The amount of EPSC amplitude rescue during the regeneration phase of the $10 \mathrm{~Hz}$ train by Epac-activation depended on both the degree of the MDL 12,330A-mediated inhibition and the duration of the inhibition (Fig. 24D).

Fig. 23 General inhibition of adenylyl cyclase activity by MDL 12, 330A affects neurotransmitter release negatively during high frequency stimulation. Autaptic neurons prepared from Dentate Gyrus were stimulated for 20 seconds at a frequency of $10 \mathrm{~Hz}$. During the first 5 seconds (I) and the last 3 seconds (III) $500 \mathrm{mM}$ sucrose solution was applied (Sucrose I \& II). After the first sucrose pulse the regeneration of neurotransmission (II) was observed either under control condition (A, EPSC $10 \mathrm{~Hz}$ sample trace) or during the application of the general adenylyl cyclase inhibitor $50 \mu \mathrm{M} \mathrm{MDL} \mathrm{12,330A.} \mathrm{(B,} \mathrm{EPSC} 10 \mathrm{~Hz}$ sample sample trace). The traces for control and drug application were recorded from the same cell. For .... AP-related currents were blanked out in the presented sample traces. C. Influence of various MDL 12,330A concentrations on the regeneration of EPSC amplitudes. For every cell the EPSC amplitudes were normalized to the average maximal EPSC amplitude during MDL12,330A application (mean \pm SEM). O control to MDL 12,330A (30 $\mu \mathrm{M}$ or $50 \mu \mathrm{M})$; $\bigcirc$ control to MDL 12,330A (150 $\mu \mathrm{M})$; $-\mathrm{MDL} 12,330 \mathrm{~A}(30 \mu \mathrm{M})(\mathrm{N}=16, \mathrm{n}=2$, $\mathrm{EPSC}_{0}=-7.3 \pm 1.1 \mathrm{nA}$, mean $\left.\pm \mathrm{SEM}\right), \bigcirc \mathrm{MDL} 12,330 \mathrm{~A}(50 \mu \mathrm{M})\left(\mathrm{N}=13, \mathrm{n}=2, \mathrm{EPSC}_{0}=-6.6\right.$ $\pm 0.7 \mathrm{nA}$, mean \pm SEM $), \bigcirc \mathrm{MDL} 12,330 \mathrm{~A}(150 \mu \mathrm{M})\left(\mathrm{N}=3, \mathrm{n}=1, \mathrm{EPSC}_{0}=-5.2 \pm 0.7 \mathrm{nA}\right.$, mean \pm SEM ). D1. MDL 12,330A-induced changes in the peak $\mathrm{Na}^{+}$-currents. D2. MDL $12,330 \mathrm{~A}$-induced changes in the peak $\mathrm{K}^{+}$-currents. Influence of various $\mathrm{MDL} 12,330 \mathrm{~A}$ concentrations $(30,50 \& 150 \mu \mathrm{M})$ on the action-potential related $\mathrm{Na}^{+}$- and $\mathrm{K}^{+}$-currents during the regeneration phase of EPSC amplitudes (mean \pm SEM). The peak AP-related currents during the regeneration phase were first normalized to the respective peak AP-related currents of the first EPSC in the train (for both control and drug condition). Subsequently, the ratio of the normalized peak $\mathrm{Na}^{+}$- and $\mathrm{K}^{+}$-currents during drug application and those measured under control condition was calculated to point out the drug-induced changes in the peak AP-related currents. 

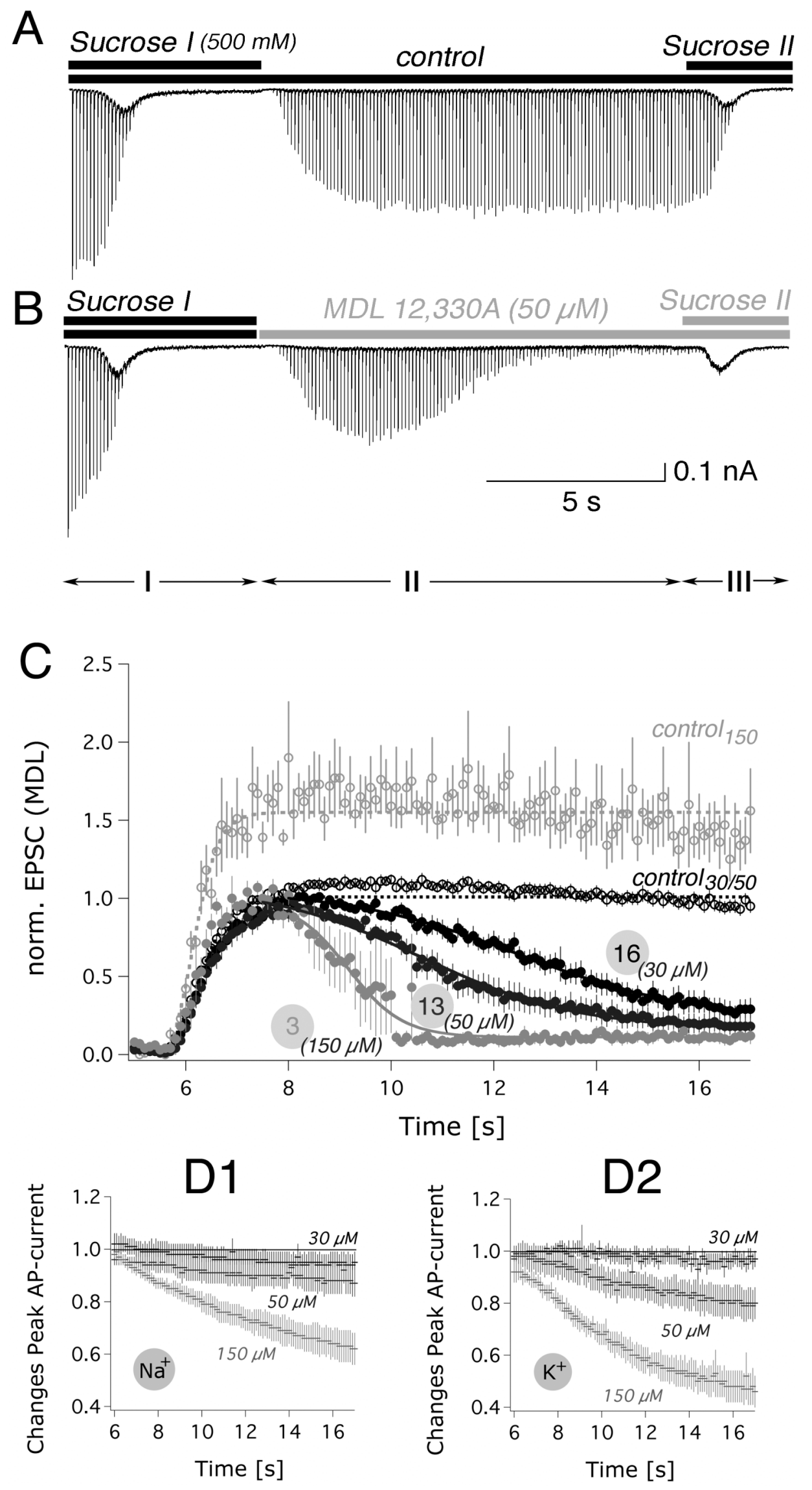

Figure 23 
Previous findings of this study showed that Epac-activation enhances neurotransmission on average by a factor of $1.23 \pm 0.03$ (mean $\pm \mathrm{SEM}, \mathrm{N}=$ 60) during $0.2 \mathrm{~Hz}$ stimulation. However, concerns that the observed potentiation of EPSC amplitudes may not account for total PKA or Epac activity could not be excluded. Constitutive activation of endogenous PKA or Epac or else an increase in the intracellular cAMP-level during $0.2 \mathrm{~Hz}$ stimulation were thought to determine the degree of Epac-mediated potentiation.

Fig. 24 MDL 12,330A-mediated inhibition of neurotransmission is partially rescued by ESCA $_{1}$. The stimulation protocol was described in the previous figure. Regeneration of neurotransmission was observed from the same cell either under control condition or during the application of various concentrations of $\mathrm{MDL} 12,330 \mathrm{~A}(30 \mu \mathrm{M}$ or $150 \mu \mathrm{M})$ in the presence $\left(^{+}\right)$or absence $(-)$of $50 \mu \mathrm{M} \mathrm{ESCA} A_{1}$. From every cell $10 \mathrm{~Hz}$ traces were recorded according to the following sequence: first control - MDL 12,330A (-) - second control - MDL 12,330A (+). After every $10 \mathrm{~Hz}$ trace EPSCs were recorded for 3 minutes at $0.2 \mathrm{~Hz}$. For every cell the EPSC amplitudes were normalized to the average maximal EPSC amplitude during MDL12,330A application. The normalized first control and second control traces do not differ (data not shown) and reach the max. steady state level of 1 . A. MDL 12, 330A (30 $\mu \mathrm{M}) \pm$ $\operatorname{ESCA}_{1}(50 \mu \mathrm{M})\left(\mathrm{N}=7, \mathrm{n}=2, \mathrm{EPSC}_{0}=-5.31 \pm 1.44 \mathrm{nA}\right.$, mean $\left.\pm \mathrm{SEM}\right) . \mathrm{B} . \mathrm{MDL} 12,330 \mathrm{~A}(150$ $\mu \mathrm{M}) \pm \mathrm{ESCA}_{1}(50 \mu \mathrm{M})\left(\mathrm{N}=3, \mathrm{n}=1, \mathrm{EPSC}_{0}=-5.22 \pm 0.65 \mathrm{nA}\right.$, mean $\left.\pm \mathrm{SEM}\right)$. C1. Changes in the peak $\mathrm{K}^{+}$-current. $\mathbf{C 2}$. Changes in the peak $\mathrm{Na}^{+}$-current. MDL 12,330A-induced changes in the peak AP-related $\mathrm{Na}^{+}$- and $\mathrm{K}^{+}$- currents in the presence or absence of $\mathrm{ESCA}_{1}$ (ratio of the normalized peak currents during drug application and those measured under the corresponding control condition, mean \pm SEM). D. EPSC amplitude reduction by MDL 12 , $330 \mathrm{~A}$ versus the cAMP rescue factor (mean \pm S.D.). The rescue of the MDL $12,330 \mathrm{~A}$ effect by the different CAMP-agonists is described by the cAMP rescue factor (ratio of the normalized EPSC amplitudes in the presence or absence of CAMP-agonist when MDL 12,330A is simultaneously applied). For the calculation of the EPSC amplitude reduction by MDL 12 , $330 \mathrm{~A}$, the normalized EPSC amplitude values during MDL 12,330A application were substracted from 1 (, the maximal relative control steady state level for the regeneration phase of neurotransmission after prior sucrose application). $\mathrm{MDL} 12,330 \mathrm{~A}(30 \mu \mathrm{M}, \mathrm{N}=7$, $\mathrm{n}=2, \mathrm{EPSC}_{0}=-5.31 \pm 1.44 \mathrm{nA}$, mean $\left.\pm \mathrm{SEM}\right) ; \quad \mathrm{MDL} 12,330 \mathrm{~A}(150 \mu \mathrm{M}, \mathrm{N}=3, \mathrm{n}=1$, $\mathrm{EPSC}_{0}=-5.22 \pm 0.65 \mathrm{nA}$, mean $\left.\pm \mathrm{SEM}\right)$. inset, average cAMP rescue factor of the MDL $12,330 \mathrm{~A}(30 \mu \mathrm{M})$ effect for an EPSC amplitude reduction of $<60 \%$ and $60-85 \%$. The rescue factors were $1.5 \pm 0.03$ and $2 \pm 0.06$ (mean \pm SEM), respectively. 
A

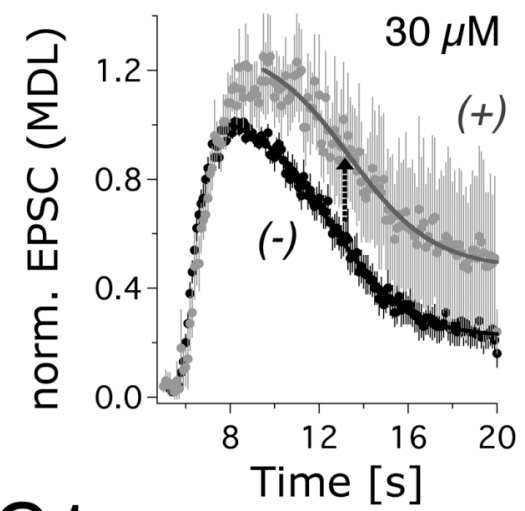

C1

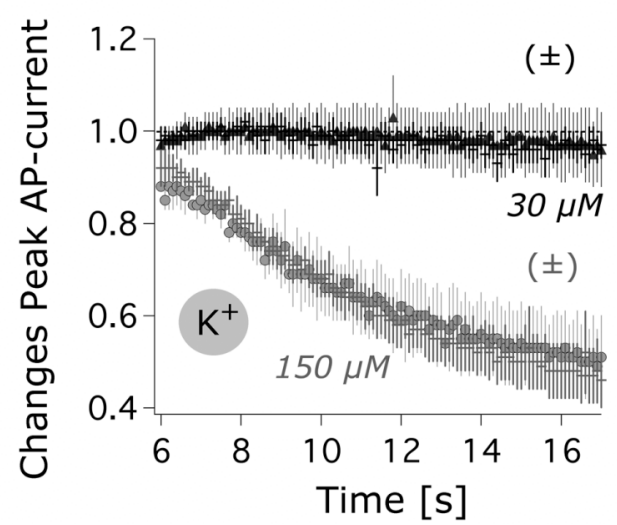

D

\section{B}
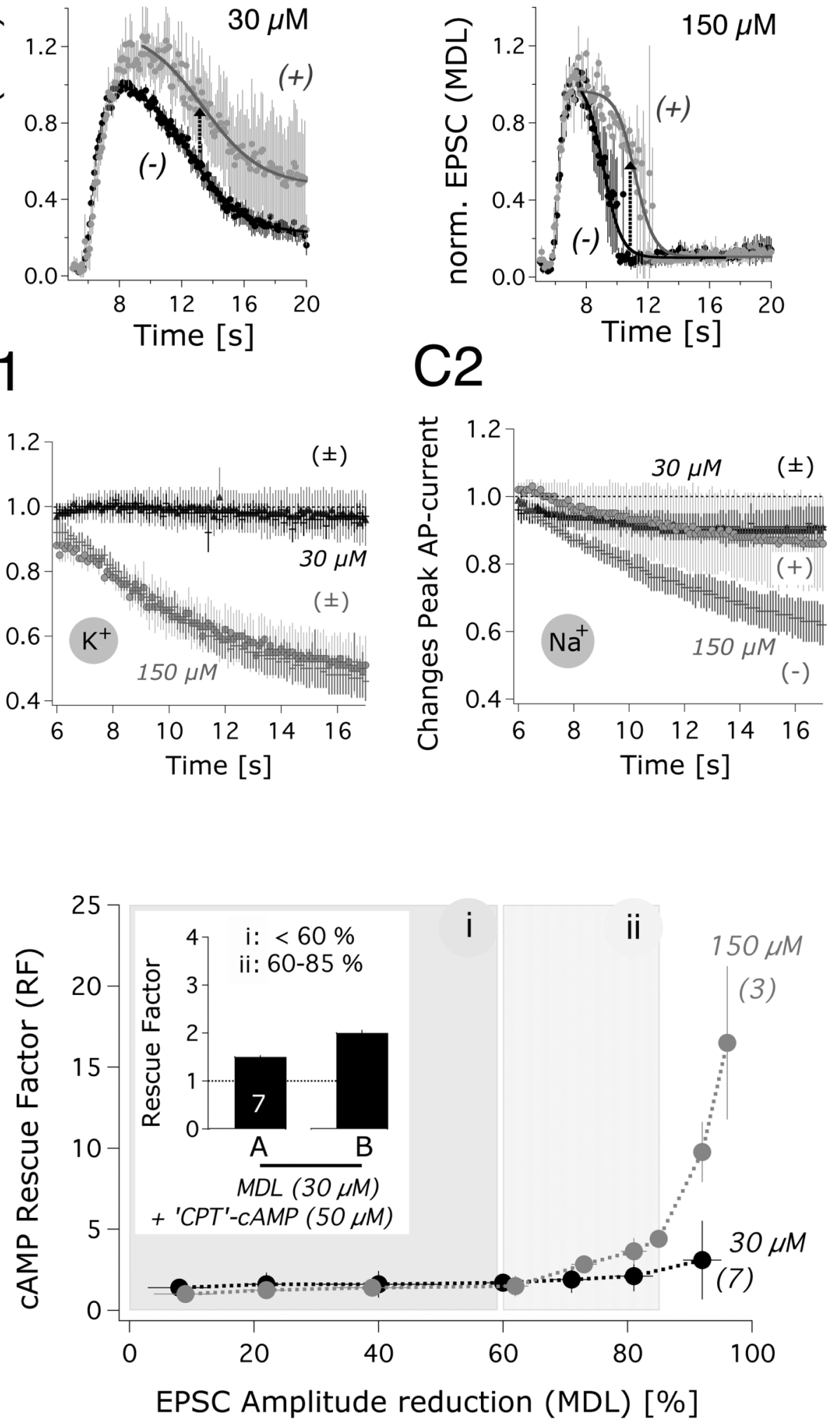

Figure 24 
Both PKA-dependent and PKA-independent cAMP-mediated signaling pathways could be involved in the maintenance of synaptic transmission during low frequency stimulation.

The dependence of the ESCA $_{1}$-mediated EPSC amplitude rescue during the regeneration phase of the $10 \mathrm{~Hz}$ train on the degree of the MDL 12,330A-mediated inhibition indeed suggests that the factor for the Epac-mediated enhancement of neurotransmitter release is dependent on the intracellular cAMP concentration of a neuron. The average neuronal basal cAMP level may range from 1-6 $\mu \mathrm{M}$, and increases upon stimulation up to 100 $\mu \mathrm{M}$ [Sudlow and Gilette, 1997].

$30 \mu \mathrm{M}$ MDL 12,330A reduced the EPSC amplitude on average by maximally $60-85 \%$. External application of ESCA $_{1}(50 \mu \mathrm{M})$ compensated for this reduction on average by a factor of $2 \pm 0.06$ (mean \pm SEM, $N=7$; Fig. 24D, inset). A reduction of EPSC amplitudes by more than $85 \%$ (as observed for $150 \mu \mathrm{M}$ MDL $12,330 \mathrm{~A}$ ) is only transiently rescued. The average maximal rescue factor for EPSC amplitude reductions greater than $85 \%$ was $9.76 \pm$ 0.41 (mean \pm SEM, $\mathrm{N}=3$ ).

Experiments performed at the calyx of Held presynapse point towards an effect of MDL 12,330A on VDCC function and calcium influx (personal communication, Dr. Nobutake Hosoi). Previously, Rampe et al. (1987) reported an inhibitory effect on slow calcium channels in rat anterior pituitary endocrine cells. Phosphorylation of presynaptic and postsynaptic calcium channels by cAMP-dependent protein kinase was shown to occur in hippocampal neurons [Hell et al., 1995]. In general it is thought that phosphorylation of VDCCs by PKA leads to an increase in calcium current [Solem et al., 1997; Kamp and Hell, 2000].

An inhibitory effect of MDL $13,220 \mathrm{~A}$ on presynaptic channels may explain the transient nature of the rescue effect by $\mathrm{ESCA}_{1}$ - calcium influx could be the limiting factor for maintenance of exocytosis during repetitive stimulation. Both cAMP and calcium are crucial for the maintenance of neurotransmitter release during high frequency stimulation. 



\section{ACKNOWLEDGMENT}

This work would not have been possible without the help and support of many people.

I express my sincere gratitude to Prof. Dr. Erwin Neher for supervising my thesis, and for giving me the opportunity to independently work in his department. You gave me the freedom to discover, make errors, and learn from my mistakes, turning my doctoral work into a process of continual learning and exploration. Special thanks for including me in the EU-Synapse project, a unique opportunity to meet leading european neuroscientists.

Thank you, Prof. Dr. Reinhard Jahn and Prof. Dr. Frauke Melchior, for being part of my thesis committee, and for helping me not to loose contact to my biochemical background. I express my gratitude to Prof. Dr. Detlef Doenecke. You made me feel comfortable as an associate fellow in the Graduate Program 521 of the German Research Foundation (Deutsche Forschungsgemeinschaft, DFG). I will certainly remember your sincere interest in my work. I am especially grateful to Dr. Holger Taschenberger for answering all my questions precisely and patiently, and for helpful discussions throughout the entire four years of my thesis work. Your critical remarks often helped me to develop new ideas and experimental strategies.

This entire work was performed in the framework of the EU-integrated project 'EUSynapse'(LSHM-CT-2005-019055). It was funded by the German Research Foundation (Deutsche Forschungsgemeinschaft, DFG), and could not have been realized without the expert technical assistance of Frank Würriehausen (computational), Frank Köhne (electronics), and the caring members of the Animal Housing Facility. Dr. Hans Dieter Schmitt shared with us the Lumilmager and provided valuable comments on western blotting.

Dr. Ekkehard Diemann was of valuable help when it came to analyse the situation of the german scientific community. You truly aided me to make reasonable decisions considering my professional career, especially on days when skies looked rather gray. You were the perfect guide to the city of Göttingen, when hunting for its scientific corners and history. Dear Dr. Diemann, you are a true mentor. I thank the student members of the Graduate 
Program 521 for providing a group feeling. I especially enjoyed the times we spent in Bad Münster am Stein/Ebernburg. To Dr. Edward Lemke I am indebted for spending our nights on the most stupid movies ever, which none of us would have watched voluntarily, if it was not to remove excessive personal neuronal activity. Certainly I will not forget any of you: Ina-Maria 'Ruthild' Herfort, Heinz-Jürgen 'Caracas' Dehne, Michael Pilot, Dirk Reuter, and Manuela Beck-Corell. Dear Ina and Heinz-Jürgen you broadened my mind with your vivid interest in all aspects of cultural life. I am very grateful to both of you for your continual moral support. Many thanks to Michael for showing me how and where to look for mushrooms in the area of Göttingen. It was great fun to prowl around in the woods! - Dirk, you often prevented a drop in my blood glucose level by frequently bringing your children's sweets into my office. Fortunately, I never caught up with your potbelly.

I am highly indebted to my family. My beloved grandparents Regina and Michael Bielz sacrificed so much to ensure the family's freedom of thought, opinion, decision, and information. Thank you mom, that you never questioned any of my choices in life, not even my scientific and professional one! Your support Renate and Helmut Gehrmann made life a lot easier for many times. I am truly blessed to know that I can always count on you all. 


\section{Curriculum Vitae}

\section{PERSONAL DATA}

$\begin{array}{ll}\text { Name } & \text { Isabella Gekel } \\ \text { Born } & 31.08 .1976, \text { Hermannstadt (Sibiu), Romania } \\ \text { Citizenship } & \text { German }\end{array}$

\section{EDUCATION}

since 2004 Ph.D. student with Dr. Erwin Neher, Max Planck Institute for Biophysical Chemistry, Department of Membrane Biophysics and Georg-August University, Department of Biology, Göttingen, Germany

2003 - $2004 \quad$ Ph.D. student (uncompleted), Graduate School for neural and behavioural sciences, Eberhard-Karls University, Tübingen, Germany

Research project: "Microstimulation-evoked fMRI for characterising cerebello-cerebral loops"

1999 - 2003 Diploma Biochemistry (M.Sc.), Eberhard-Karls University, Tübingen, Germany / Final examinations: biochemistry, physical chemistry, immunology

2001

Internship (6 month), Rockefeller University of New York, NY, U.S.A, Dr. Paul Greengard, Laboratory of Molecular and Cellular Neuroscience,

Research project: "Role of the cdc5/p35 phosphorylated $B$ subunit of PP2B for the dephosphorylation of DARPP-32"

1997 - 1999 'Vordiplom' Biochemistry (B.Sc.), University of Bielefeld, Bielefeld, Germany / study subjects: biochemistry, chemistry Final examinations: inorganic chemistry, physical chemistry, organic chemistry, biochemistry, anatomy (Tübingen)

1990 - 1997 Abitur (Final Secondary-School Examinations), Gymnasium Zum Altenforst, Troisdorf, Germany / Final examinations: Chemistry, Mathematics, French, and History

$1983-1990 \quad$ Elementary school, Hermannstadt (Sibiu), Romania

\section{MERITS/AWARDS}

since 2004 Fellow, Graduate Program 521 (GRK521), German Research Foundation (Deutsche Forschungsgemeinschaft, DFG)

2001

$1999-2003$ Foreign Exchange Scholarship, German National Merit Foundation Scholarship and Fellow, German National Merit Foundation

\section{SYMPOSIA, MEETINGS \& WORKSHOPS}

4th Neuroscientific Conference for Young Scientists Tübingen, October 2003, Hindelang-Oberjoch (Allgäu), Germany. (funded by SFB550) 
Synaptic transmission: From ion channels to neuronal network function, June 2004, Göttingen, Germany.

Joint Symposium of the Graduate Programs 521 (Göttingen) und 845 (Homburg/Kaiserslautern), September 2004, Bad Münster am Stein / Ebernburg, Germany. (funded by GRK 521)

Ribbon Synapse Symposium, September 2005, Göttingen, Germany.

Workshop "Mentoring for female scientists in the Max Planck Society", November 2005, Frankfurt am Main, Germany. (funded by the Max Planck Society)

Tutor "Sensory systems", International Max Planck Research School for Molecular Biology, March 2006 \& 2007, Göttingen, Germany.

DFG Workshop: "Das Wissen der Forschung verständlich für Laien (Get Science across to the General Public)", August 2006, Göttingen, Germany. (funded by GRK 521)

Frankfurt Institute for Advanced Studies (FIAS) International Summer School "Theoretical Neuroscience \& Complex Systems", August 2006, Frankfurt am Main, Germany. (funded by FIAS and the Max Planck Society)

Annual meeting of the EU-SYNAPSE project, December 2006, Budapest, Hungary. Contribution: Poster. (funded by EU-Synapse)

31st Göttingen Neurobiology Conference / 7th Meeting of the German

Neuroscience Society, March/April 2007, Göttingen, Germany. Contribution: Poster, Abstract. (funded by the Max Planck Society)

17th Spring School in Life Science "The Presynaptic Terminal - Assembly and Function", April/May 2007, Jerusalem, Israel. Contribution: Poster. (funded by the Hebrew University of Jerusalem, Institute for Advanced Studies and the Max Planck Society)

International Women in Science Conference "The Way Forward", May 2007, EMBL Heidelberg, Germany. (funded the Max Planck Society)

Joint Symposium of the Graduate Programs 521 (Göttingen) und 845 (Homburg/Kaiserslautern), September 2007, Bad Münster am Stein / Ebernburg, Germany. Contribution: Poster. (funded by GRK 521)

Semestral Meetings of the Graduate Program 521 (GRK521), Göttingen 2004, 2005, 2006, 2007(2x), Germany. Contribution: annual talks (30 min each)

\section{LIST OF PUBLICATIONS}

Roth P., Aulwurm S., Gekel I., Beier D., Sperry R. G., Mittelbronn M., Meyermann R., Beaman K. D., Weller M., Wischhusen J. (2006) Regeneration and Tolerance Factor: A novel mediator of glioblastoma-associated immunosupression. Cancer Research 66(7): 3852-8.

Gekel I., Neher E. (2007). EPAC: A novel modulator of short-term plasticity in cultured hippocampal neurons. 31st Göttingen Neurobiology Conference/7th Meeting of the German Neuroscience Society, April 2007.

Gekel I., Neher E. (2008) Application of an EPAC activator enhances neurotransmitter release at excitatory central synapses. Journal of Neuroscience, accepted. 

